\author{
Aus der Abteilung Humangenetik \\ (Prof. Dr. med. Dr. h. c. W. Engel) \\ im Zentrum Hygiene und Humangenetik \\ der Medizinischen Fakultät der Universität Göttingen
}

\title{
The molecular role of the heat shock protein family110 (HSP110)
}

\author{
Inaugural-Dissertation \\ zur Erlangung des Doktorgrades \\ der Medizinischen Fakultät \\ der Georg-August-Universität zu Göttingen \\ vorgelegt von \\ Belal A. Mohamed \\ aus \\ Kalyoubia, Ägypten
}

Göttingen 2012 
Dekan
I. Berichterstatter
II. Berichterstatter
III. Berichterstatter
: Prof. Dr. sc. agr. Adham
: Prof. Dr. rer. nat. mansouri
: Prof. Dr. med. Oppermann

Tag der mündlichen Prüfung : 11/12/2012
: Prof. Dr. rer. nat. H. K. Kroemer 


\section{Table of Contents}

1. Introduction

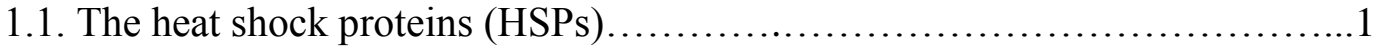

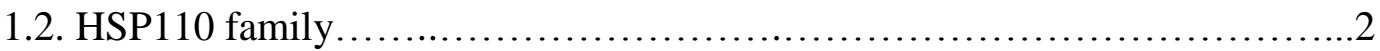

1.3. Structure of HSP110 family.........................................

1.4. The co-chaperoning activity of HSP110 family...........................4

1.5. Molecular function of HSP110 family....................................5

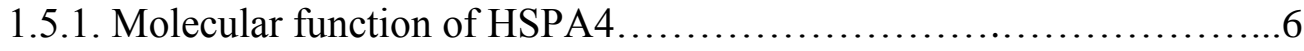

1.5.2. Molecular function of HSPA4L..................................

1.5.3. Molecular function of HSPH1 ...................................... 8

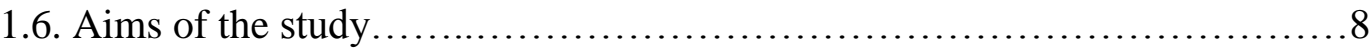

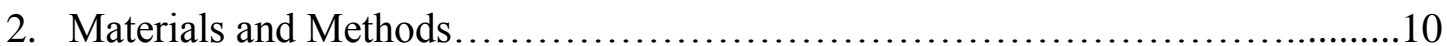

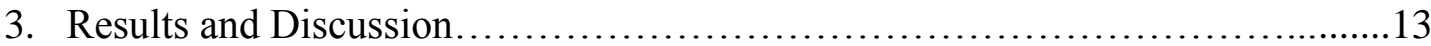

3.1. Consequences of HSPA4 ablation on male germ cells development............13

3.2. Cardioprotective role of HSPA4 ......................................... 18

3.3. Elucidating the consequence of cardiac HSPA4 overexpression.............23

3.3.1. Generation of recombinant Hspa4 adenovirus (Ad-Hspa4)..............23

3.3.2. Generation of cardiac specific Hspa4 transgenic mouse model.........26

3.4. Simultaneous deletion of murine Hspa4l and Hspa4 genes causes pulmonary immaturity and early neonatal lethality in mouse................27

3.5. Generation of Hsph1 conditional KO and Hspa4/Hsph1 DKO mice.............41

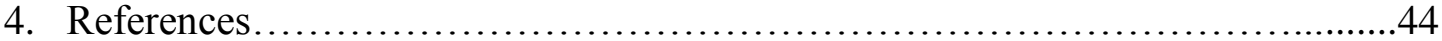

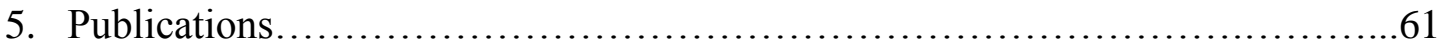

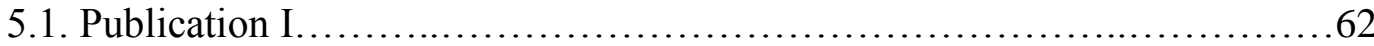

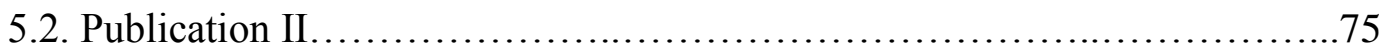

6. List of Publications...................................................... 86 


\section{Introduction}

\section{1. The heat shock proteins (HSPs)}

HSPs were first identified in Drosophila in 1962 as proteins that accumulate in the cell after exposure to elevated temperature (Ritossa, 1962). Later studies demonstrated that HSPs are a conserved set of proteins that are expressed in all prokaryotes and eukaryotes (Ritossa, 1996). The HSPs are a set of highly conserved proteins that are expressed constitutively and/or induced in response to a wide variety of stress conditions (Collins and Hightower, 1982; Khandjian and Türler, 1983; Li GC, 1985; Li GC and Laszlo, 1985; La Thangue and Latchman, 1988; Norton PM and Latchman, 1989). Induction of HSPs is mediated by the nuclear translocation of heat shock transcription factors (HSFs) and subsequent binding to heat shock elements (HSEs) in the promoter regions of $H s p$ genes (Tonkiss and Calderwood, 2005; Morimoto, 2011).

HSPs act as molecular chaperones by assisting the folding of nascent and misfolded proteins thereby preventing their aggregation (Hartl, 1991; Gething and Sambrook, 1992). Protein quality control (PQC) in the cells facilitates proper folding of nascent proteins and refolding of misfolded proteins by molecular chaperones and promotes degradation of aggregated proteins by ubiquitin-proteasome system (UPS) and to less extent by autophagy (Wang X et al., 2008). Functional defects in chaperones result in an accumulation of misfolded proteins (Patterson, 2006). Recent reports demonstrated that increased accumulation of misfolded proteins above the threshold levels impairs the functional capacity of the proteasome leading to proteasome functional insufficiency (PFI), which is thought to be involved in up to half of all human morbidities (Thomas et 
al., 1995; Bradbury, 2003; Bennett et al., 2005). These diseases include Amyotrophic Lateral Sclerosis (ALS), Alzheimer's, Huntington's, Parkinson's disease and cardiomyopathy (Ross, 1995; Taylor et al., 2002; Wong et al., 2002; Bates, 2003; Berke and Paulson, 2003; Caughey and Lansbury, 2003; Kostin et al., 2003; Nussbaum and Ellis, 2003; Weekes et al., 2003; Ross and Pickart, 2004; Sanbe et al., 2004; Selkoe, 2004; Powell, 2006; Tsukamoto et al., 2006; Birks et al., 2008).

According to molecular mass and degree of structural homology, mammalian HSPs are classified into several families including: small HSPs (25-28 kDa), HSP40 (40kDa), HSP60, HSP70 (68-80 kDa), HSP90 (83-99 kDa), and HSP110 (110 kDa) (Tomasovic et al., 1983; Welch et al., 1983; Li GC and Laszlo, 1985; Vos et al., 2008).

\section{2. HSP110 family}

HSP110 family members have been cloned from a wide range of organisms including human, mouse, Arabidopsis and yeast (Foltz et al., 1993; Mukai et al., 1993; Morozov et al., 1995; Yasuda et al., 1995; Kojima et al., 1996; Storozhenko et al., 1996; Kaneko et al., 1997a, b; Mauk et al., 1997).

The constitutive expression and stress inducibility of HSP110 family members in a wide variety of cell types leads to suggest that the HSP110 members play a protective role not only in stressed cells but also in unstressed through helping in successful folding, assembly, intracellular localization, secretion, regulation, and degradation of other proteins (Levinson et al., 1980; Landry et al., 1982; Gething, 1997). 


\section{3. Structure of HSP110 family}

The HSP110 sequence was found to share an around 30-33\% amino acid homology with members of the HSP70 family, most of which occurs in the conserved ATP-binding domain of these molecules (Lee-Yoon et al., 1995). HSP110 family contains four domains: the highly conserved N-terminal nucleotide-binding domain (NBD) (domain A in Fig. 1), which binds ATP/ADP and mediates ATP hydrolysis, the central $\beta$-sheet peptide binding domain (PBD) that binds the peptide substrate (domain B in Fig. 1), the loop domain (domain L in Fig. 1) and the C-terminal $\alpha$-helix domain that regulates substrate binding (domain $\mathrm{H}$ in Fig. 1). The C-terminal domain exhibits a high degree of sequence homology among HSP110 members, thereby providing features specific for this family (McCarty et al., 1995; Fung et al., 1996; Zhu et al., 1996).

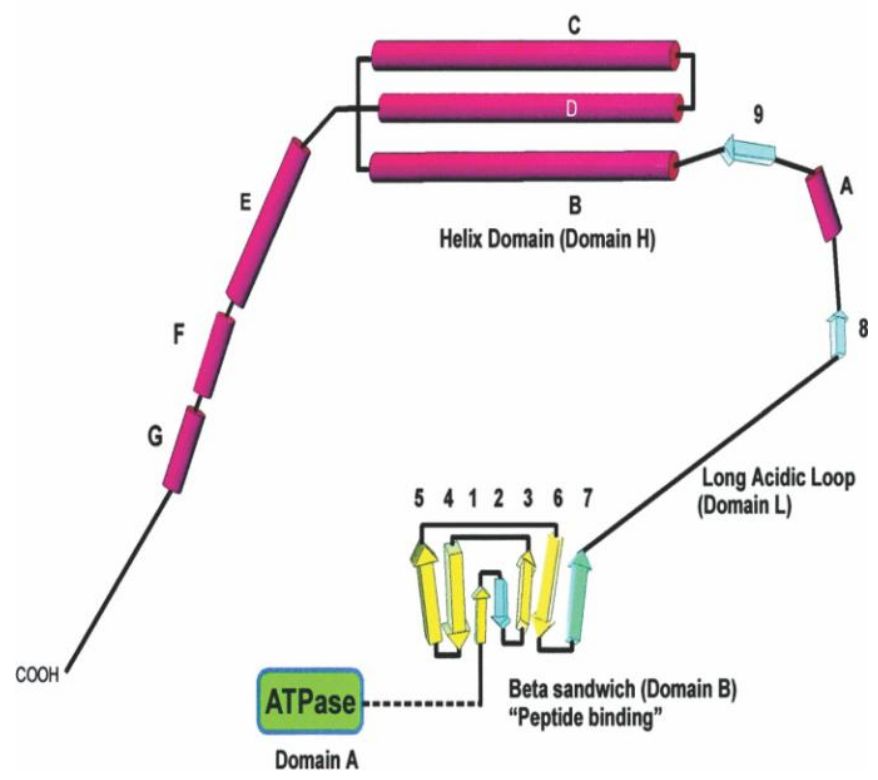

Figure 1. Predicted folding pattern for HSP110. HSP110 family contains four domains: the N-terminal ATPase (domain A), the central $\beta$-sheet peptide binding domain (PBD) (domain B), the loop domain (domain L) and the C-terminal $\alpha$-helix domain (domain H) (adapted from Oh et al., 1999, pp. 15714). 


\section{4. The co-chaperoning activity of HSP110 family}

Biochemical analyses illustrated that HSP110 family serves as co-chaperone of mammalian and yeast HSP70 chaperones, where they act as nucleotide exchange factors (NEF) during the ATP-hydrolysis cycle (Steel et al., 2004; Dragovic et al., 2006; Raviol et al., 2006; Shaner et al., 2006; Polier et al., 2008). Binding of newly synthesized polypeptides to HSP70 chaperones and the subsequent release of folded proteins is regulated by continuous cycles of adenosine triphosphate (ATP) hydrolysis and the exchange adenosine diphosphate (ADP) for ATP (Fig. 2). It is believed that the chaperones containing HSP70, HSP40 and HSP110 proteins represent the major protein folding machinery in the eukaryotic cytosol (Polier et al., 2008). In the ATP-bound state, PBD of HSP70 chaperone binds to polypeptides with low affinity. However, ATP hydrolysis to ADP by HSP40 co-chaperone leads to conformational changes that result in high affinity substrate binding by HSP70 (Fig. 2, step 1). To complete the protein folding cycle, binding of HSP110 to HSP70 in the ADP-state stimulates the release of ADP (Fig. 2, step 2). Subsequent binding of ATP induces the dissociation of HSP70-HSP110 complexes and the folded protein substrate is released (Fig. 2, step 3). HSP70 in the ATPbound state will be ready for another cycle of protein folding (Dragovic et al., 2006; Raviol et al., 2006; Polier et al., 2008; Schuermann et al., 2008). 


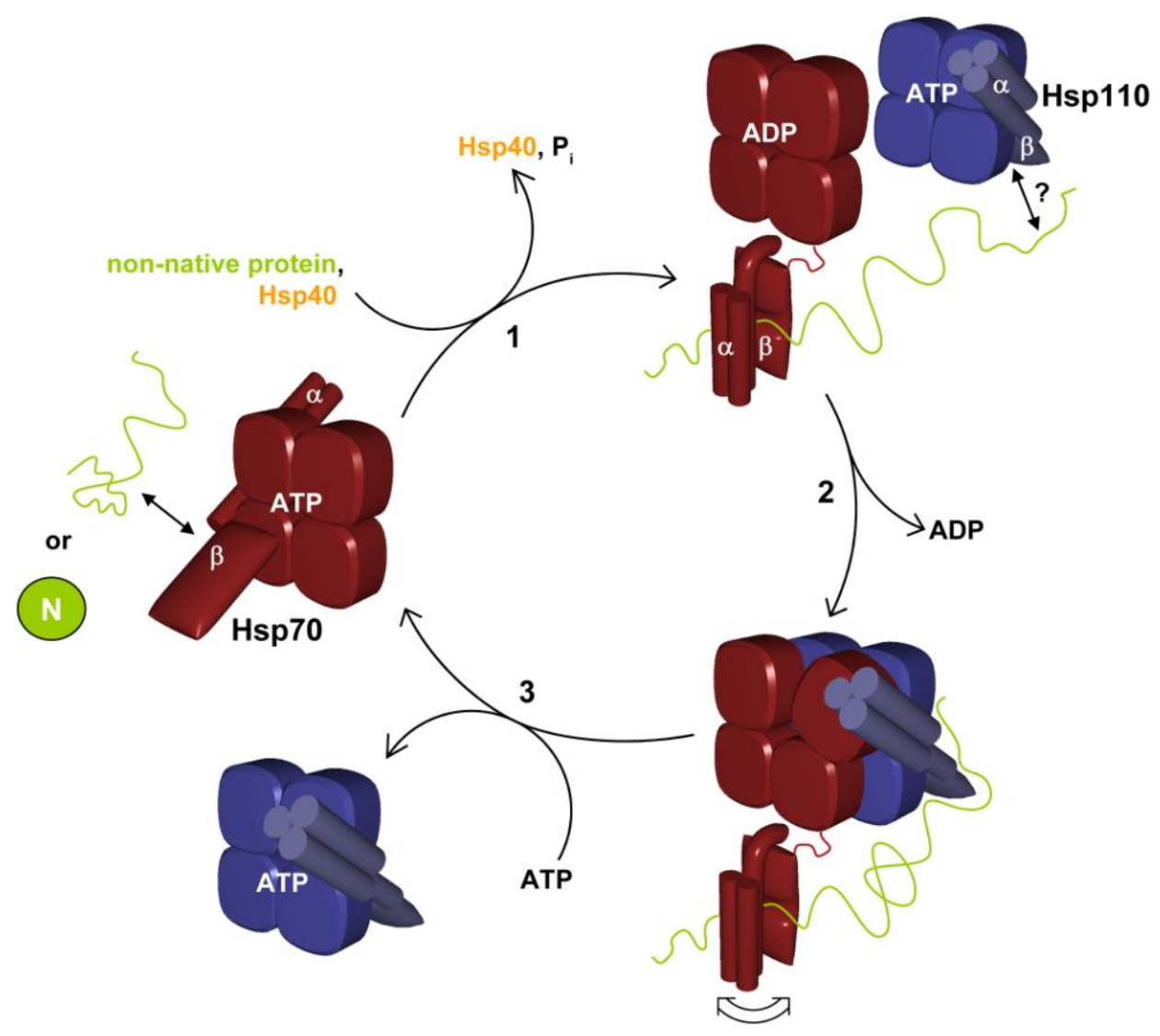

Figure 2. Schematic representation of the collaboration between HSPs for proper protein folding. HSP70 in ATP-bound state (left side). HSP40 facilitates ATP hydrolysis and subsequent binding of HSP70 to unfolded protein substrate (Step 1). HSP70 in ADP-bound state is recognized by HSP110, which binds to HSP70 mediating liberation of ADP from HSP70 (Step 2). Finally, upon binding of ATP to HSP70, the HSP70-HSP110 complex dissociates and the folded protein substrate is released (step 3). HSP70 will be ready for another cycle of folding (adapted from Polier et al., 2008, pp. 1077).

\section{5. Molecular function of HSP110 family}

The HSP110 gene family includes two genes in Saccharomyces cerevisiae known as Sse1 and Sse2 (Mukai, et al., 1993; Shirayama et al., 1993) and four genes in the mammalian genome, namely Hspa4/Apg2, Hspa4l/Apg1, Hsph1/Hsp105 and Hyoul/Grp175/orp150 (Lee-Yoon et al., 1995; Yasuda et al., 1995; Kojima et al., 1996; Kaneko et al., 1997a, b; Nonoguchi et al., 1999; Yagita et al., 1999). Apart from HYOU1, which is present in the endoplasmic reticulum (ER), all other mammalian and yeast HSP110 members are found in the cytoplasm (Chen X et al., 1996; Vos et al., 2008). 
To gain insights into the molecular function of mammalian HSP110 family members, genetic targeted disruption in mice by homologous recombination was undertaken.

\section{5. 1. Molecular function of HSPA4}

The Hspa4 gene was cloned from a mouse testis cDNA library (Kaneko et al., 1997a). Murine Hspa4 mRNA is ubiquitously expressed in all tissues, with the highest expression in testis, ovary and spleen (Kaneko et al., 1997a). In brain, HSPA4 protein was found to be expressed constitutively in rat neuronal tissues throughout entire embryonic and postnatal period, suggesting an important role of HSPA4 in these tissues under non-stress conditions (Okui et al., 2000). Hspa4 is expressed in cells of various origins, including embryonic fibroblasts, myelomonocytic leukemia, mastocytoma, Sertoli cells, bone narrow stromal cells and primary human articular chondrocytes (Kaneko et al., 1997a; Dehne et al., 2010). Strikingly, Hspa4 gene has been found among 250 genes, which are highly upregulated in pluripotent stem cells (Ramalho-Santos et al., 2002).

In contrast to most of HSPs, the expression level of Hspa4 is not induced by heat shock conditions (Kaneko et al., 1997a; Nonoguchi et al., 1999). Hspa4 expression is induced by acidic $\mathrm{pH}$ and is involved in the radioadaptive response (Kang et al., 2002; Rafiee et al., 2006). In addition, in rat transient forebrain ischemia leads to increased Hspa4 expression in cerebral cortex and hippocampus (Yagita et al., 1999; Koh et al., 2000; Lee et al., 2002). Hspa4 Overexpression in cancer BaF3-BCR/ABL cell line leads to increased cell proliferation and protection against oxidative damage suggesting an important role of HSPA4 in carcinogenesis and progression of chronic myeloid leukemia (Li C et al., 2010). Furthermore, HSPA4 has been found to be overexpressed in 
hepatocellular carcinoma (Gotoh et al., 2004). SiRNA mediated repression of HSPA4 in vitro causes a significant decrease in migration, invasion, and transformation activity in lung cancer H1299 cell line (Wu et al., 2011). It was shown that HSPA4 is involved in the progression of enterocolitis in a zebrafish model of inflammatory bowel disease, which suggests that Hspa4 expression can be used as effective read-out for genetic, chemical and environmental factors that might influence intestinal inflammation (Crawford et al., 2011).

\section{5. 2. Molecular function of HSPA4L}

Murine Hspa4l genomic sequence has been firstly determined from adult mouse testis cDNA library (Kaneko et al., 1997b). Nonoguchi et al. (2001) reported that HSPA4L is expressed in human testicular germ cells and in sperm supporting its role in spermatogenesis and fertilization. Expression level of murine $H s p a 4 l$ is highly increased in spermatogenic cells from late pachytene spermatocytes to late spermatids and in kidney where it is restricted to epithelial cells of distal convoluted tubules (Held et al., 2006). Noteworthy, Hspa4l is highly expressed in leukemia cells, and was found to elicit humoral immune responses in leukemia patients (Takahashi et al., 2007).

Murine $H s p a 4 l$ expression has been shown to be induced upon osmotic stress, heat shock and cerebral ischemia (Kojima et al., 1996; Kaneko et al., 1997b; Xue et al., 1998). Analysis of the promoter region of $H s p a 4 l$ gene revealed the presence of functional tonicity (TonE) and heat shock-responsive elements that mediate independently the induction of $\mathrm{Hspa4l}$ expression upon hypertonicity and heat shock, respectively (Kojima et al., 2004). 
Held et al. (2006) have generated Hspa4l knockout (KO) mice through gene targeting in embryonic stem cells. Hspa4l KO mice were viable and born at expected Mendelian ratio with no overt phenotypes. Adult $H s p a 4 l \mathrm{KO}$ male but not female mice were infertile due to increased apoptotic cell death of spermatocytes together with impaired sperm motility. Moreover, Hspa4l KO mice developed hydronephrosis due to upper urinary tract obstruction.

\section{5. 3. Molecular function of HSPH1}

The Hsphl genomic sequence from mouse has been isolated and characterized (Yasuda et al., 1995, 1999). Murine Hsphl is ubiquitously expressed in all tissues (Yasuda et al., 1995). HSPH1 exists as complexes associated with HSP70 and its cognate protein HSC70 (HSP70/HSC70) in mammalian cells (Hatayama et al., 1998; Wakatsuki and Hatayama, 1998).

Treatment of 3T3 fibroblast cells with DNA virus oncoprotein leads to induction of Hsphl transcript (Morozov et al., 1995). It has been reported that Hsphl is induced in neurons of the cerebral cortex and hippocampus upon exposure to cerebral ischemia (Kim H et al., 2001; Yagita et al., 2001).

\section{6. Aims of the study}

Hspa4 KO mice model was generated in the Institute of Human Genetics, Göttingen. Two lines of Hspa4 KO mice were generated in hybrid C57BL/6J x 129/SV and in inbred 129/Sv genetic background. Analysis of Hspa4 KO mice in hybrid genetic background revealed that approximately $60 \%$ of Hspa4 $\mathrm{KO}$ males were infertile. Analysis of Hspa4 
$\mathrm{KO}$ mice in the inbred background showed that Hspa4 $\mathrm{KO}$ mice displayed growth retardation and $65 \%$ of the $\mathrm{KO}$ mice died during the $1^{\text {st }} 4$ weeks after birth. Hspa4 $\mathrm{KO}$ mice which overcame the early lethality displayed impaired fertility, skeletal muscle myopathy and cardiac hypertrophy.

To definitively rule out the possibility that $\mathrm{Hspa} 4 \mathrm{l}$ expression is able to compensate for the loss of Hspa4 in Hspa4 $\mathrm{KO}$ mice, Hspa4l/Hspa4 double $\mathrm{KO}$ (DKO) mouse model was generated. Strikingly, the DKO mice did not survive and died immediately after birth.

\section{The aims of the experiments were the following:}

1. Analysis of the expression patterns of HSPA4 in different tissues and in testis during prenatal and postnatal germ cells development together with identification of possible underlying causes of impaired male fertility in Hspa4 $\mathrm{KO}$ mice.

2. Characterization of the development of hypertrophic cardiomyopathy in Hspa4 KO mice at the histological and molecular levels together with identification of possible underlying causes

3. Determination of the possible underlying causes of early postnatal lethality encountered in Hspa4l/Hspa4 DKO pups.

4. Finally, generation and characterization of Hsphl $\mathrm{KO}$ and Hspa4/Hsphl DKO mouse models were undertaken to elucidate the consequences of Hsphl deletion and simultaneous Hspa4 and Hsphl deletion. 


\section{Materials and Methods}

The following methods were used to analyze the expression pattern and role of HSPA4 during spermatogenesis. We analyzed the expression pattern of HSPA4 in the gonads during different prenatal and postnatal developmental stages and in different mutant testes by immunohistochemical analyses and Western blotting. To evaluate the role of HSPA4 in vivo, a loss of function mouse model was generated. We characterized the impact of HSPA4 ablation on the progression of spermatogenesis by histological and immunohistochemical analyses of Hspa4 $\mathrm{KO}$ testes. To determine the different sperm parameters, we used CEROS Computer assisted semen analysis system. The expression levels of some meiotic and post-meiotic marker genes were estimated by Northern blotting. To detect apoptotic cells in testes, we performed TUNEL assay (Publication I).

We performed the following methods to determine the cardioprotective role of HSPA4. Western blotting and immunofluorescence analyses were performed to elucidate the expression levels and cellular distribution of HSPA4 in the sham- and transaortic constriction (TAC) - operated hearts. We analyzed the cardiac hypertrophy and fibrosis in Hspa4 KO mice by staining of the heart sections with Hematoxylin \& eosin (H\&E) and Masson's trichrome, respectively. Cardiomyocyte diameter and cross sectional area were measured by NIH Image $\mathbf{J}$ software. The expression levels of hypertrophy related gene markers (Nppa, Nppb, Myh7 and Actal) and fibrosis related gene markers (Col3al and Collal and Tgf 1 ) were measured using quantitative real time PCR (qRT-PCR). The different parameters of heart dimension and function were measured using Two- 
dimensional directed M-mode echocardiogram. Identification of signaling pathways which mediate the development of cardiac hypertrophy was done by Western blotting and qRT-PCR analyses. To test the effects of HSPA4 loss on cardiac responses to hemodynamic stress condition, Hspa4 $\mathrm{KO}$ and WT mice were exposed to TAC. TAC was performed as previously described (Müller et al., 2008). The hypertrophic response was evaluated by histological analyses, qRT-PCR and echocardiography. To probe the ubiquitination status and the proteasome enzyme activity in Hspa4 $\mathrm{KO}$ mice, we determined the levels of ubiquitinated proteins by Western blotting, immunofluorescence analyses and 20S Proteasome Assay Kit. In order to identify the differentially expressed genes in Hspa4 $\mathrm{KO}$ hearts, global gene expression analysis was applied using the GeneChip® Mouse Gene 1.0 ST arrays (Affymetrix) (Publication II).

We did the following methods to elucidate the expression patterns and the role of HSPA4L/HSPA4 during lung morphogenesis. The expression pattern of HSPA4L and HSPA4 in the lung during different developmental stages was investigated by Western blotting and immunofluorescence analyses. To examine the effect of dual deletion of Hspa4l and Hspa4 on the lung development, we intercrossed Hspa4l $\mathrm{KO}$ and Hspa4 $\mathrm{KO}$ mice to obtain $\mathrm{Hspa}^{-/-} \mathrm{Hspa4}^{-/-}$mice. The embryonic lungs were histologically examined by staining of sections with H\&E and periodic acid Schiff (PAS). The saccular spaces and the mesenchymal thickness were measured using NIH Image J software. The expression levels of alveolar type I (ATI) and alveolar type II (ATII) pneumocytes related markers were evaluated by immunohistochemistry and Western blotting. To probe the ubiquitination status in the lung of $\mathrm{Hspa}^{\digamma_{-}^{--}} \mathrm{Hspa}^{-/-}$mice, we determined the 
level of ubiquitinated proteins by Western blotting analysis. The ultrastructure of the lung alveoli was examined by electron microscopy as described previously (Peng et al., 2006). In order to determine the cell proliferation, BrdU labeling was carried out. In situ TUNEL assay and cleaved Caspase 3 immunofluorescence analysis were performed to assess apoptosis. 


\section{Results and Discussion}

The HSPs function as molecular chaperones. The Chaperones are multifunctional antistress proteins, which regulate diverse biological processes to maintain cellular homeostasis (Gething and Sambrook, 1992; Morimoto et al., 1994; Hartl, 1996; Gething, 1997). Under pathological conditions, inducible or constitutively expressed molecular chaperones protect cells from different environmental stressors (Hishiya and Takayama, 2008).

\subsection{Consequences of HSPA4 ablation on male germ cells development}

The spermatogenesis progresses through three distinct phases, namely mitotic proliferation of spermatogonia, meiotic division of spermatocytes and postmeiotic differentiation of haploid spermatids into spermatozoa (Eddy et al., 1991). All these developmental stages represent situations where dramatic transformations, cellular proliferation and differentiation take place. The expression of different HSPs is enhanced during spermatogenesis to facilitate proper folding, transport and assembly of protein complexes required for completion of different phases of spermatogenesis (Dix et al., 1997; Dix and Hong, 1998; Meinhardt et al., 1999). Previous reports demonstrated that decreased expression of the some HSPs is associated with the pathogenesis of male infertility in human (Werner et al., 1997; Son et al., 1999; Huszar et al., 2000; Son et al., 2000; Feng et al., 2001; Adly et al., 2008). The protective role of HSPs in testis was confirmed by data showing development of overt male infertility in mutant mice with 
targeted gene disruption of different HSPs (Allen JW et al., 1996; Dix et al., 1996; Ikawa et al., 1997; Mori et al., 1997; Terada et al., 2005; Held et al., 2006).

HSPA4 is ubiquitously expressed in different tissues (Kaneko et al, 1997a; Nonoguchi et al., 1999). In the publication I, elucidation of the expression pattern and the physiological function of HSPA4 in male germ cell development were undertaken. We demonstrated that HSPA4 was ubiquitously expressed during prenatal and postnatal development in both somatic and germ cells of testis, with high enrichment in gonocytes, which represent the fetal/neonatal precursors of the undifferentiated spermatogonial stem cells (Culty, 2009). Expression of HSPA4 in male gonocytes was gradually decreased after their differentiation to spermatogonia (Fig. 1 and 2, pp. 134-135 in the Publication I). The enrichment of HSPA4 expression in the gonocytes is in accordance with previous reports, which revealed that Hspa4 is highly expressed in different tissue-specific stem cells and its expression is downregulated upon differentiation (Ramalho-Santos et al., 2002; Bhattacharya et al., 2004). The high expression of HSPA4 in gonocytes suggests an important role of HSPA4 in germ stem cells development. It is believed that molecular chaperones may protect stem cells from oxidative stress-induced aging (Ramalho-Santos et al., 2002). Caenorhabditis elegans, with extended life span, have elevated levels of molecular chaperones, which function to eliminate oxidative free radicals and consequently extend longevity (Finkel and Holbrook, 2000).

The preferential HSPA4 expression in the germ cell forced us to study the impact of Hspa4 ablation on germ cell development. Analyses of Hspa4 KO mice revealed that all Hspa4 KO mice of the hybrid 129Sv X C57Bl/6J background were born at expected Mendelian ratio. Phenotype analyses showed the Hspa4 KO mice were indistinguishable 
from WT mice with the exception of testes, which were significantly smaller. Some of Hspa4 KO mice were infertile. Male infertility was manifested by decreased number and reduced motility of spermatozoa. To identify the cause of the reduced number of spermatozoa, histological sections of Hspa4 WT and KO adult testes were analyzed. In contrast to WT control, KO testis showed diverse defects. Most of seminiferous tubules were smaller in size, vacuolated, devoid of round and elongated spermatids and contained an increased number of multinucleated abnormal spermatids. Remarkably, many pachytene spermatocytes were degenerated. Consequently, epididymidis contained less number of sperms compared to WT controls (Fig. 4, pp. 138 in the publication I).

To identify the timing of onset of spermatogenic distortion in Hspa4 $\mathrm{KO}$ mice, testicular sections from different postnatal days (P) were histologically analyzed. At P5 and P10, no apparent difference between Hspa4 WT and KO testes could be detected. Beginning from P15, we found few pachytene spermatocytes in the seminiferous tubules of $\mathrm{KO}$ compared to WT testis. These data were confirmed by immunohistochemical staining with anti-HSPA4L, which is highly expressed in germ cells from pachytene spermatocytes (Held et al. 2006). Number of HSPA4L expressing cells was significantly decreased in $\mathrm{KO}$ compared to WT testis. At P20, round spermatids were present in the majority of WT tubules, whereas Hspa4 $\mathrm{KO}$ tubules were almost devoid of spermatids and contained a reduced number of pachytene spermatocytes. At day 25, Hspa4 KO tubules showed severe depletion of germ cells (Fig. 5, pp. 139 in the Publication I). These results suggest that the Hspa4 deficiency results in either developmental delay or partial arrest of the first wave of spermatogenesis. 
To investigate whether the depletion of germ cells is due to exaggerated cell death by apoptosis, TUNEL assay was performed. A significant increase of TUNEL-positive spermatocytes was found in Hspa4 KO testis (Fig. 6, pp 140 in the Publication I). Numerous proteins, which are required for the development of male germ cells during meiotic and post-meiotic stages, are mostly translated in pachytene spermatocytes (Messina et al., 2010). Failure of molecular chaperones to direct correct folding of newly synthesized proteins in pachytene spermatocytes might lead to accumulation of misfolded and damaged proteins, which would trigger spermatocytes to release meiotic division and initiate apoptosis. Based on the high sequence similarity of HSP110 family members, we expected that the molecular chaperones that include the NEF members of HSP110 family would be abnormal or partially affected in Hspa4 $\mathrm{KO}$ mice.

Spermatogenic arrest was confirmed at the molecular level by analyzing the expression levels of some meiotic and postmeiotic gene markers in testis of WT, fertile- and infertile- KO mice. Expression of synaptonemal complex protein-3 (Sycp3) is restricted to leptotene and zygotene spermatocytes (Lammers et al., 1994). Phosphoglycerate kinase-2 (Pgk2) and acrosin (Acr) were reported to be expressed in pachytene spermatocytes (Goto et al. 1990, Kashiwabara et al., 1990; Kremling et al., 1991). Hsc70t (Hsp70 homolog gene) and transition nuclear protein 2 (Tnp2) are post-meiotic genes (Kleene and Flynn, 1987; Tsunekawa et al., 1999). While the expression level of Sycp3 showed no significant difference between WT and KO testes, the expression levels of late meiotic (Pgk2 and Acr) and postmeiotic gene markers (Hsc70t and Tnp2) were significantly reduced in infertile $\mathrm{KO}$ testes as compared to WT and fertile $\mathrm{KO}$ testes (Fig. 7, pp. 141 in the Publication I). These results further confirm that spermatogenesis in 
infertile $\mathrm{KO}$ mice is arrested at late stages of meiotic prophase I. Taken together; these data indicate that HSPA4 is required for successful completion of spermatogenesis in mouse.

The relatively leaky phenotype of Hspa4 $\mathrm{KO}$ mice led us to suggest that Hspa4 ablation could be compensated by other members of the HSP110 family. To address this hypothesis, we have determined the protein levels of HSPA4L, HSPH1 in the testes of Hspa4 WT and KO mice. Protein levels of HSPA4L, HSPH1 were not markedly different between Hspa4 $\mathrm{KO}$ and WT testes, suggesting that the depletion of HSPA4 is not compensated by an increased expression of studied HSPs in Hspa4 KO testes (Fig. 7, pp. 141 in the Publication I).

Partial penetrance of male infertility, encountered in Hspa4 $\mathrm{KO}$ mice, was also reported in other genetically modified mouse models (Bitgood et al., 1996; Pearse et al., 1997; Robertson et al., 1999; Yu et al., 2000; Adham et al., 2001; Nayernia et al., 2002; Froment et al., 2004; Burnicka-Turek et al., 2009). The causes of partial penetrance of the phenotype are often attributed to the mixed genetic background of mice used in $\mathrm{KO}$ studies, although the involvement of additional nongenetic factors cannot be excluded. A high incidence of male infertility was found among Hspa4 $\mathrm{KO}$ mice in F2 generation, which contains a high level of inter-individual genetic variability. The decline in the incidence of infertility phenotype in subsequent generations would point to a selection bias against that genotype.

The spermatogenic defects in Hspa4 KO mice resemble those of the Hsp70-2 mutants. HSP70-2 is a member of the HSP70 family which is expressed at high levels in pachytene spermatocytes during the meiotic phase of spermatogenesis (Allen RL et al., 
1988; Zakeri et al., 1988). Targeted disruption of $H s p 70-2$ resulted in male infertility associated with arrested meiosis and germ cell apoptosis (Dix et al., 1997). The possibility that HSPA4 and HSP70-2 are involved in the same pathway remains to be investigated.

\subsection{Cardioprotective role of HSPA4}

Abnormal cardiac remodeling, which includes cardiac hypertrophy and fibrosis, plays a fundamental role in the pathogenesis of cardiovascular diseases such as hypertensive heart disease and chronic heart failure (Kuwahara et al., 2003; Mann and Bristow, 2005). Several lines of evidence demonstrated the protective role of HSPs against cardiac hypertrophy (Hayashi et al., 2006; Kim YK et al., 2006; Kumarapeli et al., 2008; Cai et al., 2010; Willis and Patterson, 2010; Norton N et al., 2011; Zhang et al., 2011; Zou et al., 2011).

In the Publication II, we have determined the cardioprotective role of HSPA4. We demonstrated that HSPA4 protein levels were significantly increased in the heart of WT mice subjected to pressure overload. Consistent with the data from the animal model, expression levels of human HSPA4 were significantly elevated in cardiac samples of patients with aortic stenosis. Immunofluorescence staining of murine heart sections showed cytoplasmic localization of HSPA4 in the cardiomyocytes, while the intensity of HSPA4 fluorescence staining in TAC-operated heart was stronger (Fig. 1, pp. 462 in the Publication II). These data indicate that the heart responds to hemodynamic stress by increasing HSPA4 expression. These results point to a potentially protective role of HSPA4 against pressure overload-induced cardiac hypertrophy. To elucidate the 
cardioprotective role of HSPA4, we characterized the cardiac remodeling in Hspa4 $\mathrm{KO}$ mice. Histological analyses revealed the development of hypertrophic cardiomyopathy and fibrosis in Hspa4 KO mice (Fig. 2, pp. 463 in the Publication II). Expression profiling of the hypertrophy- and fibrosis- related gene markers revealed a significant upregulation of the studied genes in Hspa4 KO compared with WT hearts. Twodimensional directed M-mode echocardiogram analysis was performed to assess the cardiac dimension and function. Left ventricular mass (LVM), Interventricular septum dimension (IVSD), left ventricle posterior wall thickness (LVPWT) and ratio of wall thickness to heart radius (h/r) were significantly increased in Hspa4 KO hearts compared to that of control littermates (Fig. 2, pp. 463 and Supplemental Table 2 in the Publication II). Taken together, these results indicate that the deficiency of HSPA4 leads to development of baseline cardiac hypertrophy and fibrosis.

To further confirm the cardioprotective role of HSPA4, we determined the responses of Hspa4 $\mathrm{KO}$ animals to pressure overload by exposing Hspa4 WT and $\mathrm{KO}$ mice to TAC. After 2 weeks of TAC, Hspa4 KO mice exhibited exaggerated cardiac hypertrophy compared with WT controls (Fig. 3, pp. 464 and Supplemental Table 3 in the Publication II). These data reveal that HSPA4 ablation aggravates pathological cardiac hypertrophy in response to pressure overload.

Our results are consistent with previous reports showing that other members of the HSP family, such as HSP90, HSP70, HSP20, and $\alpha \mathrm{B}$-crystallin, attenuate the development of cardiac hypertrophy induced either by angiotensin II, isoproterenol stimulation, or pressure overload (Hayashi et al., 2006; Kumarapeli et al., 2008; Willis and Patterson, 2010; Zhang et al., 2011). These findings further support the idea that the members of 
HSP family may be involved in mechanisms that protect against pathological cardiac remodeling and may be effective therapeutic candidates for cardiac hypertrophy and heart failure.

To determine the signaling pathways that were affected in the heart of Hspa4 $\mathrm{KO}$ mice and might be responsible for the development of cardiac hypertrophy, we investigated the expression levels of some genes and proteins, which are suggested to be involved in development of cardiac hypertrophy. These analyses demonstrated that the transcriptional activity of NFAT and the expression levels of activated CaMKII were significantly elevated in Hspa4 KO heart (Fig. 4B-D, pp. 465 in the Publication II). Both proteins participate in signaling pathways that play critical roles in regulating hypertrophic growth of the heart (Wilkins and Molkentin, 2002). In collaboration with GATA4, activated NFAT induces the expression of fetal genes (Molkentin et al., 1998; Olson and Williams, 2000). Similarly, activated CaMKII promotes MEF2 transcriptional activity, which induces the expression of prohypertrophic genes (Passier et al., 2000). The increased activity of gp130-STAT3 signaling in response to extracellular stress was reported to induce myocardial hypertrophy (Kunisada et al., 1998; Kunisada et al., 2000). In this study, we also found a marked increase in protein level of phosphorylated STAT3 (Fig. 4A, pp. 465 in the Publication II). This result suggests that gp130-STAT3 signaling also participates in cardiac remodeling in Hspa4 $\mathrm{KO}$ mice. It remains to be determined whether the observed increase in the activity of these prohypertrophic signaling pathways is, on the one hand, the result of the development of cardiac hypertrophy in Hspa4 $\mathrm{KO}$ hearts. On the other hand, it might also have resulted from an increase of misfolded 
proteins in cardiomyocytes, causing intracellular stress and the activation of stressinduced signaling pathways.

PQC depends on sophisticated collaboration between molecular chaperones and targeted proteolysis. When PQC is impaired or overloaded, abnormal proteins accumulate and cause aberrant aggregation in the cell, thereby injuring the cell and ultimately leading to cell death (Rutkowski and Kaufman, 2004). This can be quite detrimental to post-mitotic organs such as heart and brain due to their very limited self-renewal capacity (Wang X and Robbins, 2006). Emerging data suggest that protein misfolding and aberrant aggregation are common causes of heart diseases (Heling et al., 2000; Hein et al., 2003; Kostin et al., 2003; Sanbe et al., 2004; Chen Q et al., 2005; Liu J et al., 2006; Wang X and Robbins, 2006; Wang X et al., 2008).

Given the role of HSPA4 as a co-chaperone, which functions to maintain proper protein folding, we speculated that HSPA4 ablation may impair the cardiac PQC. To address this hypothesis, we checked the level of ubiquitinated proteins in the Hspa4 KO heart. As expected, we showed an accumulation of ubiquitinated proteins in the Hspa4 KO heart compared to WT controls (Fig. 5, pp. 466 in the Publication II). These results suggest that the accumulation of ubiquitinated proteins resulting from impaired chaperone activity is possibly responsible for myocardial remodeling in Hspa4 $\mathrm{KO}$ mice.

To rule out systemic causes of the cardiac hypertrophy seen in Hspa4 $\mathrm{KO}$ mice, we characterized neonatal cardiomyocyte cultures, which were established from Hspa4 WT and KO mice. Morphometric analyses demonstrated a high ratio of cardiomyocytes with increased cross sectional area (CSA) in $\mathrm{KO}$ culture compared to that in WT control. At the molecular level, expression levels of hypertrophic markers, Nppa and Nppb, were 
significantly increased in neonatal Hspa4 $\mathrm{KO}$ cardiomyocyte compared to WT control (Fig. 6, pp. 466 in the Publication II). These data indicate that hypertrophic cardiomyocyte phenotype in Hspa4 $\mathrm{KO}$ mice is due to an intrinsic heart defect.

Microarray analysis was performed to identify gene expression profiles and expand the knowledge of pathways regulating the development of cardiac hypertrophy in Hspa4 $\mathrm{KO}$ mice. RNA from the hearts of 3.5-week-old Hspa4 WT and KO mice were isolated, labeled and subjected to microarray screening. We selected 3.5 week-old-mice for identification of differentially expressed genes because this time largely precedes any pathological manifestations in Hspa4 $\mathrm{KO}$ heart, so that secondary alterations in gene expression were less likely. Results of microarray analysis identified 97 differentially expressed genes in Hspa4 KO heart (Fig. 7, pp. 467 and Supplemental Tables 4, 5 in the Publication II). Among the differentially expressed genes, several of them encode for proteins that are involved in ion channel signaling, including the voltage-gated potassium channels KCNE1 and KCND2, the potassium/sodium hyperpolarization-activated cyclic nucleotide-gated channel 1 (HCN1), sodium channel-gated, type IV, alpha subunit (SCN4A) and leucine glioma inactivation 1 (LGI1) that regulates the activity of voltagegated potassium channels (Schulte et al., 2006). It remains to be addressed whether the observed alterations in the expression of these genes could lead to electric remodeling in Hspa4 KO hearts; and further, if this is responsible for development of cardiac hypertrophy. Interestingly, Maplc3a, Dub2a and Dcunldl genes, which their coded proteins play a potential role in PQC machinery (Baek et al., 2001; Kouroku et al., 2007; Kim AY et al., 2008), were significantly altered in the Hspa4 KO hearts compared with WT controls. However, verification of these results by qRT-PCR and immunoblot 
analyses is required. These might provide mechanistic insights into the function of HSPA4 in chaperone mediated protein folding and give explanation for development of cardiac hypertrophy upon HSPA4 ablation.

In conclusion, we have demonstrated that lack of HSPA4 led to cardiac hypertrophy and fibrosis. Moreover, our data revealed the distinct, non-redundant role of HSPA4 in the PQC that maintains the proper protein folding and homeostasis in the cardiomyocytes.

\subsection{Elucidating the consequence of cardiac HSPA4 overexpression}

We have shown that deficiency of HSPA4 led to baseline cardiac hypertrophy and an exaggerated hypertrophic response to TAC-induced pressure overload. To investigate whether forced expression of HSPA4 in the heart will be sufficient to protect against cardiac hypertrophy, we performed gain-of-function experiments in vitro and in vivo.

\subsubsection{Generation of recombinant Hspa4 adenovirus (Ad-Hspa4)}

To evaluate the ability of HSPA4 to attenuate cardiomyocyte hypertrophy in vitro, recombinant adenovirus was generated in collaboration with Dr. S. Lutz (Department of Pharmacology, Medical Faculty, Göttingen). Briefly, we have constructed an Ad-Hspa4 by cloning the full-length murine Hspa4 cDNA into the shuttle vector pAdTrack-CMV and subsequent cotransformation of this vector and pAdEasy-1 into electrocompetent AdEasier bacteria (Stratagene) as described previously (He et al., 1998). Expression of Hspa4 in the Ad-Hspa4 is driven by the constitutive active CMV

promoter. The virus also encodes the enhanced green fluorescent protein (EGFP) as a reporter gene. The EGFP is under the control of a separate CMV promoter (Fig. 3). The 


\section{EGFP adenovirus (Ad-EGFP) was used as the appropriate control}

adenovirus. Recombinant viral backbones from transformed AdEasier bacteria were collected and used for transfection of human embryonic kidney cells (HEK-293). After three weeks of transfection, Ad-Hspa4 adenovirus was harvested and used for transfection of neonatal rat cardiomyocytes (NRCMs).
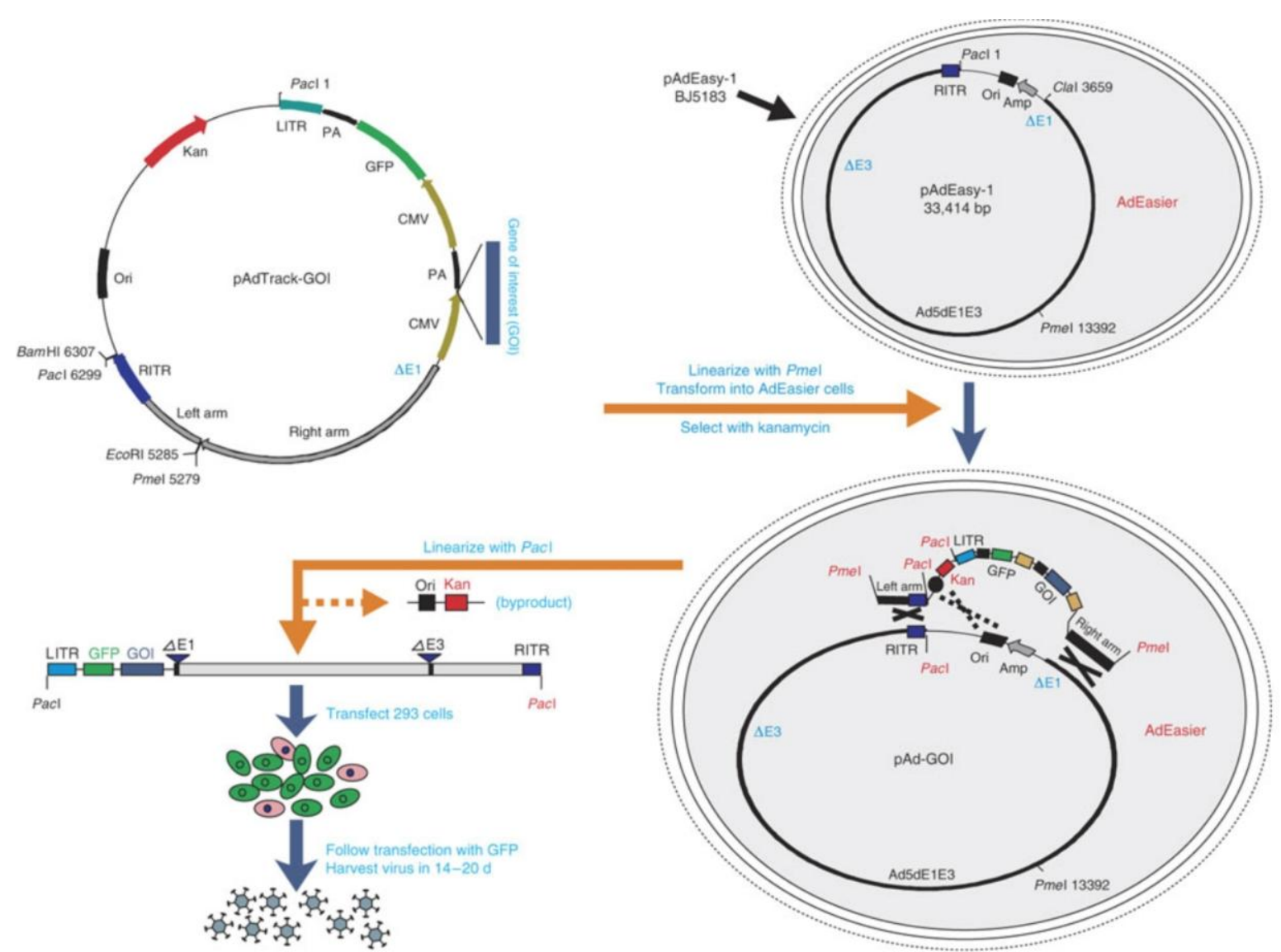

Figure 3. Schematic representation of the AdEasy technology. The Hspa4 cDNA was cloned into a pAdTrack-CMV shuttle vector and subsequently transformed into competent AdEasier cells, which are BJ5183 derivatives containing the adenoviral backbone plasmid pAdEasy-1. The confirmed recombinant adenovirus plasmids were digested with PacI to liberate both inverted terminal repeats (ITRs) and transfected into HEK-293 cells. HEK-293 cells express recombinant adenovirus E1, allowing them to produce adenoviruses from backbone vectors without the E1 gene. Recombinant adenoviruses are typically generated within 14-20 d. The 'left arm' and 'right arm' represent the regions mediating homologous recombination between the shuttle vector and the adenoviral backbone vector. Alternative homologous recombination between two Ori sites is shown with dotted lines. PA: polyadenylation site; LITR: left-hand ITR and packaging signal; RITR: right-hand ITR (Adapted from He et al., 1998, pp. 2511). 
The efficiency of gene transfer was evaluated by confocal fluorescence microscopy of EGFP expression in cardiac myocytes $24 \mathrm{hrs}$ after infection. The number of cells infected was more than $95 \%$ of the cultured NRCMs (Fig. 4A). To confirm the overexpression of HSPA4 in infected NRCMs, protein lysates from Ad-Hspa4- and control Ad-EGFPinfected NRCMs were isolated and subjected to Western blotting. As shown in Figure 4B, the protein level of HSPA4 was significantly increased in Ad-Hspa4- infected NRCMs compared to control.

To elucidate the impact of forced HSPA4 expression on cardiomyocyte hypertrophy, AdHspa4- infected NRCMs will be treated with phenylephrine (PE), an agonist for cardiac hypertrophy. The hypertrophic response will be evaluated by morphometric analysis of cardiomyocytes areas, sarcomeric rearrangement by immunostaining with $\alpha$-actinin antibody, measurement of the expression levels of hypertrophic markers (Nppa and $N p p b$ ) and quantification of EGFP synthesis as a surrogate for overall protein synthesis in Ad-Hspa4- and control Ad-EGFP- infected cells.

We have demonstrated that ablation of HSPA4 leads to impaired folding capacity of chaperones with subsequent accumulation of ubiquitinated proteins in the myocardium (Publication II). To test whether HSPA4 overexpression could enhance the chaperone mediated folding machinery and reduce ubiquitinated proteins accumulation, protein lysates from Ad-Hspa4- and control Ad-EGFP-infected NRCMs were isolated and subjected to immunoblotting. Interestingly, the total ubiquitinated proteins were significantly decreased in infected Ad-Hspa4 cells compared to that in Ad-EGFP control (Fig. 4C). This result suggests that HSPA4 plays a fundamental role in the chaperone mediated protein folding. 
A)
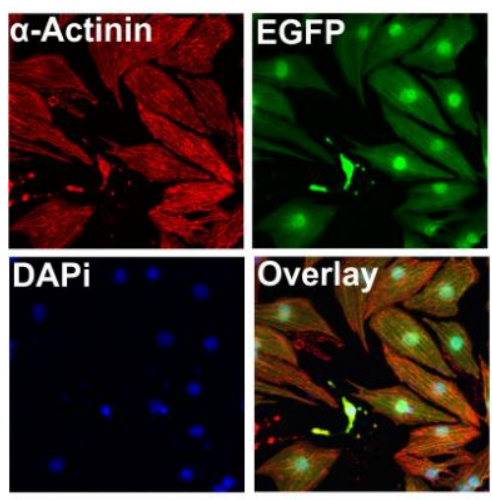

B)

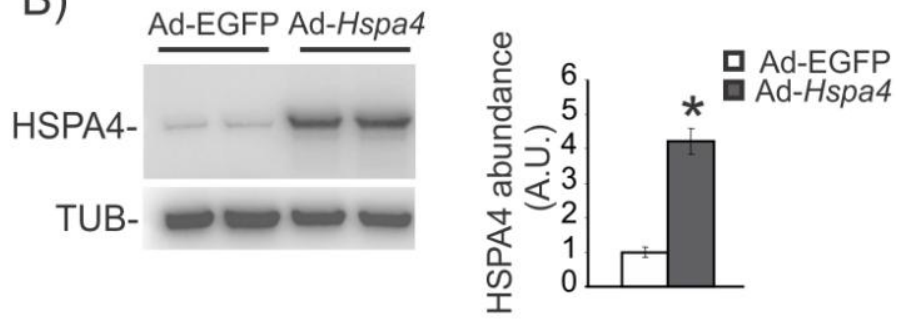

C)

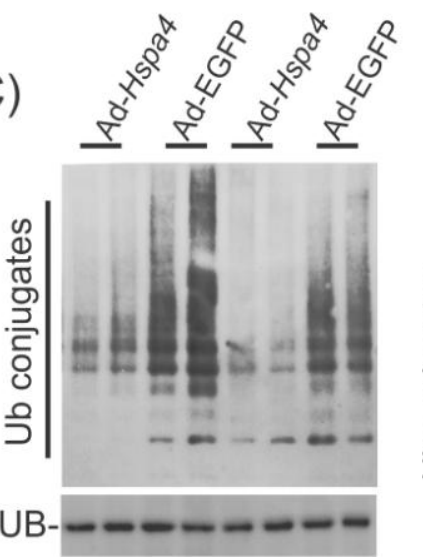

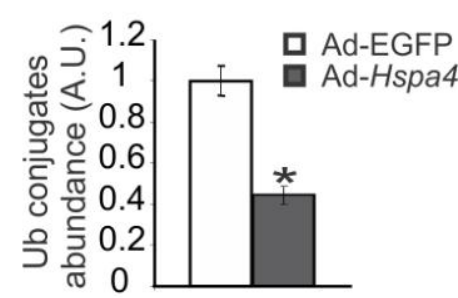

Figure 4. Analysis of Ad-Hspa4- infected NRCMs. A, Cultured NRCMs were infected with Ad-Hspa4. Co-expression of the green fluorescent protein (EGFP) tracer and $\alpha$-actinin indicates efficient infection of more than $95 \%$ of the cardiomyocytes. B, Immunoblotting shows increasing HSPA4 protein levels in AdHspa4- infected cardiomyocytes. Western blots were probed with antibodies directed against HSPA4 and $\alpha$-tubulin (TUB). In the bar graph presenting in the right panel, expression levels of HSPA4 were normalized to that of $\alpha$-tubulin. Values are expressed as mean \pm SD. HSPA4 protein levels in Ad-EGFP control culture serve as reference. $* P<0.05$ vs control, A.U. indicates arbitrary units. C, Western blot analyses of total ubiquitinated proteins in Ad-Hspa4- and Ad-EGFP- infected NRCMs. Representative image and pooled densitometry data are shown. Values are expressed as mean \pm SD. HSPA4 protein levels in Ad-EGFP control culture serve as reference. ${ }^{*} P<0.05$ vs control, A.U. indicates arbitrary units.

\subsubsection{Generation of cardiac specific Hspa4 transgenic mouse model}

To investigate the cardioprotective effect of HSPA4 overexpression against pressure overload-induced cardiac hypertrophy in vivo, we decided to generate a mouse model with cardiac-specific overexpression of HSPA4. Towards this end, murine Hspa4 cDNA was generated by PCR, cloned into pGEM-T Easy vector (Promega, Madison WI, USA) and verified by DNA sequencing. The Hspa4 cDNA was then cloned downstream of the cardiac specific $\alpha$-MHC promoter. The plasmid containing the $\alpha$-MHC promoter was 
provided by Prof. Dr. W.-H. Zimmermann (Department of Pharmacology, Medical Faculty, Göttingen). The cardiac $\alpha$-MHC promoter is exclusively transactivated in cardiomyocytes (Fig. 5).

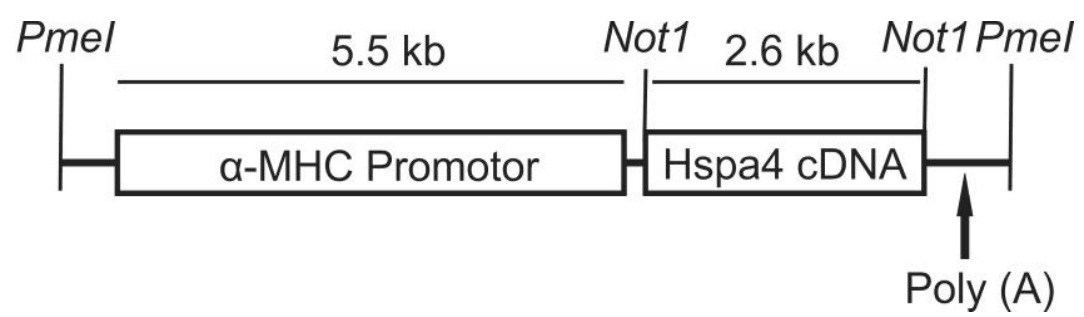

Figure 5. Schematic diagram of the transgene construct used for the generation of Hspa4 transgenic mice. The construct contains the $\alpha-\mathrm{MHC}$ gene promoter, the full-length mouse Hspa4 cDNA clone, and a polyadenylylation sequence (poly A).

In future experiments, the recombinant $\alpha$-MHC-Hspa4 fragment will be microinjected into nuclei of fertilized oocytes collected from mice of FVB strain. The microinjected oocytes will be transferred into oviducts of pseudopregnant females. Genomic integration, copy number and expression of transgenic allele in the transgenic founders will be determined by qRT-PCR analysis and Western blotting. To evaluate the cardioprotective effect of forced HSPA4 expression against pressure overload-induced cardiac hypertrophy, Hspa4 transgenic and WT mice will be subjected to TAC operation. After two weeks, we will determine the extent of cardiac hypertrophy by echocardiogram, histology, expression levels of hypertrophy and fibrosis related markers in both genotypes.

\subsection{Simultaneous deletion of murine $\mathrm{Hspa} 4 \mathrm{l}$ and $\mathrm{Hspa} 4$ genes causes pulmonary immaturity and early neonatal lethality in mouse}


The HSP110 gene family includes two genes in Saccharomyces cerevisiae known as Sse1 and Sse2 (Mukai, et al., 1993; Shirayama et al., 1993). Ablation of Sse1 resulted in growth defect and temperature sensitivity, whereas Sse2 loss had no overt phenotype (Mukai, et al., 1993). However, deletion of both Sse1 and Sse2 genes was lethal, indicating a unique important cellular function of both proteins in yeast (Shaner et al., 2005; Trott et al., 2005). Given the ubiquitous patterns of $\mathrm{Hspa} 4 \mathrm{l}$ and $\mathrm{Hspa4}$ expression and their high sequence homology (Kaneko et al., 1997a, b), it is conceivable that mutual functional compensation could confound the phenotype of Hspa4l- and Hspa4- KO mice. To address this hypothesis, we have generated and analyzed the Hspa4l/Hspa4 DKO mice. $\mathrm{Hspa}_{4} \mathrm{l}^{--} \mathrm{Hspa}^{-/-}$mice died shortly after birth. To get insight into the underlying cause of death, we closely monitored the fate of E18.5 embryos, which was just prior to the delivery day, delivered by Caesarean section (C-section). Inactivation of HSPA4L and HSPA4 in lung of $\mathrm{Hspa}^{\gamma^{--}} \mathrm{Hspa4}^{-/}$embryos was confirmed by Western blotting (Fig. 6A).

At E18.5 the body weight of $\mathrm{Hspa}^{-l^{--}} \mathrm{Hspa}^{-/-}$embryos was significantly smaller than that of controls (WT, Hspa4l ${ }^{-/}$and $\mathrm{Hspa}^{-/}$embryos) (Fig. 6B, C). Hspa4l $\mathrm{H}^{--} \mathrm{Hspa}^{-/-}$ embryos made visible effort to breath. However, in contrast to control embryos, $\mathrm{Hspa}_{\mathrm{H}} \mathrm{l}^{-}$ $\mathrm{Hspa}^{-/-}$embryos were less active and became cyanotic and died of respiratory distress during $1 \mathrm{hr}$ after revival. These observations suggest that HSPA4L and HSPA4 are essential for embryonic development and that simultaneous ablation of both genes leads to embryonic growth retardation and early neonatal death. Histological analyses revealed no overt abnormalities in other tissues including heart (data not shown) in $\mathrm{Hspa}^{-/-}$ $\mathrm{Hspa4}^{-/}$embryos, raising the possibility that the pulmonary defect is responsible for 
neonatal lethality. While organ weights of heart, kidney and liver were similar between genotypes (data not shown), we observed that the lung of $\mathrm{Hspal}^{-/} \mathrm{Hspa}^{-/-}$embryos at E18.5 were significantly smaller compared with controls (Fig. 6D). This finding indicates that the $\mathrm{Hspa}_{\mathrm{Al}} \mathrm{I}^{--} \mathrm{Hspa4}^{-/}$embryos develop pulmonary hypoplasia. Lungs dissected from $\mathrm{Hspa}_{4} \mathrm{l}^{-\mathrm{Hspa}^{-/}}$embryos did not float on water, indicating that the lungs are not inflated with air (Fig. 6E).

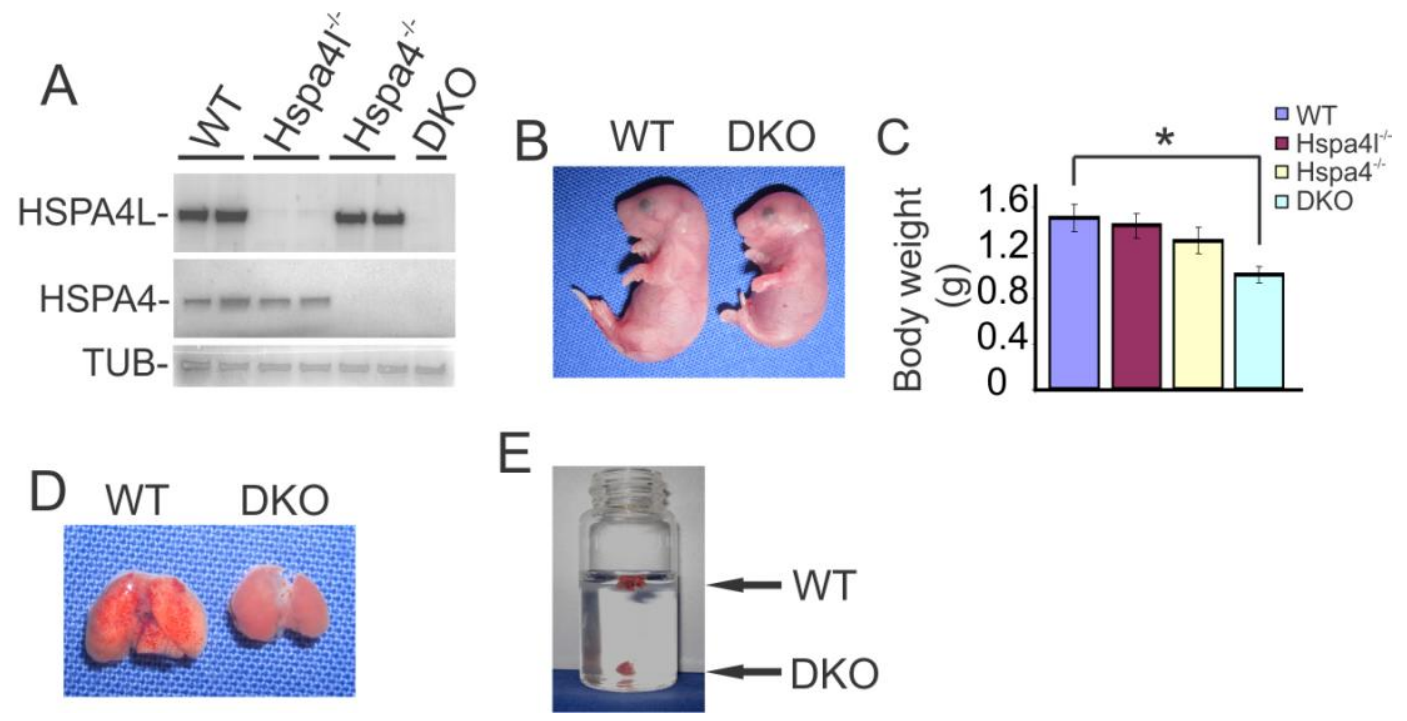

Figure 6. Simultaneous ablation of HSPA4L and HSPA4 led to pulmonary hypoplasia. (A) Western blotting for the expression of HSPA4L and HSPA4 proteins in extracts of lungs from wild type (WT),

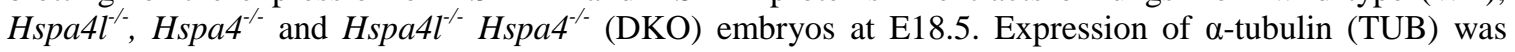
used as a loading control. (B) Representative image of WT and DKO embryos at E18.5. (C) The body weight of E18.5 WT, $\mathrm{Hspa4l}^{--}, \mathrm{Hspa}^{-/}$and DKO embryos. Five to seven embryos per genotype were used in this analysis. Value is presented as mean $\pm \mathrm{SD}, * P<0.05$ vs WT. (D) Gross images of the lung tissue isolated from WT and DKO embryos at E18.5. (E) The floating lung assay for WT and DKO embryos. DKO lung (the lower one) has sunk, while the WT lung is floating in the PBS. DKO, double knockout.

Prior to investigation of the pulmonary phenotype of DKO embryos, the expression level and distribution pattern of HSPA4L and HSPA4 during lung development were studied. Immunoblot analysis showed that both HSPA4L and HSPA4 proteins were ubiquitously 
expressed in lung during the embryonic (E12.5-E18.5) and postnatal days (P1, P2, P45)

(Fig. 7A).
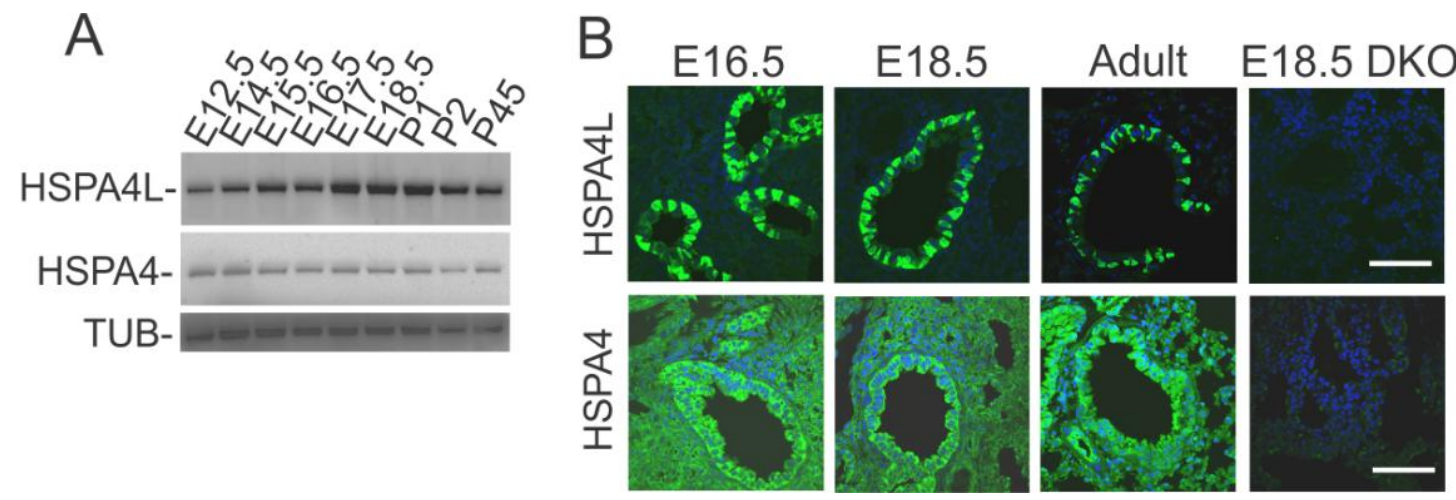

Figure 7. Expression of HSPA4L and HSPA4 in embryonic and adult murine lung. (A) Western blot analysis for the expression of HSPA4L and HSPA4 in WT lung at different developmental stages. Expression of $\alpha$-tubulin (TUB) was used as a loading control. (B) Cellular distribution of HSPA4L- and HSPA4-positive cells in the lung. Immunofluorescence study of HSPA4L and HSPA4 in lung sections from WT mice of E16.5, E18.5- and of adult- stage and from $\mathrm{Hspa4l}^{-\alpha} \mathrm{Hspa}^{-{ }^{-\alpha}}$ (DKO) embryos at E18.5. Nuclei were stained blue with DAPI. Bar $=30 \mu \mathrm{m}$. DKO, double knockout.

Multiple cell types are present in the lung, including epithelial, mesenchymal and endothelial cells. To elucidate the cellular distribution of HSPA4L and HSPA4 proteins in the lung, paraffin sections of lungs isolated from embryonic and adult WT mice were subjected to immunofluorescence analysis. HSPA4L immunoreactivity was identified exclusively in a subpopulation of bronchial and bronchiolar epithelial cells in both embryonic and adult lung sections (Fig. 7B). Detectable HSPA4 immunoreactivity was ubiquitously distributed in all pulmonary cells with stronger signals identified in bronchial and bronchiolar epithelial cells (Fig. 7B). No immunoreactivity was observed for HSPA4L and HSPA4 in the lung sections derived from E18.5 $\mathrm{Hspa}^{-/} \mathrm{Hspa}^{-/-}$ embryos (Fig. 7B) confirming the specificity of the antibodies used. These data demonstrate an extensive overlap in the expression pattern of HSPA4L and HSPA4 in bronchial epithelium. 
In the mouse, lung development is divided into four stages (Maeda et al., 2007). During the pseudoglandular stage (E9.5-E16.5) branching morphogenesis generates the respiratory tree, and the pulmonary vasculature starts to develop. At the canalicular stage (E16.5-E17.5) the terminal bronchioles expand to form the respiratory ducts and sacs. The saccular stage (E17.5-PN5) is characterized by thinning of the mesenchyme and the differentiation of ATI and ATII pneumocytes, which are responsible for gas exchange and surfactant synthesis, respectively (Williams and Mason, 1977; Weaver TE and Conkright, 2001; Boggaram, 2003). The alveolar stage occurs after birth and is characterized by the remodeling of saccules into alveoli.

In the lung of $\mathrm{Hspa4l}^{-/} \mathrm{Hspa}^{-/}$embryos at E15.5, branching morphogenesis and canalicular stages occured normally compared to age matched controls (Fig. 8A). These data suggest that early signaling events inclding, mesenchymal FGF-10, endodermally derived FGF-R2, SHH/GLI 2,3 and retinoic acid receptors, which transpire between foregut endoderm and surrounding splanchnic mesoderm (Mendelsohn et al., 1994; Bellusci et al., 1997; Litingtung et al., 1998; Min et al., 1998; De Moerlooze et al., 2000) are unaffected in the $\mathrm{Hspa}^{-/-} \mathrm{Hspa}^{-/}$lung.

Diminished saccular expansions with concomitant increased mesenchymal tissue, which are consistent with pulmonary immaturity, were evident in the lung at E17.5 and became exaggerated at E18.5 and E19.5 stages (Fig. 8A). Morphometric analysis demonstrated a significant decrease of saccular size and increased thickness of mesenchymal septa in the $\mathrm{Hspa}_{4} \mathrm{l}^{-/} \mathrm{Hspa}^{-/-}$lung compared with controls (Fig. 8B, C). 


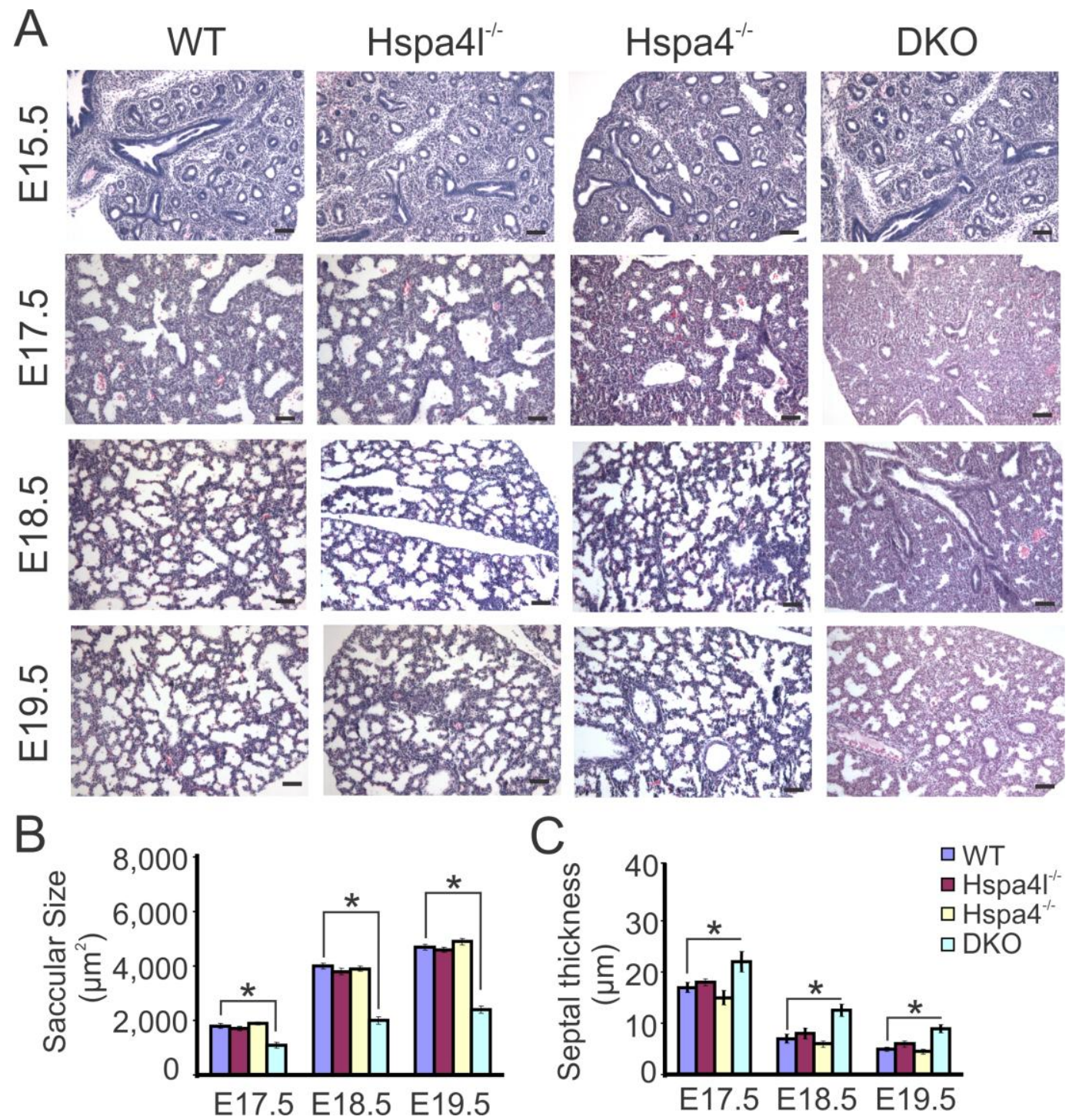

Figure 8. Delayed maturation of distal pulmonary epithelium in $H_{s p a} 4 l^{--} H s p a 4^{-\kappa}$ embryos. (A) Lung sections from embryos were prepared at the indicated developmental stages and stained with H\&E.

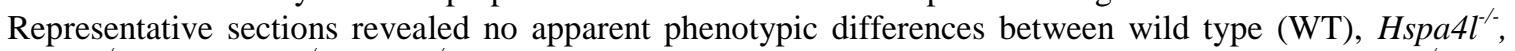

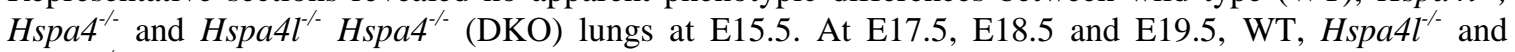
$\mathrm{Hspa}^{-/}$lungs have dilated terminal sacs and a thinned mesenchyme. In contrast, DKO lung has reduced terminal sacs with thickened intervening mesenchyme. Bar $=50 \mu \mathrm{m}$. (B and C) Morphometric analysis of lung saccular airspace (B) and mesenchymal septal thickness (C) in E17.5, E18.5 and E19.5 embryos. $* P<$ 0.05 vs WT, $\mathrm{n}=5$ per genotype per embryonic stage. DKO, double knockout.

The limited saccular expansion in the lung at the end of gestation forced us to investigate the maturation status of ATII pneumocytes. Immature ATII cells are glycogen-rich and when they differentiate, glycogen is converted into phospholipids, which are mixed with surfactant-associated proteins (SPs) to form the surfactant complexes (Ronney et al., 
1994; Ridsdale and Post, 2004). In ATII pneumocytes, synthesized surfactant is stored in the cytoplasmic lamellar bodies. Immaturity of type II pneumocytes, which is associated with high glycogen content and decreased surfactant production, leads to respiratory distress and poor neonatal survival (Whitsett and Weaver, 2002). Thus, we stained E18.5 lung sections with PAS to assess intracellular glycogen in the ATII cells. Indeed, the proportion of glycogen-rich cells in the alveolar epithelium of the $\mathrm{Hspa}_{\mathrm{S}} \mathrm{I}^{--} \mathrm{Hspa}^{-/-}$lung was more than fivefold higher than that in the WT, $\mathrm{Hspa}_{4} \mathrm{l}^{--}$and $\mathrm{Hspa}^{-{ }^{--}}$control lungs (Fig. 9A, B). To further substantiate this result, we examined the morphology of ATII cells using transmission electron microscopy. As illustrated in Figure 9C, ATII pneumocytes from $\mathrm{Hspa}_{\mathrm{S}} \mathrm{l}^{--} \mathrm{Hspa}^{-4_{-}}$embryos contained abundant glycogen, smaller and less number of lamellar bodies when compared to WT littermates. These findings suggest that maturation of ATII cells is impaired in the $\mathrm{Hspa}^{-l^{-/}} \mathrm{Hspa} 4^{-/}$lung.

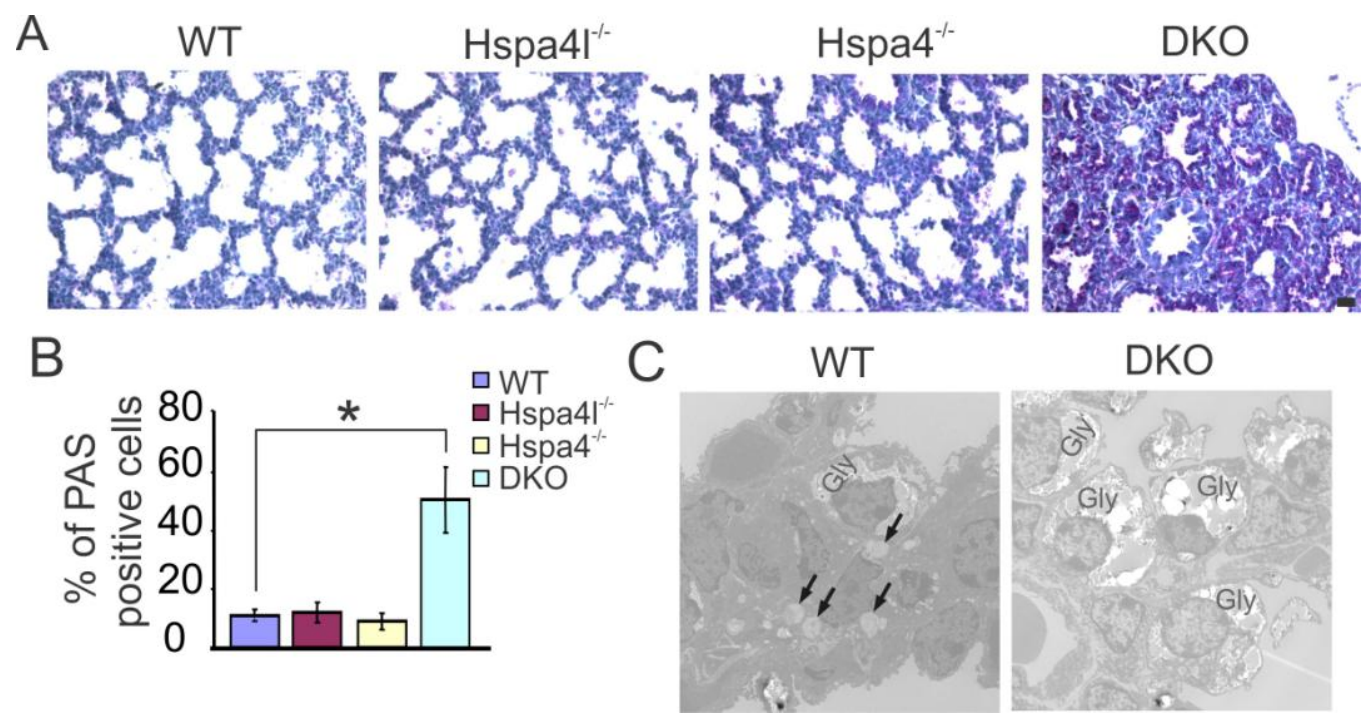

Figure 9. Glycogen accumulation and poor lamellar bodies in ATII pneumocytes of $\mathrm{Hspa}^{-/ \sim} \mathrm{Hspa}^{-/}$lung. (A) PAS stains indicating cytoplasmic glycogen in lung sections from E18.5 wild type (WT), Hspa4l ${ }^{-1}$, $\mathrm{Hspa}^{-/}$and $\mathrm{Hspa4l}^{--} \mathrm{Hspa4}^{-/}$(DKO) embryos. Bar $=20 \mu \mathrm{m}$. (B) Quantitation of PAS-positive cells. More than 800 alveolar epithelial cells were randomly examined for each genotype for the statistical comparison. $* P<0.05$ vs WT, $\mathrm{n}=3-4$ per genotype. (C) Electron microscopy of E18.5 WT and DKO lungs demonstrates ultrastructure immaturity of the ATII cells in the peripheral lung saccules of DKO lung. 
Cuboidal ATII cells of WT lung were found to contain numerous lamellar bodies (arrows). In ATII cells of DKO lung, lamellar bodies are scanty and the cytoplasm is occupied by glycogen (Gly). DKO, double knockout.

To confirm impaired maturation of ATII pneumocytes, we then directly assessed the

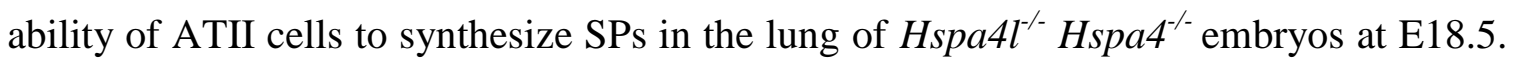
The SPs include SP-A, SP-B, SP-C, and SP-D (Rooney et al., 1994). Immunofluorescence analyses were performed using antibodies against mature SP-B and proSP-C. In comparison to WT, $\mathrm{Hspa}^{\mathrm{C}^{--}}$and $\mathrm{Hspa}^{-/-}$control lungs, the number of proSP-C- and SP-B-positive cells was significantly reduced in $\mathrm{Hspat}^{-/-} \mathrm{Hspa4}^{-/}$lung (Fig. 10A). In agreement with the immunofluorescence results, Western blotting revealed that protein levels of mature SP-B and proSP-C were significantly decreased in $\mathrm{Hspa}_{\mathrm{H}} \mathrm{I}^{-}$ $\mathrm{Hspa}^{-/-}$compared to control lungs (Fig. 10B). These reduced levels of SPs together with abnormal accumulation of intracellular glycogen in the pulmonary epithelial cells denote that the maturation of pulmonary ATII cells is severely impaired in embryonic lung of $\mathrm{Hspa4l}^{--} \mathrm{Hspa4}^{-/-}$embryos.

Expression of SPs in ATII epithelial cells normally increases prior to birth (Randell and Young, 2004). Of these, SP-B and SP-C play pivotal roles in surfactant function and homeostasis (Clark et al., 1995; Clark et al., 2001; Ikegami et al., 2003; Shulenin et al., 2004). Mutations in SP-B cause lethal respiratory distress in human and mouse (Nogee et al., 1994; Clark et al., 1995; Nogee et al., 2000). Targeted disruption of SP-B in mouse perturbed formation of lamellar bodies, causing respiratory failure shortly after birth (Clark et al., 1995). Reduction of SP-B was also found to be associated with surfactant dysfunction and respiratory failure in the perinatal and postnatal periods (Gregory et al., 1991). The reduced expression of SP-B and proSP-C may be responsible for the alveolar 
collapse, which leads to respiratory failure and neonatal lethality in $\mathrm{Hspa}_{\mathrm{Al}} \mathrm{l}^{-} \mathrm{Hspa}^{-/-}$ embryos.

Because ATI cells differentiate from ATII cells (Warburton et al., 2000; Bhaskaran et al., 2007), it is reasonable to hypothesize that immature ATII cells will impair maturity of ATI cells. To address this hypothesis, we performed immunofluorescence analysis with antibody against Aquaporin 5 (AQP5). AQP5 is a water channel protein and its expression is restricted to ATI pneumocytes (Verkman et al., 2000; Williams, 2003). AQP5 immunostaining was widespread in cells lining the distal airspaces in E18.5 lung of WT, $\mathrm{Hspa}_{\mathrm{S}} \mathrm{I}^{--}$and $\mathrm{Hspa}_{4}^{-{ }_{-}}$embryos. In contrast, AQP5 displayed a differential pattern of expression in the $\mathrm{Hspall}^{-/} \mathrm{Hspa}^{-/}$lung. In some areas of the lung, AQP5 immunostaining was present in the apical membrane of ATI cells, while AQP5-positive cells were lacked in other regions of the lung (Fig. 10A). Consistent with this finding, Western blot analysis demonstrated a significant reduction in the expression levels of AQP5 protein in the lung of $\mathrm{Hspa}_{4} \mathrm{l}^{--} \mathrm{Hspa}^{-/-}$embryos (Fig. 10B). These results suggest that the respiratory distress seen in $\mathrm{Hspal}^{--} \mathrm{Hspa}^{-/-}$embryos could be also due to an impaired gas exchange resulting from decreased numbers of mature ATI cells. Taken together, these data indicate that dual deletion of HSPA4L and HSPA4 leads to delayed maturation of alveolar epithelium. 

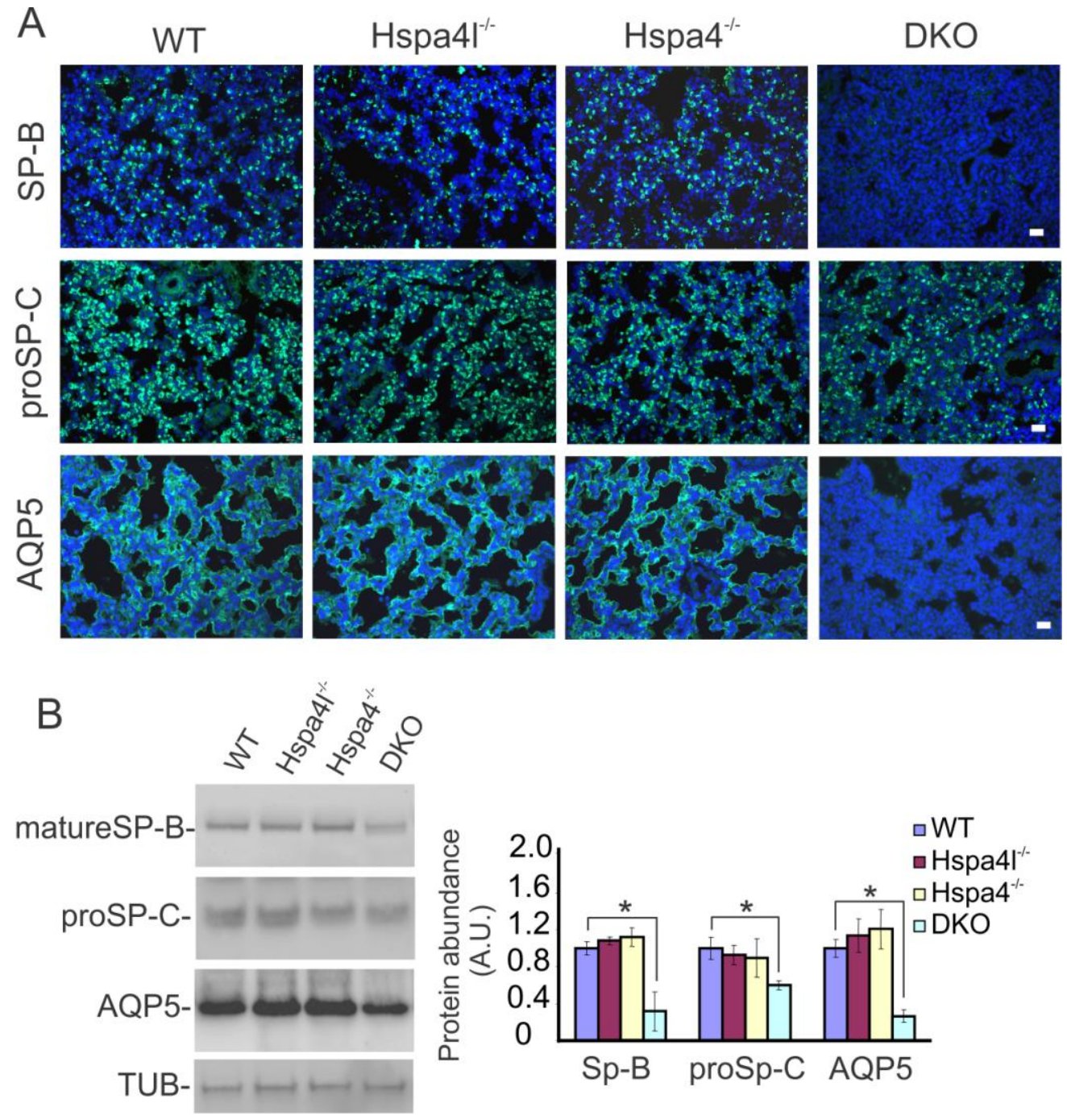

Figure 10. Diminished expression of SP-B, proSP-C and AQP5 in the lung of $\mathrm{Hspa}_{4} \mathrm{I}^{--} \mathrm{Hspa}^{-/}$embryos.

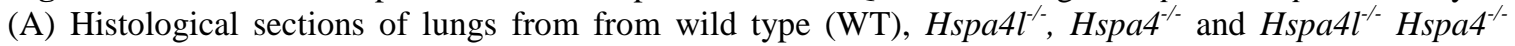
(DKO) embryos at E18.5 were immunostained with antibodies against SP-B, proSP-C and AQP5. Scale bars: $20 \mu \mathrm{m}$. (B) Immunoblotting of lung homogenates from different genotypes was probed with antibodies directed against SP-B, proSP-C, AQP5 and $\alpha$-tubulin. In the bar graph presented in the right panel, expression levels of SP-B, proSP-C and AQP5 proteins were normalized to that of $\alpha$-tubulin. Values are expressed as mean \pm SD. protein levels in WT lung served as reference. ${ }^{*} P<0.05$ vs control, $\mathrm{n}=3-4$ per genotype. A.U. indicates arbitrary units. DKO, double knockout.

Normal growth of an organ depends on precise control of cell proliferation and cell death.

Cell proliferation not only sustains overall lung growth in the embryo, but also influences lung remodeling during stages of gestation (Weaver M et al., 2000). Many genes and signaling pathways critical to these processes have been described (Chinoy et al., 2001; 
Compernolle et al., 2002; Wan et al., 2005; Martis et al., 2006; Ban et al., 2007; Shu et al., 2007). Hspa4l and Hspa4 expressions are induced in carcinomas and are thought to play a role during proliferation (Kaneko et al., 1997a, b; Nakatsura et al., 2001; Gotoh et al., 2004; Tsapara et al., 2006; Takahashi et al., 2007; Li C et al., 2010). We assessed cell

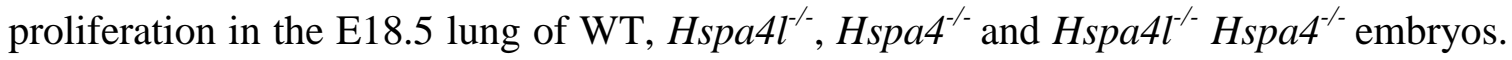
Relative to WT, Hspa4l $l^{--}$and $H_{s p a 4^{-/}}$lungs, increased cell proliferation was demonstrated in $\mathrm{Hspa}_{\mathrm{H}} \mathrm{l}^{--} \mathrm{Hspa}^{-/}$lungs as quantified by increased number of BrdUpositive cells and a significant upregulation of Cyclin D1 that is considered as one of the key factors regulating progression through the G1/S transition of the cell cycle (Hansen and Albrecht, 1999; Ciemerych and Sicinski, 2005; Golsteyn, 2005; Harper and Brooks, 2005).

It has been reported that alveolar and mesenchymal cells undergo apoptosis during normal lung development and maturation (Kresch et al., 1998; Scavo et al., 1998; Stiles et al., 2001; Sutherland et al., 2001). Precise control of the cell deletion by apoptosis is essential during normal lung development (De Paepe et al., 1999). A combination of in situ TUNEL assay and immunostaining for cleaved Caspase 3 was performed. As shown in Figure 11C and D, there was a significant decrease in the number of cleaved Caspase 3- and TUNEL-positive cells in the lung of E18.5 $\mathrm{Hspa4l}^{--} \mathrm{Hspa}^{-/-}$embryos.

Taken together, increased cell proliferation and diminished cell apoptosis could be a potential mechanism contributing to increased mesenchymal thickness observed in the lung of $\mathrm{Hspa4l}^{--} \mathrm{Hspa4}^{--}$embryos. 


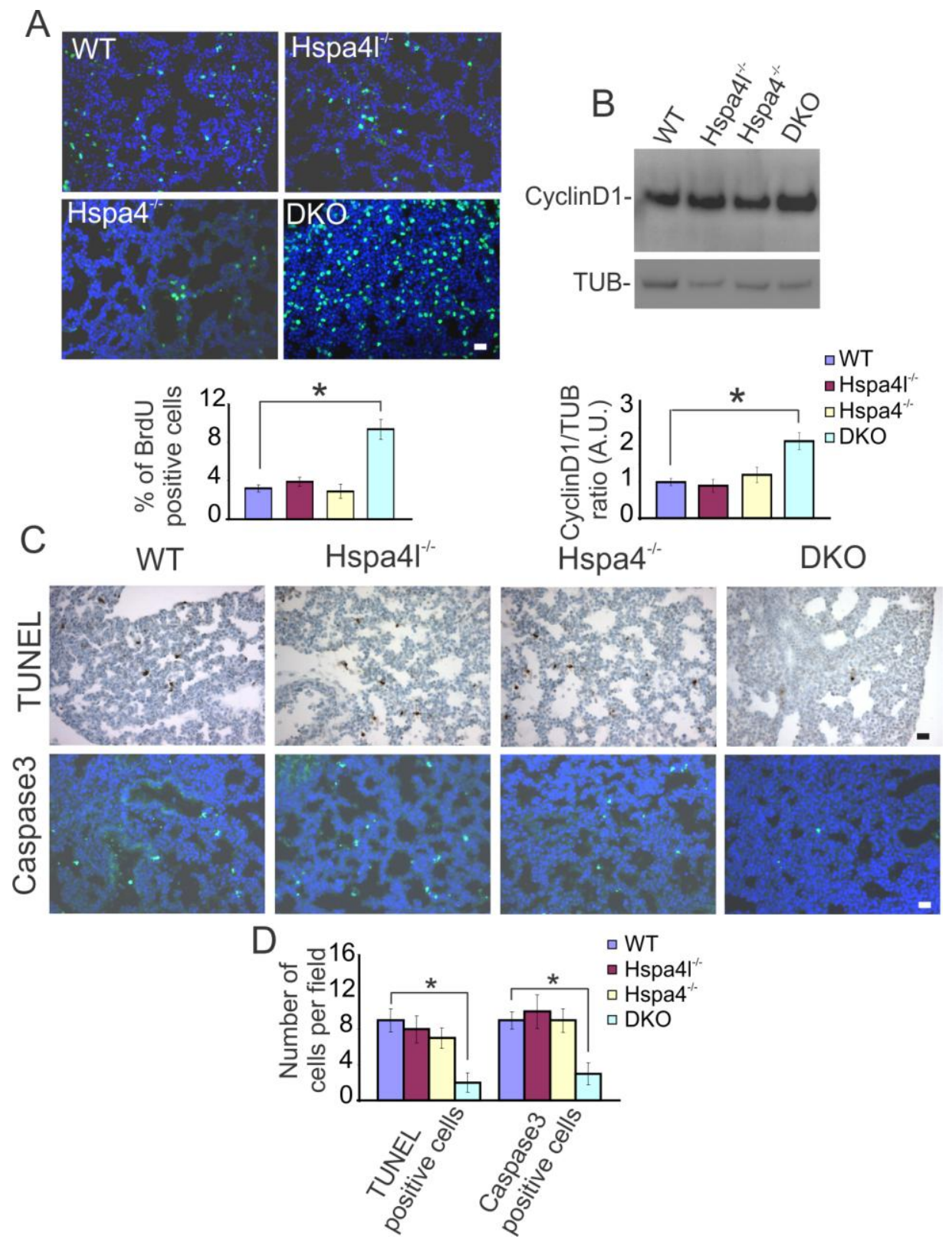

Figure 11. Increased proliferation and diminished apoptosis in the $H s p a 4 T^{-/} H s p a 4^{-1}$ lungs. (A) Immunofluorescence staining was performed using antibodies against $\mathrm{BrdU}$ in lung sections of wild type

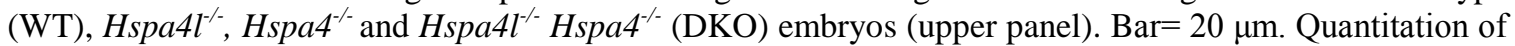
BrdU-positive cells (lower panel). More than 1000 alveolar epithelial cells were randomly examined for each genotype for the statistical comparison. $* P<0.05$ vs WT, $\mathrm{n}=3-4$ per genotype. (B) Western blotting was probed with antibodies directed against Cyclin D1 and $\alpha$-tubulin (TUB). In the bar graph presented in the lower panel, expression levels of Cyclin D1 were normalized to that of $\alpha$-tubulin. Values are expressed as mean $\pm \mathrm{SD}$. Cyclin D1 protein levels in WT lung served as reference. ${ }^{*} P<0.05$ vs control, $\mathrm{n}=3-4$ per genotype. A.U. indicates arbitrary units. (C) In situ TUNEL assay and cleaved Caspase 3 immunostaining. Bar $=20 \mu \mathrm{m}$. (D) Quantitation of TUNEL- and Caspase 3-positive cells. ${ }^{*} P<0.05$ vs WT, $\mathrm{n}=3-4$ per genotype. DKO, double knockout. 
To verify whether simultaneous depletion of HSPA4L and HSPA4 impaired the chaperone activity in the lung, Western blotting with protein extracts from lung of WT,

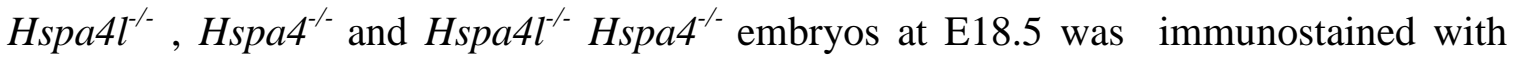
anti-Ubiquitin antibody. As shown in Figure 12A, levels of ubiquitinated proteins were significantly increased in extract of $\mathrm{Hspa}^{-/} \mathrm{Hspa}^{-/}$lung compared to that in lung extracts of other genotypes. Although, we have shown an increased accumulation of ubiquitinated proteins in the heart of postnatal $\mathrm{Hspa}^{-/-}$mice (Publication II), Western blot analysis did not show elevated levels of ubiquitinated proteins in the myocardial lysates derived from E18.5 $\mathrm{Hspa}^{-\mathrm{I}^{-}} \mathrm{Hspa}^{-/-}$embryos (Fig. 12B). These results suggest that dual depletion of HSPA4L/HSPA4 affects the folding capacity of chaperones in the embryonic lung.

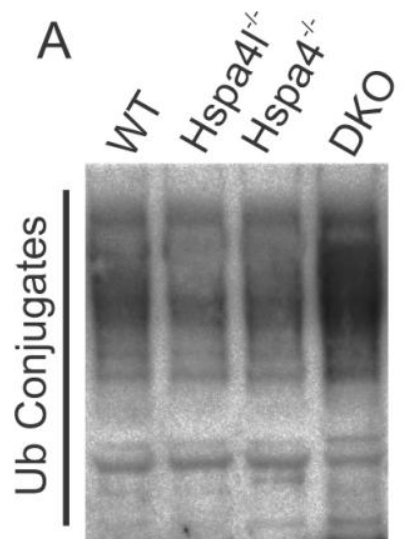

TUB-
B

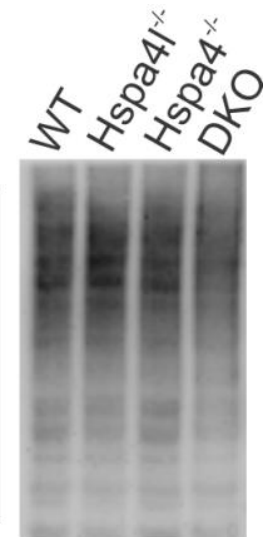

TUB-

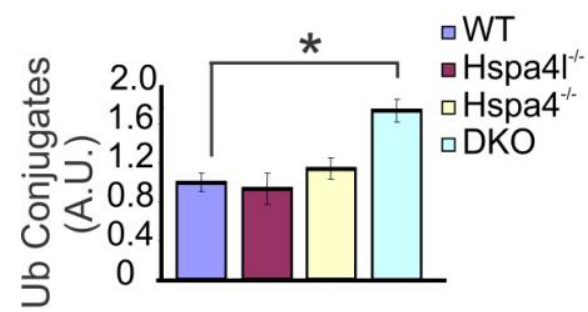

Figure 12. Increased accumulation of ubiquitinated proteins in $H s p a 4 l^{-\kappa} H s p a 4^{-/}$lungs. (A) Total

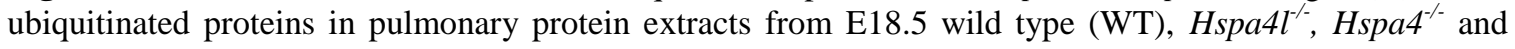


$\mathrm{Hspa}_{4} \mathrm{H}^{--} \mathrm{Hspa}^{-/-}$(DKO) embryos were analyzed by immunoblots (left panel). Histograms show relative abundance of ubiquitinated proteins in protein extracts (right panel). Expression of $\alpha$-tubulin (TUB) was used as a loading control. Values are expressed in mean \pm SD. Ubiquitinated proteins in WT samples were expressed as 1.0. $* P<0.05$ vs WT, $\mathrm{n}=4$ per group. A.U. indicates arbitrary units. (B) Western blotting for the abundance of ubiquitinated proteins in the heart of E18.5 WT, Hspa4l $\mathrm{I}^{--}, \mathrm{Hspa}^{-/}$and DKO embryos. DKO, double knockout.

Increased accumulation of misfolded proteins above the threshold level impairs the functional capacity of the proteasome (Bennett et al., 2005). The ubiquitin- proteasome system (UPS) is also responsible for the degradation of the majority of cellular proteins that are no longer needed. Dysfunctional protein degradation will affect not only PQC but also many other cellular processes (Carrier et al., 2010; Fasanaro et al., 2010; Hedhli and Depre, 2010; Luo et al., 2010). Previous study has addressed the link between SPs synthesis and the efficient proteasomal activity. The result of this study revealed that impaired activity of proteasome in lung cell lines leads to inhibition of SPs synthesis, in particular SP-B and SP-C (Das and Boggaram, 2007). Moreover, mutations in SP-C in vivo and in vitro especially in BRICHOS domain are associated with accumulation of misfolded proteins and proteasomal dysfunction, which lead to deterioration of lung development (Bridges et al., 2003; Mulugeta et al., 2005). It will be important to deeply assess the proteasomal function in the lung of $\mathrm{Hspa}_{4} \mathrm{I}^{-\mathrm{Hspa}^{-/}}$mice to determine whether the proteasome is indeed defective. This ill give a solid proof that the surfactant deficiency and neonatal lethality exhibited by $\mathrm{Hspa}^{-/-} \mathrm{Hspa4}^{-/}$pups is indeed a consequence of proteasomal dysfunction. Taken together, our data suggest that ablation of deficiency of HSPA4L/HSPA4 leads to accumulation of misfolded and ubiquitinated proteins, which overwhelm and distort the capacity of proteasome in the lung of $\mathrm{Hspa}_{\mathrm{A}} \mathrm{I}^{--}$ $\mathrm{Hspa}^{-/}$pups. 
We have demonstrated that HSPA4L and HSPA4 were ubiquitously expressed in the lung during prenatal and postnatal development. However, targeted disruption of either Hspa4l or Hspa4 did not impair embryonic development. Growth retardation and impaired lung maturation demonstrated in $\mathrm{Hspa}_{4} \mathrm{l}^{--} \mathrm{Hspa}^{-/-}$embryos suggest that a possible functional redundancy might exist between HSPA4L and HSPA4 during embryonic development. In conclusion, our in vivo data provide novel molecular evidence of previously unknown contribution of both HSPA4L and HSPA4 to the maturation of alveolar epithelium.

\subsection{Generation of $\mathrm{Hsph1}$ conditional KO and Hspa4/Hsph1 DKO mice}

In order to determine the physiological function of the third member of Hspl10 family, namely Hsphl gene, we generated Hsphl deficient mice. To generate Hsphl chimeric mice, we used commercial $H s p h 1$ recombinant embryonic stem cells (ESCs) produced by European Conditional Mouse Mutagenesis Program (EUCOMM). The genome of homologous recombinant ES cells contains 2 loxP sites, which flank exons 9 and 10 of Hsph1 gene (Fig. 13A). To verify the correct homologous recombination in Hsphl gene, Southern hybridization was performed. The external probe detected a 15.5-kb BamHI fragment of the WT allele and a 11.5-kb BamHI recombinant fragment of the floxed allele (Fig. 13B). The recombinant ESCs were injected into C57BL/6J blastocysts. The microinjected blastocysts were transferred into uteri of pseudopregnant females. We obtained two germ-line transmitting chimeras, which were mated with C57B1/6J females to produce heterozygous mice $\left(H s p h l^{F /+}\right)$. To delete the floxed sequence, heterozygous mice were intercrossed with CreEII transgenic mice. The CreEII transgenic mice have the Cre-recombinase gene under the control of the EII promoter, which directs transcription 
of Cre-recombinase in oocyte and 1-cell stage of embryonic development. Expression of CreEII results in deletion of floxed Hsphl sequences in all cells of the developing embryo including the germ cells (Lakso et al., 1996). To determine whether Cremediated recombination was successful, we analyzed genomic DNA of the progeny using PCR with oligonucleotide primers F1, F2 and R. The PCR amplifies a 322-bp fragment of WT, a 350-bp fragment of floxed and a 420-bp fragment of deleted Hsphl alleles (Fig. 13C). RT-PCR with RNA isolated from the brain confirmed the absence of Hsphl transcript in $H s p h 1^{\Delta / \Delta}$ mice (Fig. 13D).

Breeding of $H s p h 1^{\Delta /+}$ animals produced $H s p h 1^{+/+}, H s p h 1^{\Delta /+}$, and $H s p h 1^{\Delta / \Delta}$ litters. Of 220 pups born and examined at the age of 3 to 4 weeks, 56 were $H s p h I^{+/+}, 111$ were $H s p h 1^{\Delta /+}$, and 53 were $H s p h 1^{\Delta / \Delta}$. These numbers are compatible with Mendelian ratios expected for nondeleterious alleles. Thus, $H s p h 1$ is not essential for embryonic development or viability of adult animals. The $H s p h 1^{\Delta / \Delta}$ mice did not show overt abnormalities. Histological analysis of various tissues failed to detect any significant differences between $H s p h 1^{\Delta / \Delta}$ and WT mice (data not shown). During our work to generate Hsphl KO mice, two reports have described the consequence of targeted disruption of Hsphl gene (Nakamura et al., 2008; Eroglu et al., 2010). Nakamura et al. (2008) have reported that the HSPH1 deletion did not affect the embryonic development, viability and fertility of mutant mice. However, Hsphl $\mathrm{KO}$ mice are resistant to ischemic injury and that the protective effects of HSPH1 deficiency in cerebral ischemia may be mediated by an increase in the chaperone activity of HSP70. Results of other group have demonstrated that lack of HSPH1 in mice is associated with tauopathy and neurodegeneration, which suggests that HSPH1 plays a protective role against 
neurodegenerative diseases such as Alzheimer's disease and other tauopathies (Eroglu et al., 2010).

To address whether there is a functional redundancy between HSPA4 and HSPH1, we decided to generate $H s p a 4 / H s p h 1$ DKO mice. Toward this end, $H s p a 4^{+/-}$mice were bred with $\mathrm{Hsph}^{\Delta / \Delta}$ mice to obtain $\mathrm{Hspa}^{+/-} \mathrm{Hsph}^{\Delta /+}$, which will be intercrossed in order to have $H \operatorname{spa} 4^{-/-} \mathrm{Hsph}^{\Delta / \Delta}$ mice. Analysis and characterization of the $H \operatorname{spa4^{--}} \mathrm{Hsph}^{\Delta / \Delta}$ mice will be undertaken.

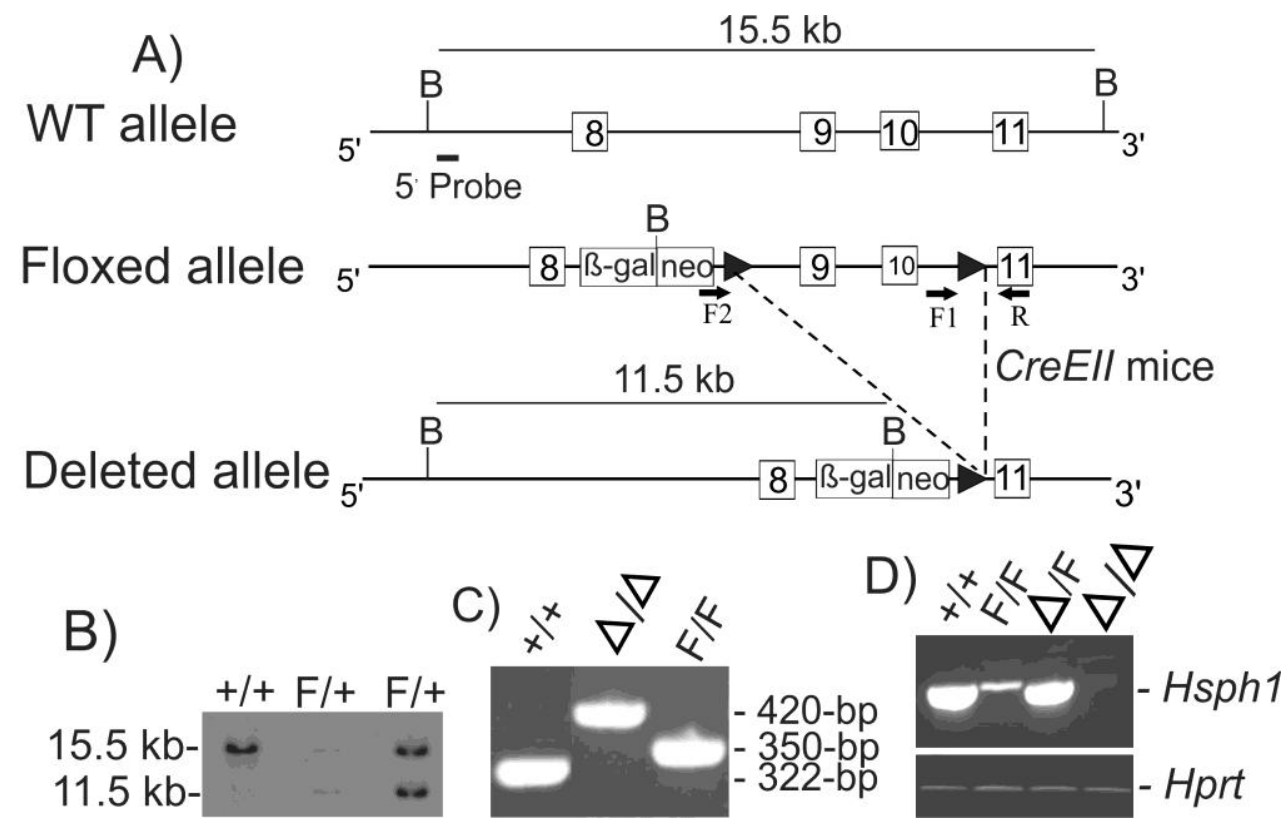

Figure 13. Generation of $H s p h l$ conditional KO mice and analysis of genotypes. A, Schematic diagram of targeting strategy. Arrows indicate the primers used for genotyping. Black triangles indicate loxP sites. Exons 9 and 10 (open boxed 9 and 10) were flanked by loxP sites and can be excised by Cre recombinase. Abbreviations: B, BamHI; neo, neomycin resistant cassette; $\beta$-gal, $\beta$-galactosidase cassette. B, Southern blot analysis of WT and targeted ESCs DNA using a 5' external probe. Genomic DNA extracted from ESCs was digested with BamHI and probed with an external probe, which detected a $15.5-\mathrm{kb}$ BamHI fragment in the WT allele and a 11.5-kb BamHI recombinant fragment in conditional allele. Locations of the probes are indicated in A. C, Genotyping of various $H s p h l$ alleles by PCR of DNA isolated from mice tail. Primers are designed to distinguish WT (+/+, 322-bp), floxed (F/F, 350-bp), and deleted ( $\Delta / \Delta, 420-\mathrm{bp})$ $H s p h l$ alleles. D, RT-PCR analysis was performed with RNA of brain from $H s p h l^{+/+}, H s p h l^{\mathrm{F} / \mathrm{F}}, H s p h 1^{\Delta / \mathrm{F}}$ and $H s p h l^{\Delta / \Delta}$ animals. A 450-bp product of $H s p h l$ gene was obtained from RNA of $H s p h 1^{+/+}, H s p h l^{\mathrm{F} / \mathrm{F}}$ and $H s p h 1^{\Delta / \mathrm{F}}$ animals, but no band was visible in case of $H s p h 1^{\Delta / \Delta}$ mice. The integrity of the RNA was verified by using Hprt primers. 


\section{References}

Adham IM, Nayernia K, Burkhardt-Göttges $\quad$ E, Topaloglu $\quad$ O, Dixkens $\quad$ C, Holstein AF, Engel W (2001): Teratozoospermia in mice lacking the transition protein 2 (Tnp2). Mol Hum Reprod 7, 513-520

Adly MA, Assaf HA, Hussein MR (2008): Heat shock protein 27 expression in the human testis showing normal and abnormalspermatogenesis. Cell Biol Int $\underline{32}$, 1247-1255

Allen JW, Dix DJ, Collins BW, Merrick BA, He C, Selkirk JK, Poorman-Allen P, Dresser ME, Eddy EM (1996): HSP70-2 is part of the synaptonemal complex in mouse and hamster spermatocytes. Chromosoma 104, 414-421

Allen RL, O'Brien DA, Jones CC, Rockett DL, Eddy EM (1988): Expression of heat shock proteins by isolated mouse spermatogenic cells. Mol Cell Biol $\underline{8}, 3260-3266$

Baek KH, Mondoux MA, Jaster R, Fire-Levin E, D'Andrea AD (2001): DUB-2A, a new member of the DUB subfamily of hematopoietic deubiquitinating enzymes. Blood $\underline{98}$, 636-642

Ban N, Matsumura Y, Sakai H, Takanezawa Y, Sasaki M, Arai H, Inagaki N (2007): $\mathrm{ABCA} 3$ as a lipid transporter in pulmonary surfactant biogenesis. J Biol Chem $\underline{282}$, 9628-9634

Bates G (2003): Huntingtin aggregation and toxicity in Huntington's disease. Lancet $\underline{361}$, $1642-1644$

Bellusci S, Furuta Y, Rush MG, Henderson R, Winnier G, Hogan BL (1997): Involvement of Sonic hedgehog (Shh) in mouse embryonic lung growth and morphogenesis. Development 124, 53-63

Bennett EJ, Bence NF, Jayakumar R, Kopito RR (2005): Global impairment of the ubiquitin-proteasome system by nuclear or cytoplasmic protein aggregates precedes inclusion body formation. Mol Cell $\underline{17}, 351-365$

Berke SJ, Paulson HL (2003): Protein aggregation and the ubiquitin proteasome pathway: gaining the UPPer hand on neurodegeneration. Curr Opin Genet Dev 13, 253-261

Bhaskaran M, Kolliputi N, Wang Y, Gou D, Chintagari NR, Liu L (2007): Transdifferentiation of alveolar epithelial type II cells to type I cells involves autocrine signaling by transforming growth factor beta 1 through the Smad pathway. J Biol Chem 282, 3968-3976 
Bhattacharya B, Miura T, Brandenberger R, Mejido J, Luo Y, Yang AX, Joshi BH, Ginis I, Thies RS, Amit M et al. (2004): Gene expression in human embryonic stem cell lines: unique molecular signature. Blood 103, 2956-2964

Birks EJ, Latif N, Enesa K, Folkvang T, Luong le A, Sarathchandra P, Khan M, Ovaa H, Terracciano CM, Barton PJ et al. (2008): Elevated p53 expression is associated with dysregulation of the ubiquitin-proteasome system in dilated cardiomyopathy. Cardiovasc Res $\underline{79}, 472-480$

Bitgood MJ, Shen L, McMahon AP (1996): Sertoli cell signaling by Desert hedgehog regulates the male germline. Curr Biol $\underline{6}, 298-304$

Boggaram V (2003): Regulation of lung surfactant protein gene expression. Front Biosci $\underline{8}, \mathrm{~d} 751-764$

Bradbury J (2003): Alpha-synuclein gene triplication discovered in Parkinson's disease. Lancet Neurol $\underline{2}, 715$

Bridges JP, Wert SE, Nogee LM, Weaver TE (2003): Expression of a human surfactant protein $\mathrm{C}$ mutation associated with interstitial lung disease disrupts lung development in transgenic mice. J Biol Chem 278, 52739-52746

Burnicka-Turek O, Shirneshan K, Paprotta I, Grzmil P, Meinhardt A, Engel W, Adham IM (2009): Inactivation of insulin-like factor 6 disrupts the progression of spermatogenesis at late meiotic prophase. Endocrinology 150, 4348-4357

Cai WF, Zhang XW, Yan HM, Ma YG, Wang XX, Yan J, Xin BM, Lv XX, Wang QQ, Wang ZY et al. (2010): Intracellular or extracellular heat shock protein 70 differentially regulates cardiac remodelling in pressure overload mice. Cardiovasc Res $\underline{88}, 140-149$

Carrier L, Schlossarek S, Willis MS, Eschenhagen T (2010): The ubiquitin-proteasome system and nonsense-mediated mRNA decay in hypertrophic cardiomyopathy. Cardiovasc Res $\underline{85}$, 330-338

Caughey B, Lansbury PT (2003): Protofibrils, pores, fibrils, and neurodegeneration: separating the responsible protein aggregates from the innocent bystanders. Annu Rev Neurosci 26, 267-298

Chen Q, Liu JB, Horak KM, Zheng H, Kumarapeli AR, Li J, Li F, Gerdes AM, Wawrousek EF, Wang X (2005): Intrasarcoplasmic amyloidosis impairs proteolytic function of proteasomes in cardiomyocytes by compromising substrate uptake. Circ Res 97, 1018-1026 
Chen X, Easton D, Oh HJ, Lee-Yoon DS, Liu X, Subjeck J (1996): The 170 kDa glucose regulated stress protein is a large HSP70-, HSP110-like protein of the endoplasmic reticulum. FEBS Lett $\underline{380}, 68-72$

Chinoy MR, Chi X, Cilley RE (2001): Down-regulation of regulatory proteins for differentiation and proliferation in murine fetal hypoplastic lungs: altered mesenchymalepithelial interactions. Pediatr Pulmonol 32, 129-141

Ciemerych MA, Sicinski P (2005): Cell cycle in mouse development. Oncogene 24, 2877-2898

Clark JC, Wert SE, Bachurski CJ, Stahlman MT, Stripp BR, Weaver TE, Whitsett JA (1995): Targeted disruption of the surfactant protein B gene disrupts surfactant homeostasis, causing respiratory failure in newborn mice. Proc Natl Acad Sci USA $\underline{92}$, 7794-7798

Clark JC, Tichelaar JW, Wert SE, Itoh N, Perl AK, Stahlman MT, Whitsett JA (2001): FGF-10 disrupts lung morphogenesis and causes pulmonary adenomas in vivo. Am J Physiol Lung Cell Mol Physiol 280, L705-715

Collins PL, Hightower LE (1982): Newcastle disease virus stimulates the cellular accumulation of stress (heat shock) mRNAs and proteins. J Virol $\underline{44}, 703-707$

Compernolle V, Brusselmans K, Acker T, Hoet P, Tjwa M, Beck H, Plaisance S, Dor Y, Keshet E, Lupu F et al. (2002): Loss of HIF-2alpha and inhibition of VEGF impair fetal lung maturation, whereas treatment with VEGF prevents fatal respiratory distress in premature mice. Nat Med $\underline{8}, 702-710$

Crawford KC, Vega Flores M, Oehlers SH, Hall CJ, Crosier KE, Crosier PS (2011): Zebrafish heat shock protein a4 genes in the intestinal epithelium are up-regulated during inflammation. Genesis $\underline{49}$, 905-911

Culty M (2009): Gonocytes, the forgotten cells of the germ cell lineage. Birth Defects Res C Embryo Today $\underline{87}$, 1-26

Das A, Boggaram V (2007): Proteasome dysfunction inhibits surfactant protein gene expression in lung epithelial cells: mechanism of inhibition of SP-B gene expression. Am J Physiol Lung Cell Mol Physiol 292, L74-84

Dehne T, Schenk R, Perka C, Morawietz L, Pruss A, Sittinger M, Kaps C, Ringe J (2010): Gene expression profiling of primary human articular chondrocytes in highdensity micromasses reveals patterns of recovery, maintenance, re- and dedifferentiation. Gene $\underline{462}, 8-17$

De Moerlooze L, Spencer-Dene B, Revest JM, Hajihosseini M, Rosewell I, Dickson C (2000): An important role for the IIIb isoform of fibroblast growth factor receptor 2 
(FGFR2) in mesenchymal-epithelial signalling during mouse organogenesis. Development $127,483-492$

De Paepe ME, Sardesai MP, Johnson BD, Lesieur-Brooks AM, Papadakis K, Luks FI (1999): The role of apoptosis in normal and accelerated lung development in fetal rabbits. J Pediatr Surg 34, 863-870

Dix DJ, Allen JW, Collins BW, Mori C, Nakamura N, Poorman-Allen P, Goulding EH, Eddy EM (1996): Targeted gene disruption of Hsp70-2 results in failed meiosis, germ cell apoptosis, and male infertility. Proc Natl Acad Sci USA 93, 3264-3268

Dix DJ, Allen JW, Collins BW, Poorman-Allen P, Mori C, Blizard DR, Brown PR, Goulding EH, Strong BD, Eddy EM (1997): HSP70-2 is required for desynapsis of synaptonemal complexes during meiotic prophase in juvenile and adult mouse spermatocytes. Development 124, 4595-4603

Dix DJ, Hong RL (1998): Protective mechanisms in germ cells: stress proteins in spermatogenesis. Adv Exp Med Biol 444, 137-143

Dragovic Z, Broadley SA, Shomura Y, Bracher A, Hartl FU (2006): Molecular chaperones of the Hsp110 family act as nucleotide exchange factors of Hsp70s. EMBO $\mathrm{J} \underline{25}, 2519-2528$

Eddy EM, McGee RS, Willis WD, O'Brien DA (1991): Immunodissection of sperm surface modifications during epididymal maturation. Bull Assoc Anat (Nancy) 25, 139144

Eroglu B, Moskophidis D, Mivechi NF (2010): Loss of Hsp110 leads to age-dependent tau hyperphosphorylation and early accumulation of insoluble amyloid beta. Mol Cell Biol 30, 4626-4643

Fasanaro P, Capogrossi MC, Martelli F (2010): Regulation of the endothelial cell cycle by the ubiquitin-proteasome system. Cardiovasc Res $\underline{85}$, 272-280

Feng HL, Sandlow JI, Sparks AE (2001): Decreased expression of the heat shock protein hsp70-2 is associated with the pathogenesis of male infertility. Fertil Steril $\underline{76}, 1136-1139$

Finkel T, Holbrook NJ (2000): Oxidants, oxidative stress and the biology of ageing. Nature $\underline{408}, 239-247$

Foltz KR, Partin JS, Lennarz WJ (1993): Sea urchin egg receptor for sperm: sequence similarity of binding domain and hsp70. Science $\underline{259}, 1421-1425$

Froment P, Staub C, Hembert S, Pisselet C, Magistrini M, Delaleu B, Seurin D, Levine JE, Johnson L, Binoux M et al. (2004): Reproductive abnormalities in human insulin-like growth factor-binding protein-1 transgenic male mice. Endocrinology 145, 2080-2091 
Fung KL, Hilgenberg L, Wang NM, Chirico WJ (1996): Conformations of the nucleotide and polypeptide binding domains of a cytosolic Hsp70 molecular chaperone are coupled. J Biol Chem 271, 21559-21565

Gething MJ (1997): Protein folding. The difference with prokaryotes. Nature $\underline{388}$, 329331

Gething MJ, Sambrook J (1992): Protein folding in the cell. Nature 355, 33-45

Golsteyn RM (2005): Cdk1 and Cdk2 complexes (cyclin dependent kinases) in apoptosis: a role beyond the cell cycle. Cancer Lett $\underline{217}, 129-138$

Goto M, Koji T, Mizuno K, Tamaru M, Koikeda S, Nakane PK, Mori N, Masamune Y, Nakanishi Y (1990): Transcription switch of two phosphoglycerate kinase genes during spermatogenesis as determined with mouse testis sections in situ. Exp Cell Res $\underline{186}, 273-278$

Gotoh K, Nonoguchi K, Higashitsuji H, Kaneko Y, Sakurai T, Sumitomo Y, Itoh K, Subjeck JR, Fujita J (2004): Apg-2 has a chaperone-like activity similar to Hsp110 and is overexpressed in hepatocellular carcinomas. FEBS Lett $\underline{560}, 19-24$

Gregory TJ, Longmore WJ, Moxley MA, Whitsett JA, Reed CR, Fowler AA 3rd, Hudson LD, Maunder RJ, Crim C, Hyers TM (1991): Surfactant chemical composition and biophysical activity in acute respiratory distress syndrome. J Clin Invest $\underline{88}, 1976-1981$

Hansen LK, Albrecht JH (1999): Regulation of the hepatocyte cell cycle by type I collagen matrix: role of cyclin D1. J Cell Sci 112, 2971-2981

Harper JV, Brooks G (2005): The mammalian cell cycle: an overview. Methods Mol Biol 296, 113-153

Hartl FU (1991): Heat shock proteins in protein folding and membrane translocation. Semin Immunol $\underline{3}, 5-16$

Hartl FU (1996): Molecular chaperones in cellular protein folding. Nature $\underline{381}, 571-580$

Hatayama T, Yasuda K, Yasuda K (1998): Association of HSP105 with HSC70 in high molecular mass complexes in mouse FM3A cells. Biochem Biophys Res Commun 248, 395-401

Hayashi M, Imanaka-Yoshida K, Yoshida T, Wood M, Fearns C, Tatake RJ, Lee JD (2006): A crucial role of mitochondrial Hsp40 in preventing dilated cardiomyopathy. Nat Med $\underline{12}, 128-132$ 
He TC, Zhou S, da Costa LT, Yu J, Kinzler KW, Vogelstein B (1998): A simplified system for generating recombinant adenoviruses. Proc Natl Acad Sci USA $\underline{95}, 2509-2514$

Hedhli N, Depre C (2010): Proteasome inhibitors and cardiac cell growth. Cardiovasc Res $\underline{85}, 321-329$

Hein S, Arnon E, Kostin S, Schönburg M, Elsässer A, Polyakova V, Bauer EP, Klövekorn WP, Schaper J (2003): Progression from compensated hypertrophy to failure in the pressure-overloaded human heart: structural deterioration and compensatory mechanisms. Circulation 107, 984-991

Held T, Paprotta I, Khulan J, Hemmerlein B, Binder L, Wolf S, Schubert S, Meinhardt A, Engel W, Adham IM (2006): Hspa4l-deficient mice display increased incidence of male infertility and hydronephrosis development. Mol Cell Biol 26, 8099-8108

Heling A, Zimmermann R, Kostin S, Maeno Y, Hein S, Devaux B, Bauer E, Klövekorn WP, Schlepper M, Schaper W et al. (2000): Increased expression of cytoskeletal, linkage, and extracellular proteins in failing human myocardium. Circ Res $\underline{86}, 846-853$

Hishiya A, Takayama S (2008): Molecular chaperones as regulators of cell death. Oncogene 27, 6489-6506

Huszar G, Stone K, Dix D, Vigue L (2000): Putative creatine kinase M-isoform in human sperm is identifiedas the 70-kilodalton heat shock protein HspA2. Biol Reprod $\underline{63}$, 925932

Ikawa M, Wada I, Kominami K, Watanabe D, Toshimori K, Nishimune Y, Okabe M (1997): The putative chaperone calmegin is required for sperm fertility. Nature $\underline{387}, 607-$ 611

Ikegami M, Dhami R, Schuchman EH (2003): Alveolar lipoproteinosis in an acid sphingomyelinase-deficient mouse model of Niemann-Pickdisease. Am J Physiol Lung Cell Mol Physiol 284, L518-525

Kaneko Y, Kimura T, Kishishita M, Noda Y, Fujita J (1997a): Cloning of apg-2 encoding a novel member of heat shock protein 110 family. Gene $\underline{189}, 19-24$

Kaneko Y, Nishiyama H, Nonoguchi K, Higashitsuji H, Kishishita M, Fujita J (1997b): A novel hsp110-related gene, apg-1, that is abundantly expressed in the testis responds to a low temperature heat shock rather than the traditional elevated temperatures. Biol Chem 272, 2640-2645

Kang CM, Park KP, Cho CK, Seo JS, Park WY, Lee SJ, Lee YS (2002): Hspa4 (HSP70) is involved in the radioadaptive response: results from mouse splenocytes. Radiat Res $\underline{157}, 650-655$ 
Kashiwabara S, Arai Y, Kodaira K, Baba T (1990): Acrosin biosynthesis in meiotic and postmeiotic spermatogenic cells. Biochem Biophys Res Commun 173, 240-245

Khandjian EW, Türler H (1983): Simian virus 40 and polyoma virus induce synthesis of heat shock proteins in permissive cells. Mol Cell Biol $\underline{3}, 1-8$

Kim AY, Bommeljé CC, Lee BE, Yonekawa Y, Choi L, Morris LG, Huang G, Kaufman A, Ryan RJ, Hao B et al. (2008): SCCRO (DCUN1D1) is an essential component of the E3 complex for neddylation. J Biol Chem $\underline{283}$, 33211-33220

Kim H, Huh PW, Kim C, Kim YJ, Park EM, Park YM (2001): Cerebral activation and distribution of inducible hsp110 and hsp70 mRNAs following focal ischemia in rat. Toxicology 167, 135-144

Kim YK, Suarez J, Hu Y, McDonough PM, Boer C, Dix DJ, Dillmann WH (2006): Deletion of the inducible $70-\mathrm{kDa}$ heat shock protein genes in mice impairs cardiac contractile function and calcium handling associated with hypertrophy. Circulation $\underline{113}$, 2589-2597

Kleene KC, Flynn JF (1987): Characterization of a cDNA clone encoding a basic protein, TP2, involved in chromatin condensation during spermiogenesis in the mouse. $\mathrm{J}$ Biol Chem $\underline{262}, 17272-17277$

Koh HS, Moon IS, Lee YH, Shong M, Kwon OY (2000): Expression of an HSP110 family, ischemia-responsive protein (irp94), in the rat brain after transient forebrain ischemia. Z Naturforsch C $\underline{55}$, 449-454

Kojima R, Randall J, Brenner BM, Gullans SR. Osmotic stress protein 94 (Osp94) (1996): A new member of the Hsp110/SSE gene subfamily. J Biol Chem 271, 1232712332

Kojima R, Randall JD, Ito E, Manshio H, Suzuki Y, Gullans SR (2004): Regulation of expression of the stress response gene, Osp94: identification of the tonicity response element and intracellular signalling pathways. Biochem J $\underline{380}$, 783-794

Kostin S, Pool L, Elsässer A, Hein S, Drexler HC, Arnon E, Hayakawa Y, Zimmermann R, Bauer E, Klövekorn WP et al. (2003): Myocytes die by multiple mechanisms in failing human hearts. Circ Res 92, 715-724

Kouroku Y, Fujita E, Tanida I, Ueno T, Isoai A, Kumagai H, Ogawa S, Kaufman RJ, Kominami E, Momoi T (2007): ER stress (PERK/eIF2alpha phosphorylation) mediates the polyglutamine-induced LC3 conversion, an essential step for autophagy formation. Cell Death Differ 14, 230-239 
Kremling H, Keime S, Wilhelm K, Adham IM, Hameister H, Engel W (1991): Mouse proacrosin gene: nucleotide sequence, diploid expression, and chromosomal localization. Genomics $\underline{11}$, 828-834

Kresch MJ, Christian C, Wu F, Hussain N (1998): Ontogeny of apoptosis during lung development. Pediatr Res $\underline{43}$, 426-431

Kumarapeli AR, Su H, Huang W, Tang M, Zheng H, Horak KM, Li M, Wang X (2008): Alpha B-crystallin suppresses pressure overload cardiac hypertrophy. Circ Res 103, 1473-1482

Kunisada K, Tone E, Fujio Y, Matsui H, Yamauchi-Takihara K, Kishimoto T (1998): Activation of gp130 transduces hypertrophic signals via STAT3 in cardiac myocytes. Circulation $\underline{98}, 346-352$

Kunisada K, Negoro S, Tone E, Funamoto M, Osugi T, Yamada S, Okabe M, Kishimoto T, Yamauchi-Takihara K (2000): Signal transducer and activator of transcription 3 in the heart transduces not only a hypertrophic signal but a protective signal against doxorubicin-induced cardiomyopathy. Proc Natl Acad Sci USA 97, 315-319

Kuwahara K, Saito Y, Takano M, Arai Y, Yasuno S, Nakagawa Y, Takahashi N, Adachi Y, Takemura G, Horie M et al. (2003): NRSF regulates the fetal cardiac gene program and maintains normal cardiac structure and function. EMBO J 22, 6310-6321

Lakso M, Pichel JG, Gorman JR, Sauer B, Okamoto Y, Lee E, Alt FW, Westphal H (1996): Efficient in vivo manipulation of mouse genomic sequences at the zygote stage. Proc Natl Acad Sci USA 93, 5860-5865

Lammers JH, Offenberg HH, van Aalderen M, Vink AC, Dietrich AJ, Heyting C (1994): The gene encoding a major component of the lateral elements of synaptonemal complexes of the rat is related to X-linked lymphocyte-regulated genes. Mol Cell Biol $\underline{14}$, $1137-1146$

Landry J, Bernier D, Chrétien P, Nicole LM, Tanguay RM, Marceau N (1982): Synthesis and degradation of heat shock proteins during development and decay of thermotolerance. Cancer Res 42, 2457-2461

La Thangue NB, Latchman DS (1988): A cellular protein related to heat-shock protein 90 accumulates during herpes simplex virus infection and is overexpressed in transformed cells. Exp Cell Res 178, 169-179

Lee MY, Choi YS, Choi JS, Min DS, Chun MH, Kim ON, Lee SB, Kim SY (2002): An immunohistochemical study of APG-2 protein in the rat hippocampus after transient forebrain ischemia. Brain Res 924, 237-241 
Lee-Yoon D, Easton D, Murawski M, Burd R, Subjeck JR (1995): Identification of a major subfamily of large hsp70-like proteins through the cloning of the mammalian 110$\mathrm{kDa}$ heat shock protein. J Biol Chem $\underline{270}$, 15725-15733

Levinson W, Oppermann H, Jackson J (1980): Transition series metals and sulfhydryl reagents induce the synthesis of four proteins in eukaryotic cells. Biochim Biophys Acta $\underline{606}, 170-180$

Li C, Liu D, Yuan Y, Huang S, Shi M, Tao K, Feng W (2010): Overexpression of Apg-2 increases cell proliferation and protects from oxidative damage in BaF3-BCR/ABL cells. Int J Oncol $\underline{36}$, 899-904

Li GC (1985): Elevated levels of 70,000 dalton heat shock protein in transiently thermotolerant Chinese hamster fibroblasts and in their stable heat resistant variants. Int $\mathbf{J}$ Radiat Oncol Biol Phys $\underline{11}$, 165-177

Li GC, Laszlo A (1985): Amino acid analogs while inducing heat shock proteins sensitize $\mathrm{CHO}$ cells to thermal damage. J Cell Physiol 122, 91-97

Litingtung Y, Lei L, Westphal H, Chiang C (1998): Sonic hedgehog is essential to foregut development. Nat Genet 20, 58-61

Liu J, Chen Q, Huang W, Horak KM, Zheng H, Mestril R, Wang X (2006): Impairment of the ubiquitin- proteasome system in desminopathy mouse hearts. FASEB J 20, 362364

Luo W, Zhong J, Chang R, Hu H, Pandey A, Semenza GL (2010): Hsp70 and CHIP selectively mediate ubiquitination and degradation of hypoxia-inducible factor (HIF)1alpha but Not HIF-2alpha. J Biol Chem 285, 3651-3663

Maeda Y, Davé V, Whitsett JA (2007): Transcriptional control of lung morphogenesis. Physiol Rev $\underline{87}, 219-244$

Mann DL, Bristow MR (2005): Mechanisms and models in heart failure: the biomechanical model and beyond. Circulation 111 , 2837-2849

Martis PC, Whitsett JA, Xu Y, Perl AK, Wan H, Ikegami M (2006): C/EBPalpha is required for lung maturation at birth. Development 133, 1155-1164

Mauk R, Jaworski D, Kamei N, Glabe CG (1997): Identification of a 97-kDa heat shock protein from $\mathrm{S}$. franciscanus ovaries with $94 \%$ amino acid identity to the S. purpuratus egg surface receptor for sperm. Dev Biol 184, 31-37

McCarty JS, Buchberger A, Reinstein J, Bukau B (1995): The role of ATP in the functional cycle of the DnaK chaperone system. J Mol Biol 249, 126-137 
Meinhardt A, Wilhelm B, Seitz J (1999): Expression of mitochondrial marker proteins during spermatogenesis. Hum Reprod Update $\underline{5}, 108-119$

Mendelsohn C, Lohnes D, Décimo D, Lufkin T, LeMeur M, Chambon P, Mark M (1994): Function of the retinoic acid receptors (RARs) during development (II). Multiple abnormalities at various stages of organogenesis in RAR double mutants. Development 120, 2749-2771

Messina V, Di Sauro A, Pedrotti S, Adesso L, Latina A, Geremia R, Rossi P, Sette C (2010): Differential contribution of the MTOR and MNK pathways to the regulation of mRNA translation in meiotic and postmeiotic mouse male germ cells. Biol Reprod $\underline{83}$, 607-615

Min H, Danilenko DM, Scully SA, Bolon B, Ring BD, Tarpley JE, DeRose M, Simonet WS (1998): Fgf-10 is required for both limb and lung development and exhibits striking functional similarity to Drosophila branchless. Genes Dev 12, 3156-3161

Molkentin JD, Lu JR, Antos CL, Markham B, Richardson J, Robbins J, Grant SR, Olson EN (1998): A calcineurin-dependent transcriptional pathway for cardiac hypertrophy. Cell 93, 215-228

Mori C, Nakamura N, Dix DJ, Fujioka M, Nakagawa S, Shiota K, Eddy EM (1997): Morphological analysis of germ cell apoptosis during postnatal testis development in normal and Hsp 70-2 knockout mice. Dev Dyn 208, 125-136

Morimoto RI (2011): The heat shock response: systems biology of proteotoxic stress in aging and disease. Cold Spring Harb Symp Quant Biol 드, 91-99

Morimoto RI, Tissieres A, Georgopoulos C, eds.: Heat Shock Proteins: Structure, Function and Regulation. Cold Spring Harbor Lab. Press. Cold Spring Harbor, NY. 1994

Morozov A, Subjeck J, Raychaudhuri P (1995): HPV16 E7 oncoprotein induces expression of a $110 \mathrm{kDa}$ heat shock protein. FEBS Lett $\underline{371}$, 214-218

Müller P, Kazakov A, Semenov A, Böhm M, Laufs U (2008): Pressure-induced cardiac overload induces upregulation of endothelial and myocardial progenitor cells. Cardiovasc Res $\underline{77}, 151-159$

Mukai H, Kuno T, Tanaka H, Hirata D, Miyakawa T, Tanaka C (1993): Isolation and characterization of SSE1 and SSE2, new members of the yeast HSP70 multigene family. Gene $\underline{132}, 57-66$

Mulugeta S, Nguyen V, Russo SJ, Muniswamy M, Beers MF (2005): A surfactant protein $\mathrm{C}$ precursor protein BRICHOS domain mutation causes endoplasmic reticulum stress, proteasome dysfunction, and caspase 3 activation. Am J Respir Cell Mol Biol 32, 521530 
Nakamura J, Fujimoto M, Yasuda K, Takeda K, Akira S, Hatayama T, Takagi Y, Nozaki K, Hosokawa N, Nagata K (2008): Targeted disruption of Hsp110/105 gene protects against ischemic stress. Stroke $\underline{39}$, 2853-2859

Nakatsura T, Senju S, Yamada K, Jotsuka T, Ogawa M, Nishimura Y (2001): Gene cloning of immunogenic antigens overexpressed in pancreatic cancer. Biochem Biophys Res Commun 281, 936-944

Nayernia K, Adham IM, Burkhardt-Göttges E, Neesen J, Rieche M, Wolf S, Sancken U, Kleene K, Engel W (2002): Asthenozoospermia in mice with targeted deletion of the sperm mitochondrion-associatedcysteine-rich protein (Smcp) gene. Mol Cell Biol 22, 3046-3052

Nogee LM, Garnier G, Dietz HC, Singer L, Murphy AM, deMello DE, Colten HR (1994): A mutation in the surfactant protein B gene responsible for fatal neonatal respiratory disease in multiple kindreds. J Clin Invest 93, 1860-1863

Nogee LM, Wert SE, Proffit SA, Hull WM, Whitsett JA (2000): Allelic heterogeneity in hereditary surfactant protein B (SP-B) deficiency. Am J Respir Crit Care Med 161, 973981

Nonoguchi K, Itoh K, Xue JH, Tokuchi H, Nishiyama H, Kaneko Y, Tatsumi K, Okuno H, Tomiwa K, Fujita J (1999): Cloning of human cDNAs for Apg-1 and Apg-2, members of the Hsp1 10 family, and chromosomal assignment of their genes. Gene 237, 21-28

Nonoguchi K, Tokuchi H, Okuno H, Watanabe H, Egawa H, Saito K, Ogawa O, Fujita J (2001): Expression of Apg-1, a member of the Hsp110 family, in the human testis and sperm. Int J Urol $\underline{8}, 308-314$

Norton N, Li D, Rieder MJ, Siegfried JD, Rampersaud E, Züchner S, Mangos S, Gonzalez-Quintana J, Wang L, McGee S et al. (2011): Genome-wide studies of copy number variation and exome sequencing identify rare variants in BAG3 as a cause of dilated cardiomyopathy. Am J Hum Genet $\underline{88}, 273-282$

Norton PM, Latchman DS (1989): Levels of the 90kd heat shock protein and resistance to glucocorticoid-mediated cell killing in a range of human and murine lymphocyte cell lines. J Steroid Biochem $\underline{33}$, 149-154

Nussbaum RL, Ellis CE (2003): Alzheimer's disease and Parkinson's disease. N Engl J Med $\underline{348}, 1356-1364$

Oh HJ, Easton D, Murawski M, Kaneko Y, Subjeck JR (1999): The chaperoning activity of hsp110. Identification of functional domains by use of targeted deletions. J Biol Chem 274, 15712-15718 
Okui M, Ito F, Ogita K, Kuramoto N, Kudoh J, Shimizu N, Ide T (2000): Expression of APG-2 protein, a member of the heat shock protein 110 family, in developing rat brain. Neurochem Int $\underline{36}, 35-43$

Olson EN, Williams RS (2000): Calcineurin signaling and muscle remodeling. Cell 101, 689-692

Passier R, Zeng H, Frey N, Naya FJ, Nicol RL, McKinsey TA, Overbeek P, Richardson JA, Grant SR, Olson EN (2000): CaM kinase signaling induces cardiac hypertrophy and activates the MEF2 transcription factor in vivo. J Clin Invest $\underline{105}, 1395-1406$

Patterson C (2006): Search and destroy: the role of protein quality control in maintaining cardiac function. J Mol Cell Cardiol $\underline{40}, 438-441$

Pearse RV 2nd, Drolet DW, Kalla KA, Hooshmand F, Bermingham JR Jr, Rosenfeld MG (1997): Reduced fertility in mice deficient for the POU protein sperm-1. Proc Natl Acad Sci USA $\underline{94}, 7555-7560$

Peng X, Kraus MS, Wei H, Shen TL, Pariaut R, Alcaraz A, Ji G, Cheng L, Yang Q, Kotlikoff MI et al. (2006): Inactivation of focal adhesion kinase in cardiomyocytes promotes eccentric cardiac hypertrophy and fibrosis in mice. J Clin Invest 116, 217-227

Polier S, Dragovic Z, Hartl FU, Bracher A (2008): Structural basis for the cooperation of Hsp70 and Hsp110 chaperones in protein folding. Cell 133, 1068-1079

Powell SR (2006): The ubiquitin-proteasome system in cardiac physiology and pathology. Am J Physiol Heart Circ Physiol 291, H1-19

Rafiee P, Theriot ME, Nelson VM, Heidemann J, Kanaa Y, Horowitz SA, Rogaczewski A, Johnson CP, Ali I, Shaker R et al. (2006): Human esophageal microvascular endothelial cells respond to acidic $\mathrm{pH}$ stress by PI3K/AKT and p38 MAPK-regulated induction of Hsp70 and Hsp27. Am J Physiol Cell Physiol 291, C931-945

Ramalho-Santos M, Yoon S, Matsuzaki Y, Mulligan RC, Melton DA (2002): "Stemness": transcriptional profiling of embryonic and adult stem cells. Science 298, 597-600

Randell SH, Young SL: In Fetal and Neonatal Physiology (ed. R. Polin, W. W. Fox and S. H. Abman). Saunders. Philadelphia. 2004, pp. 1034-1040

Raviol H, Sadlish H, Rodriguez F, Mayer MP, Bukau B (2006): Chaperone network in the yeast cytosol: Hsp110 is revealed as an Hsp70 nucleotide exchange factor. EMBO J $\underline{25}, 2510-2518$

Ridsdale R, Post M (2004): Surfactant lipid synthesis and lamellar body formation in glycogen-laden type II cells. Am J Physiol Lung Cell Mol Physiol 287, L743-751 
Ritossa F (1962): A new puffing pattern induced and temperature shock and DNP in Drosophila. Cell Mol Life Sci 18, 571-573

Ritossa F (1996): Discovery of the heat shock response. Cell Stress Chaperones $\underline{1}$, 97-98

Robertson KM, O'Donnell L, Jones ME, Meachem SJ, Boon WC, Fisher CR, Graves KH, McLachlan RI, Simpson ER (1999): Impairment of spermatogenesis in mice lacking a functional aromatase (cyp 19) gene. Proc Natl Acad Sci USA 96, 7986-7991

Rooney SA, Young SL, Mendelson CR (1994): Molecular and cellular processing of lung surfactant. FASEB J $\underline{8}, 957-967$

Ross CA (1995): When more is less: pathogenesis of glutamine repeat neurodegenerative diseases. Neuron $\underline{15}, 493-496$

Ross CA, Pickart CM (2004): The ubiquitin-proteasome pathway in Parkinson's disease and other neurodegenerative diseases. Trends Cell Biol 14, 703-711

Rutkowski DT, Kaufman RJ (2004): A trip to the ER: coping with stress. Trends Cell Biol 14, 20-28

Sanbe A, Osinska H, Saffitz JE, Glabe CG, Kayed R, Maloyan A, Robbins J (2004): Desmin-related cardiomyopathy in transgenic mice: a cardiac amyloidosis. Proc Natl Acad Sci USA 101, 10132-10136

Scavo LM, Ertsey R, Chapin CJ, Allen L, Kitterman JA (1998): Apoptosis in the development of rat and human fetal lungs. Am J Respir Cell Mol Biol 18, 21-31

Schuermann JP, Jiang J, Cuellar J, Llorca O, Wang L, Gimenez LE, Jin S, Taylor AB, Demeler B, Morano KA et al. (2008): Structure of the Hsp110:Hsc70 nucleotide exchange machine. Mol Cell $\underline{31}, 232-243$

Schulte U, Thumfart JO, Klöcker N, Sailer CA, Bildl W, Biniossek M, Dehn D, Deller T, Eble S, Abbass K et al. (2006): The epilepsy linked Lgi1 protein assembles into presynaptic Kv1 channels and inhibits inactivation by Kvbeta1. Neuron 49, 697-706

Selkoe DJ (2004): Cell biology of protein misfolding: the examples of Alzheimer's and Parkinson's diseases. Nat Cell Biol $\underline{6}, 1054-1061$

Shaner L, Wegele H, Buchner J, Morano KA (2005): The yeast HSP110 SSE1 functionally interacts with the HSP70 chaperones SSA and SSB. J Biol Chem $\underline{280}$, 41262-41269

Shaner L, Sousa R, Morano KA (2006): Characterization of Hsp70 binding and nucleotide exchange by the yeast Hsp110 chaperone Sse1. Biochemistry $\underline{45}$, 1507515084 
Shirayama MK, Kawakami Y, Matsui K, Tanaka A, Toh-e (1993): MSI3, a multicopy suppressor of mutants hyperactivated in the RAS-cAMP pathway, encodes a novel HSP70 protein of Saccharomyces cerevisiae. Mol Gen Genet 240, 323-332

Shu W, Lu MM, Zhang Y, Tucker PW, Zhou D, Morrisey EE (2007): Foxp2 and Foxp1 cooperatively regulate lung and esophagus development. Development 134, 1991-2000

Shulenin S, Nogee LM, Annilo T, Wert SE, Whitsett JA, Dean M (2004): ABCA3 gene mutations in newborns with fatal surfactant deficiency. N Engl J Med 5ㅜ, 1296-1303

Son WY, Hwang SH, Han CT, Lee JH, Kim S, Kim YC (1999): Specific expression of heat shock protein HspA2 in human male germ cells. Mol Hum Reprod $\underline{5}$, 1122-1126

Son WY, Han CT, Hwang SH, Lee JH, Kim S, Kim YC (2000): Repression of hspA2 messenger RNA in human testes with abnormal spermatogenesis. Fertil Steril $\underline{73}$, 11381144

Steel GJ, Fullerton DM, Tyson JR, Stirling CJ (2004): Coordinated activation of Hsp70 chaperones. Science $\underline{303}$, 98-101

Stiles AD, Chrysis D, Jarvis HW, Brighton B, Moats-Staats BM (2001): Programmed cell death in normal fetal rat lung development. Exp Lung Res 27, 569-587

Storozhenko S, De Pauw P, Kushnir S, Van Montagu M, Inzé D (1996): Identification of an Arabidopsis thaliana cDNA encoding a HSP70-related protein belonging to the HSP110/SSE1 subfamily. FEBS Lett $\underline{390}$, 113-118

Sutherland LM, Edwards YS, Murray AW (2001): Alveolar type II cell apoptosis. Comp Biochem Physiol A Mol Integr Physiol 129, 267-285

Takahashi H, Furukawa T, Yano T, Sato N, Takizawa J, Kurasaki T, Abe T, Narita M, Masuko M, Koyama S et al. (2007): Identification of an overexpressed gene, HSPA4L, the product of which can provoke prevalent humoral immune responses in leukemia patients. Exp Hematol 35, 1091-1099

Taylor JP, Hardy J, Fischbeck KH (2002): Toxic proteins in neurodegenerative disease. Science 296, 1991-1995

Terada K, Yomogida K, Imai T, Kiyonari H, Takeda N, Kadomatsu T, Yano M, Aizawa S, Mori M (2005): A type I DnaJ homolog, DjA1, regulates androgen receptor signaling and spermatogenesis. EMBO J 24, 611-622

Thomas M, Massimi P, Jenkins J, Banks L (1995): HPV-18 E6 mediated inhibition of p53 DNA binding activity is independent of E6 induced degradation. Oncogene 10, 261268 
Tomasovic SP, Steck PA, Heitzman D (1983): Heat-stress proteins and thermal resistance in rat mammary tumor cells. Radiat Res $\underline{95}$, 399-413

Tonkiss J, Calderwood SK (2005): Regulation of heat shock gene transcription in neuronal cells. Int J Hyperthermia 21, 433-444

Trott A, Shaner L, Morano KA (2005): The molecular chaperone Sse1 and the growth control protein kinase Sch9 collaborate to regulateprotein kinase A activity in Saccharomyces cerevisiae. Genetics $\underline{170}$, 1009-1021

Tsapara A, Matter K, Balda MS (2006): The heat-shock protein Apg-2 binds to the tight junction protein ZO-1 and regulates transcriptional activity of ZONAB. Mol Biol Cell $\underline{17}$, $1322-1330$

Tsukamoto M, Hirasaki S, Kuribayashi T, Matsuo A, Matsui H, Sawada T, Nakamura T, Azuma A, Sugihara H, Matsubara H (2006): Systolic outward motion of the left ventricular apical wall as detected by magnetic resonance tagging in patients with apical hypertrophic cardiomyopathy. J Cardiovasc Magn Reson $\underline{8}$, 453-460

Tsunekawa N, Matsumoto M, Tone S, Nishida T, Fujimoto H (1999): The Hsp70 homolog gene, Hsc70t, is expressed under translational control during mouse spermiogenesis. Mol Reprod Dev 52, 383-391

Verkman AS, Matthay MA, Song Y (2000): Aquaporin water channels and lung physiology. Am J Physiol Lung Cell Mol Physiol 278, L867-879

Vos MJ, Hageman J, Carra S, Kampinga HH (2008): Structural and functional diversities between members of the human HSPB, HSPH, HSPA, and DNAJ chaperone families. Biochemistry $\underline{47}, 7001-7011$

Wakatsuki T, Hatayama T (1998): Characteristic expression of 105-kDa heat shock protein (HSP105) in various tissues of nonstressed and heat-stressed rats. Biol Pharm Bull 21, 905-910

Wan H, Dingle S, Xu Y, Besnard V, Kaestner KH, Ang SL, Wert S, Stahlman MT, Whitsett JA (2005): Compensatory roles of Foxa1 and Foxa2 during lung morphogenesis. J Biol Chem $\underline{280}$, 13809-13816

Wang X, Robbins J (2006): Heart failure and protein quality control. Circ Res 99, 13151328

Wang X, Su H, Ranek MJ (2008): Protein quality control and degradation in cardiomyocytes. J Mol Cell Cardiol 노, 11-27

Warburton D, Schwarz M, Tefft D, Flores-Delgado G, Anderson KD, Cardoso WV (2000): The molecular basis of lung morphogenesis. Mech Dev 92, 55-81 
Weaver M, Dunn NR, Hogan BL (2000): Bmp4 and Fgf10 play opposing roles during lung bud morphogenesis. Development 127, 2695-2704

Weaver TE, Conkright JJ (2001): Function of surfactant proteins B and C. Annu Rev Physiol 63, 555-578

Weekes J, Morrison K, Mullen A, Wait R, Barton P, Dunn MJ (2003): Hyperubiquitination of proteins in dilated cardiomyopathy. Proteomics $\underline{3}$, 208-216

Welch WJ, Garrels JI, Thomas GP, Lin JJ, Feramisco JR (1983): Biochemical characterization of the mammalian stress proteins and identification of two stressproteins as glucose- and $\mathrm{Ca} 2+-$ ionophore-regulated proteins. J Biol Chem $\underline{258}$, $7102-7111$

Werner A, Meinhardt A, Seitz J, Bergmann M (1997): Distribution of heat-shock protein 60 immunoreactivity in testes of infertile men. Cell Tissue Res $\underline{288}, 539-544$

Whitsett JA, Weaver TE (2002): Hydrophobic surfactant proteins in lung function and disease. N Engl J Med 347, 2141-2148

Wilkins BJ, Molkentin JD (2002): Calcineurin and cardiac hypertrophy: where have we been? Where are we going? J Physiol 541, 1-8

Williams MC (2003): Alveolar type I cells: molecular phenotype and development. Annu Rev Physiol 65, 669-695

Williams MC, Mason RJ (1977): Development of the type II cell in the fetal rat lung. Am Rev Respir Dis $\underline{115}, 37-47$

Willis MS, Patterson C (2010): Hold me tight: Role of the heat shock protein family of chaperones in cardiac disease. Circulation $\underline{122}, 1740-1751$

Wong PC, Cai H, Borchelt DR, Price DL (2002): Genetically engineered mouse models of neurodegenerative diseases. Nat Neurosci $\underline{5}, 633-639$

Wu CY, Lin CT, Wu MZ, Wu KJ (2011): Induction of HSPA4 and HSPA14 by NBS1 overexpression contributes to NBS1-induced in vitro metastatic and transformation activity. J Biomed Sci $\underline{18}, 1$

Xue JH, Fukuyama H, Nonoguchi K, Kaneko Y, Kido T, Fukumoto M, Fujibayashi Y, Itoh K, Fujita J (1998): Induction of Apg-1, a member of the heat shock protein 110 family, following transient forebrain ischemia in the rat brain. Biochem Biophys Res Commun 247, $796-801$

Yagita Y, Kitagawa K, Taguchi A, Ohtsuki T, Kuwabara K, Mabuchi T, Matsumoto M, Yanagihara T, Hori M (1999): Molecular cloning of a novel member of the HSP110 
family of genes, ischemia-responsive protein94 kDa (irp94), expressed in rat brain after transient forebrain ischemia. J Neurochem $\underline{72}$, 1544-1551

Yagita Y, Kitagawa K, Ohtsuki T, Tanaka S, Hori M, Matsumoto M (2001): Induction of the HSP110/105 family in the rat hippocampus in cerebral ischemia and ischemic tolerance. J Cereb Blood Flow Metab 21, 811-819

Yasuda K, Nakai A, Hatayama T, Nagata K (1995): Cloning and expression of murine high molecular mass heat shock proteins, HSP105. J Biol Chem 270, 29718-29723

Yasuda K, Ishihara K, Nakashima K, Hatayama T (1999): Genomic cloning and promoter analysis of the mouse 105-kDa heat shock protein (HSP105) gene. Biochem Biophys Res Commun 256, 75-80

Yu YE, Zhang Y, Unni E, Shirley CR, Deng JM, Russell LD, Weil MM, Behringer RR, Meistrich ML (2000): Abnormal spermatogenesis and reduced fertility in transition nuclear protein 1-deficient mice. Proc Natl Acad Sci USA 97, 4683-4688

Zakeri ZF, Wolgemuth DJ, Hunt CR (1988): Identification and sequence analysis of a new member of the mouse HSP70 gene family and characterization of its unique cellular and developmental pattern of expression in the male germ line. Mol Cell Biol $\underline{8}$, 29252932

Zhang Y, Jiang DS, Yan L, Cheng KJ, Bian ZY, Lin GS (2011): HSP75 protects against cardiac hypertrophy and fibrosis. J Cell Biochem 112, 1787-1794

Zhu X, Zhao X, Burkholder WF, Gragerov A, Ogata CM, Gottesman ME, Hendrickson WA (1996): Structural analysis of substrate binding by the molecular chaperone DnaK. Science $\underline{272}, 1606-1614$

Zou Y, Li J, Ma H, Jiang H, Yuan J, Gong H, Liang Y, Guan A, Wu J, Li L et al. (2011): Heat shock transcription factor 1 protects heart after pressure overload through promoting myocardial angiogenesis in male mice. J Mol Cell Cardiol 51, 821-829 


\section{Publications}

\section{Publication I:}

Held T, Barakat AZ, Mohamed BA, Paprotta I, Meinhardt A, Engel W, Adham IM (2011): Heat-shock protein HSPA4 is required for progression of spermatogenesis. Reproduction 142,133-144.

\section{Publication II:}

Mohamed BA, Barakat AZ, Zimmermann WH, Bittner RE, Mühlfeld C, Hünlich M, Engel W, Maier LS, Adham IM (2012): Targeted disruption of Hspa4 gene leads to cardiac hypertrophy and fibrosis. J Mol Cell Cardiol 53, 459-468. 


\subsection{Publication I}

Heat-shock protein HSPA4 is required for progression of spermatogenesis

DOI: 10.1530/REP-11-0023

Torsten Held, Amal Z Barakat, Belal A Mohamed, Ilona Paprotta, Andreas Meinhardt, Wolfgang Engel, Ibrahim M Adham

Status: Published in Reproduction Journal (Impact factor 3.049), Volume 142 (2011), pp. 133-144

\section{Author contributions to the work:}

1. Torsten Held: Participated in generation of Hspa4 $\mathrm{KO}$ construct, histological and immunohistochemical studies

2. Amal Z Barakat: Participated in histological and immunohistochemical analyses, performed Northern blot analysis and participated in TUNEL assay for detection of apoptotic cells

3. Belal A Mohamed: Performed the experiments to identify HSPA4 expression in different murine tissues and in testes of different developmental stages, studied cellular distribution of HSPA4 in the prenatal testes, carried out statistical analysis of the data, participated in data interpretation and was involved in manuscript preparation

4. Ilona Paprotta: Performed genotyping of the mice

5. Andreas Meinhardt: Evaluated the results of histological analyses

6. Wolfgang Engel: Conceived and designed the experiments, interpretation of the data, gave critical comments and recommendations, and financial support

7. Ibrahim M Adham: Conceived and designed the experiments, interpretation of the data and critical review of the manuscript 


\title{
Heat-shock protein HSPA4 is required for progression of spermatogenesis
}

\author{
Torsten Held, Amal Z Barakat, Belal A Mohamed, Ilona Paprotta, Andreas Meinhardt ${ }^{1}$, \\ Wolfgang Engel and Ibrahim M Adham \\ Institute of Human Genetics, University of Göttingen, D-37073 Göttingen, Germany and ${ }^{1}$ Department of Anatomy \\ and Cell Biology, University of Giessen, D-35378 Giessen, Germany
}

Correspondence should be addressed to I M Adham; Email: iadham@gwdg.de

T Held and A Z Barakat are contributed equally to this work and should be considered co-first authors

\begin{abstract}
Heat-shock protein 110 (HSP110) family members act as nucleotide exchange factors (NEF) of mammalian and yeast HSP70 chaperones during the ATP hydrolysis cycle. In this study, we describe the expression pattern of murine HSPA4, a member of the HSP110 family, during testis development and the consequence of HSPA4 deficiency on male fertility. HSPA4 is ubiquitously expressed in all the examined tissues. During prenatal and postnatal development of gonad, HSPA4 is expressed in both somatic and germ cells; however, expression was much higher in germ cells of prenatal gonads. Analyses of $\mathrm{Hspa4-deficient} \mathrm{mice} \mathrm{revealed} \mathrm{that} \mathrm{all} \mathrm{homozygous} \mathrm{mice} \mathrm{on} \mathrm{the}$ hybrid C57BL/6 $\times 129 / S v$ genetic background were apparently healthy. Although HSPA4 is expressed as early as E13.5 in male gonad, a lack of histological differences between $\mathrm{Hspa}^{-/-}$and control littermates suggests that Hspa4 deficiency does not impair the gonocytes or their development to spermatogonia. Remarkably, an increased number of the Hspa4-deficient males displayed impaired fertility, whereas females were fertile. The total number of spermatozoa and their motility were drastically reduced in infertile $\mathrm{Hspa4-deficient}$ mice compared with wild-type littermates. The majority of pachytene spermatocytes in the juvenile $\mathrm{Hspa}^{-/-}$mice failed to complete the first meiotic prophase and became apoptotic. Furthermore, down-regulation of transcription levels of genes known to be expressed in spermatocytes at late stages of prophase I and post-meiotic spermatids leads to suggest that the development of most spermatogenic cells is arrested at late stages of meiotic prophase I. These results provide evidence that HSPA4 is required for normal spermatogenesis. Reproduction (2011) 142 133-144
\end{abstract}

\section{Introduction}

Complexes containing heat-shock proteins (HSPs) represent the major components of molecular chaperones that facilitate the folding and assembly of newly synthesized proteins and the selection of unfolded proteins for degradation in different cellular compartments such as cytosol, endoplasmic reticulum, and mitochondria (Hartl 1996). Based on the molecular weight, HSPs are divided into structurally unrelated HSP110, HSP90, HSP70, HSP60, and HSP27 protein families (Vos et al. 2008).

The HSP110 gene family includes two genes in Saccharomyces cerevisiae known as SSE1 and SSE2 and four genes in the mammalian genome, namely HSPA4I/APG1, HSPA4/APG2, HSPH1/HSP105, and HYOU1/GRP175/ORP150. Except HYOU1, which is present in the endoplasmic reticulum, all other members of mammalian and yeast HSP110 are found in the cytosolic compartment (Vos et al. 2008). Primary structure of HSP110 proteins is highly related to HSP70 and consists of a nucleotide-binding domain (NBD) and

C 2011 Society for Reproduction and Fertility ISSN 1470-1626 (paper) 1741-7899 (online) a peptide-binding domain (PBD) that are connected by a flexible linker region (Mayer \& Bukau 2005, Liu \& Hendrickson 2007). However, biochemical analyses revealed that HSP110 members are co-chaperones of mammalian and yeast HSP70 chaperones and act as nucleotide exchange factors (NEF) during the ATP hydrolysis cycle (Steel et al. 2004, Dragovic et al. 2006, Raviol et al. 2006, Polier et al. 2008, Schuermann et al. 2008). Binding of newly synthesized polypeptides to HSP70 chaperone and subsequent release of folded proteins is regulated by a continuous cycle of ATP hydrolysis and exchange of ATP to ADP.

Beside HSP110 proteins, there are other unrelated nucleotide exchange factors of BAG and HSPBiP1 protein families. It is believed that the chaperones containing HSP70, HSP40, and HSP110 proteins represent the major protein folding machine of the eukaryotic cytosol (Polier et al. 2008).

Male germ cells undergo a dramatic developmental process, which is precisely controlled at the level of transcription and translation. After colonizing the 


\section{T Held, A Z Barakat and others}

primordial germ cells in mouse testis, gonocytes proliferate until day 15.5 and arrest in the G1 of cell cycle (Vergouwen et al. 1991, Nagano et al. 2000). Shortly after birth, gonocytes resume mitotic activity and develop into type A spermatogonia (Mclean et al. 2003). Primary spermatocytes undergo meiotic division to produce haploid round spermatids that are subsequently differentiated into mature sperm. Chaperone activities are required to mediate folding of de novo synthesized proteins and refolding of misfolded proteins during development of male germ cells (Eddy 1999). Mutation in the Hspa2 gene (Hsp70-2), which is highly expressed in pachytene spermatocytes, leads to arrest the spermatogenesis in meiotic prophase I and the majority of late pachytene spermatocytes are eliminated by apoptosis (Dix et al. 1997). Loss of DNAJA1, a co-chaperone of HSP70s in protein folding, results in severe defects of spermatogenesis (Terada et al. 2005).

To date, relatively little is known about the expression and the physiological function of HSPA4. In adult mouse, Hspa4 mRNA is detected in most tissues, with the highest expression in testis, ovary, and spleen (Kaneko et al. 1997). In vitro studies have shown that the expression of Hspa4 is not inducible by heat shock (Nonoguchi et al. 1999). Interestingly, expression of Hspa4 is up-regulated in some leukemia and solid tumors (Gotoh et al. 2004, Li et al. 2010).
To determine the expression pattern of HSPA4, we investigated the expression of HSPA4 in different tissues and during prenatal and postnatal testis development. To examine the function of HSPA4 in vivo, we generated Hspa4-deficient mice and subsequently determined the effect of HSPA4 deficiency on germ cell development.

\section{Results}

\section{HSPA4 is highly expressed in embryonic gonocytes and oogonia}

To investigate the expression pattern of HSPA4, northern blot analysis was performed with total RNA from different tissues of adult mice. The $358 \mathrm{bp}$ cDNA probe containing the coding sequence of the C-terminus recognized two Hspa4 transcripts of 4.8 and $3.2 \mathrm{~kb}$ in all studied tissues. Expression levels of the $3.2 \mathrm{~kb}$ transcript were relatively higher in testis (Fig. 1A). Analysis of Hspa4 cDNA sequences in database revealed that a cDNA sequence (Gl 60360215; AK 220167) contains two predicted polyadenylation sites that are spanning $1.75 \mathrm{~kb}$ region. To confirm that both mRNA isoforms result from alternative splicing of the 3 '-untranslated region, an RNA blot was hybridized with the $596 \mathrm{bp}$ cDNA probe containing the sequence between both polyA signals. This probe only detected the $4.8 \mathrm{~kb}$ transcript (Fig. 1B). To further confirm these
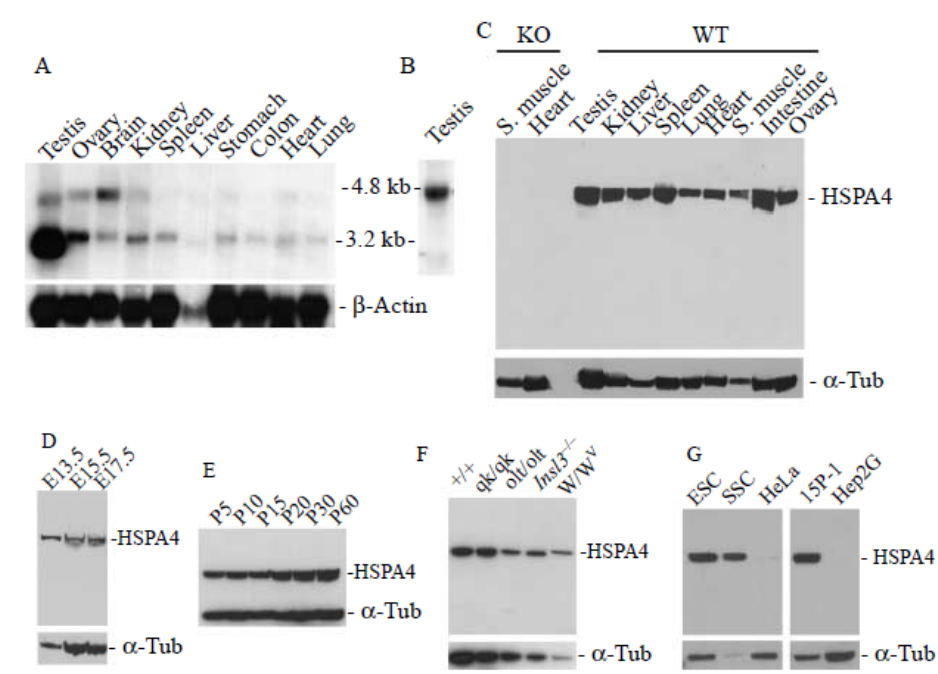

Figure 1 Expression pattern of HSPA4 in different tissues, fetal and postnatal testes, testes of different mutant mice, and different cell lines. (A) Northern blot with total RNA from different tissues of 3-month-old mice was hybridized with the 358 bp Hspa 4 cDNA probe. The same blot was rehybridized with a $\beta$-actin cDNA probe. (B) RNA blot with RNA of adult testis was hybridized with the 596 bp $H$ spa4 cDNA probe. (C) Immunoblot of HSPA4 expression in cellular extracts from different tissues of 3-month-old wild-type (WT) and mutant mice (KO) revealed that anti-HSPA4 recognized a $96 \mathrm{kDa}$ protein in all wild-type tissue, but not in Hspa4-deficient tissues. (D and E) Expression of HSPA4 during prenatal (D) and postnatal testis development (E) was examined by immunoblotting using total lysates obtained from testes of E13.5, E15.5, and E17.5 embryos, and from P5, P10, P15, P20, P30, and P60 mice. The anti- $\alpha$-tubulin antibody $(\alpha$-Tub) was used as a control. (F) Western blot with lysates obtained from testes of wild-type $(+/+)$ and different mutant mice was probed with anti-HSPA4 antibody. (G) Immunoblot of HSPA4 expression in cellular extracts from different cell lines. ESC, embryonic stem cells; SSC, spermatogonial stem cells; HeLa, HeLa cells; 15P-1, Sertoli cells, Hep2G, Hepatoma cells. 
results, western blot containing protein extracts of different wild-type and Hspa4-deficient tissues was probed with the anti-HSPA4 antibody. Immunoblot analysis revealed that the anti-HSPA4 recognized a $96 \mathrm{kDa}$ protein in all wild-type tissues, but not in Hspa4deficient tissues (Fig. 1C). To evaluate the expression pattern of HSPA4 during testis development, immunoblot analysis was performed with testis extracts obtained from mice at the different stages of prenatal and postnatal development. HSPA4 was detected throughout the prenatal and postnatal development of testis as shown in Fig. 1D and E. Expression levels of the HSPA4 are markedly increased in testis after postnatal day 20 suggesting an increased expression of the HSPA4 in haploid spermatids. We also examined the expression of HSPA4 in testes of mouse mutants. HSPA4 was present in testes of $W / W^{2}$ mutant mice that lack most germ cells as well as in testes of $q k / q k$, olt/olt, and Ins/3 $3^{-1-}$ mutant mice, in which spermatogenesis is arrested at different stages (Fig. 1F; Lyon \& Searle 1989, Chubb 1992, Zimmermann et al. 1999). Further immunoblot analysis was performed with protein extracts isolating from embryonic stem cells, spermatogonial stem cells (Guan et al. 2006), Sertoli cell line 15P-1 (Rassoulzadegan et al. 1993), HeLa, and hepatoma Hep2G cell line. HSPA4 was expressed in embryonic, spermatogonial stem, and
Sertoli cell lines, whereas its expression levels were lower in both HeLa and Hep2G (Fig. 1G). These results suggest that HSPA4 is expressed in somatic and germ cells of testis. To determine the cellular localization of HSPA4, immunocytochemical analysis was performed on sections of fetal and newborn testis and ovary after embryonic day 13.5. We observed that HSPA4 is highly enriched in male gonocytes of E13.5, whereas lower levels of HSPA4-immunostaining were seen in somatic cells (Fig. 2A). Expression of HSPA4 remains at high levels in gonocytes throughout fetal stages (Fig. 2B and C). After migration of gonocytes from central to peripheral layer of seminiferous tubules during neonatal development and their start to differentiate to differentiated spermatogonia in 5-day-old testis, HSPA4 still expressed but at lower level than in fetal gonocytes (Fig. 2D). In adult testis, the expression of HSPA4 is slightly increased in post-meiotic germ cells (Fig. 2E). The HSPA4-specific immunostaining was confirmed by the absence of HSPA4-immunostaining in adult Hspa4deficient testis (Fig. 2F). Immunofluorescence with antibodies directed against undifferentiated spermatogonia marker PLZF revealed that HSPA4 and PLZF are expressed in the same population of spermatogonia (Fig. 2G-I). When the preleptotene spermatocytes enter meiosis in 10-day-old testis, differentiated
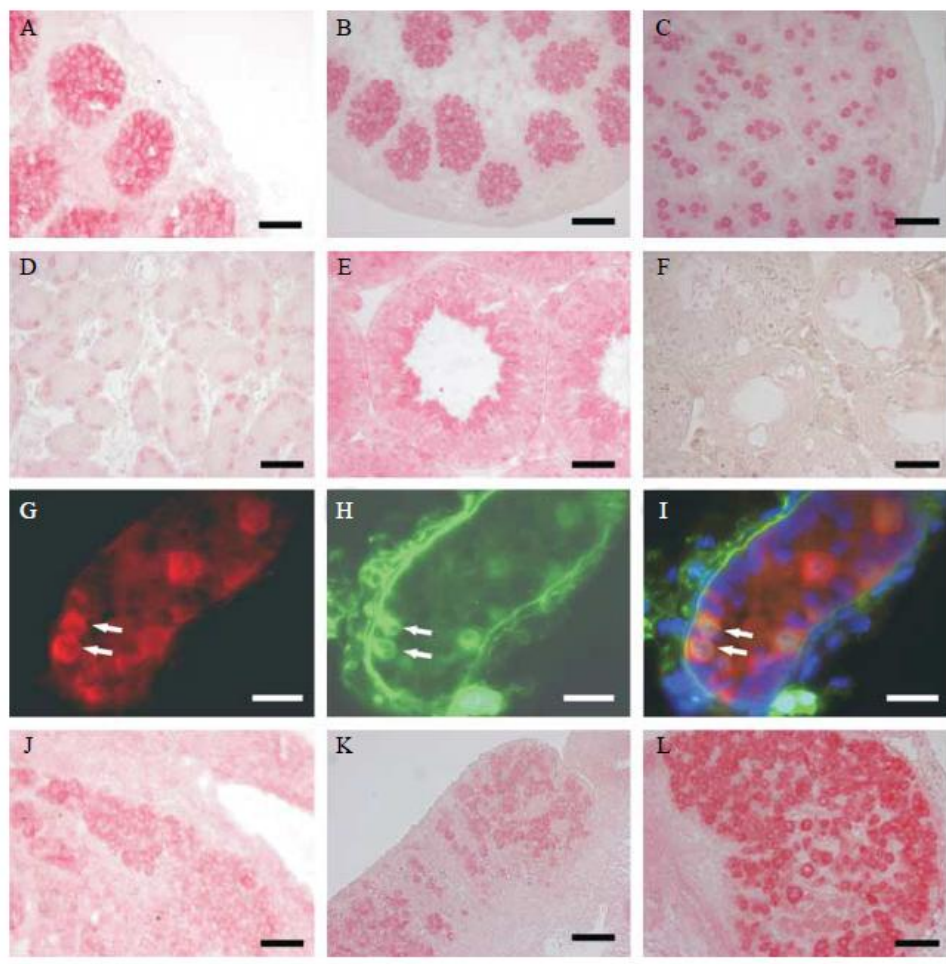

Figure 2 Cellular localization of HSPA4 during testis and ovary development. (A-F) Immunohistochemistry of paraffin sections with anti-HSPA4 shows an abundance of HSPA4 in the gonocytes of wild-type testes at E13.5 (A), E15.5 (B), E18.5 (C), and in spermatogonia at P5 (D). In 3-monthold wild-type testis, expression of the HSPA4 is slightly increased in post-meiotic germ cells (E). A negative control of immunohistochemistry is the absence of HSPA4-specific immunostaining in adult Hspa4-deficient testis (F). (G-I) Expression of the HSPA4 in undifferentiated spermatogonia of wild-type mice is confirmed by immunofluorescence of testis at P5 with anti-HSPA4 (G) and antiPLZF $(H)$. HSPA4 and PLZF are expressed in the same population of spermatogonia (arrows). HSPA4 (red fluorescence) and PLZF (green fluorescence) are shown separately $(\mathrm{G}$ and $\mathrm{H})$ and merged (I). DAPI (blue fluorescence) was used for nuclear staining (I). (J-L) Immunohistochemistry with HSPA4 antibody was performed on ovary sections of E13.5 (J), E15.5 (K), and E18.5 (L). Scale bar A-F and $\mathrm{J}-\mathrm{L}=50 \mu \mathrm{m} ; \mathrm{G}-\mathrm{I}=20 \mu \mathrm{m}$. 
spermatogonia, leptotene, and zygotene spermatocytes are expressed HSPA4 at very low levels (data not shown). In prenatal ovary, oogonia of E13.5 show weak staining (Fig. 2J), whereas HSPA4 is highly expressed in oogonia of E15.5 and E18.5 (Fig. 2K and L). The high enrichment of HSPA4 in gonocytes and oogonia throughout their embryonic development suggests that the absence of HSPA4 protein might directly affect the development of germ cells in both male and female embryos.

\section{Hspa4 deficiency results in impaired male fertility}

To investigate the function of HSPA4, we inactivated the Hspa4 in mouse ESC. Hspa4-targeting vector was designed to replace a $3.0 \mathrm{~kb}$ genomic fragment containing exon 1 by neomycin resistance gene (Fig. 3A). Recombinant Hspa4 ${ }^{+}{ }^{-}$ESCs were analyzed by Southern blot hybridization (Fig. 3B) and then used to generate chimeric mice. Chimeric mice were intercrossed with $\mathrm{C} 57 \mathrm{BL} / 6 \mathrm{~J}$ females to establish the Hspa4 mutant allele on a $\mathrm{C} 57 \mathrm{BL} / 6 \mathrm{~J} \times 129 / \mathrm{Sv}$ hybrid genetic background. Interbreeding of heterozygous mice yielded a normal Mendelian ratio of $\mathrm{Hspa}^{+/+}, \mathrm{Hspa}^{+/-}$, and $\mathrm{Hspa}^{-/-}$offspring. These results indicate that there is no lethality caused by the Hspa4 mutation. Male and female Hspa4-deficient mice developed into apparently normal adults. In Hspa4-null allele, exon 1 containing the translation initiation codon ATG is deleted.
Therefore, we expected that the targeted Hspa4 allele would be transcribed into an untranslated $\mathrm{Hspa} 4$ mRNA. The inactivation of Hspa4 was confirmed by RT-PCR and northern and western blot analyses. The 596 bp cDNA probe recognized a weak band in RNA from $\mathrm{Hspa}^{-/-}$ testis (Fig. 3C). RT-PCR with primers containing sequences of exons 1 and 3 was not able to amplify the Hspa4 cDNA fragment from testicular RNAs of Hspa4-deficient mice (Fig. 3D). At protein level, the HSPA4 antibody recognized the expected $96 \mathrm{kDa}$ HSPA4 protein in testes of wild-type and heterozygous animals, whereas the corresponding protein band was not detected in testes of Hspa4-deficient mice (Fig. 3E). These results confirm that the targeted disruption of Hspa4 generated a null mutation.

To study the consequence of Hspa4 mutation on female and male fertility, we intercrossed 13 males and seven females from F2 generation with wild-type mice of strain CD1 over a period of 3 months. All mating of Hspa4-deficient females were reproductive, and the average litter size $(9.2 \pm 2.4, n=18)$ was not significantly different compared to breeding with wild-type females $(9.6 \pm 1.6, n=15)$. Breeding of male mutants revealed that fertility was heterogeneous among males. Of the 13 males, eight did not produce a single litter, whereas the remaining five produce litter size $(11.1 \pm 3.4$, $n=16)$ similar to those of their wild-type littermates $(14.6 \pm 1.2, n=15)$.

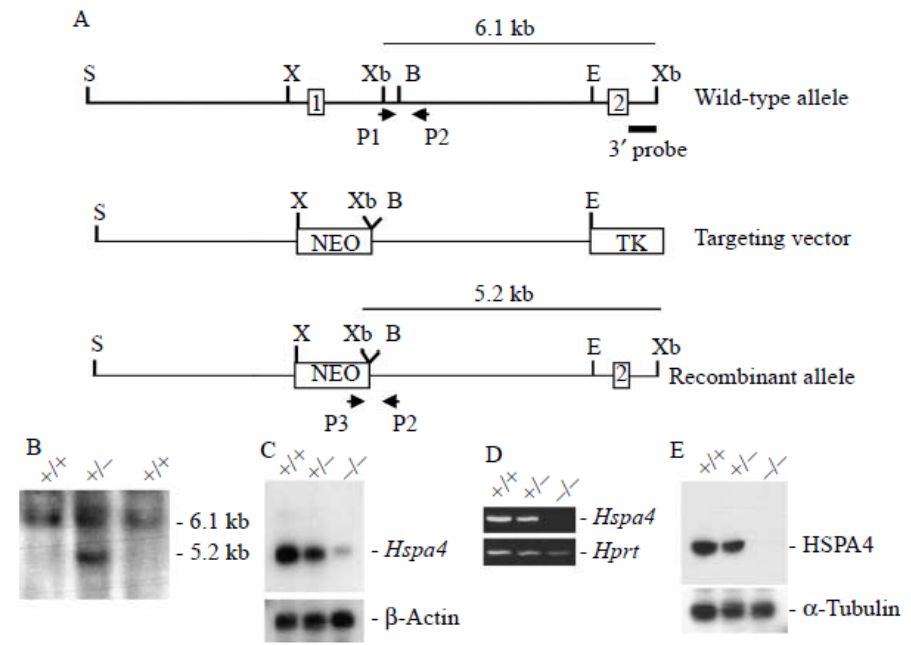

Figure 3 Targeted disruption of the Hspa4 gene. (A) Schematic representation of wild-type, targeted vector and recombinant allele. Exons are represented as numbered boxes. A $3.0 \mathrm{~kb}$ genomic fragment containing exon 1 was replaced by $p g k$-neo selection cassette (NEO). TK box represents thymidine kinase. The $3^{\prime}$ external probe used and the predicted length of Xbal restriction fragments in Southern blot analysis are shown. The primers $\mathrm{P} 1$, P2, and P3 used to amplify the wild-type and mutant alleles by PCR are also indicated. Restriction sites relevant for generation of knockout vector and for screening strategies are Spel (S), Xhol (X), Xbal (Xb), BamHI (B) and EcoRI (E). (B) Southern blot analysis of recombinant ES cell (ESC) clones. Genomic DNA from ESC clones was digested with Xbal and probed with the 3'-probe shown in panel A. (C) Northern blot with testicular RNA of $\mathrm{Hspa}^{+/+}, \mathrm{Hspa}^{+/+}$, and $\mathrm{Hspa}_{4}{ }^{-/}$mice was hybridized with the 596 bp $\mathrm{H}_{\text {spa4 }}$ and $\beta$-actin cDNA probes. (D) RT-PCR analysis using testicular RNA and primers located in exons 1 and 3 of $H s p a 4$ confirmed the absence of exon 1 in $H s p a 4$ targeted transcripts. Amplification of Hprt cDNA in assays with RNA of three genotypes was used as a control. (E) Western blot with whole protein extracts from testes of $\mathrm{Hspa4}^{+/+}, \mathrm{Hspa}^{+/-}$, and $H$ spa $4^{-/-}$mice was probed with HSPA4 and $\alpha$-tubulin antibodies. 
To verify whether the Hspa4 deficiency results in disruption of spermatogenesis and/or sperm motility, we analyzed the number and the motility of spermatozoa collected from the cauda epididymides of 5-month-old wild-type, fertile, and infertile $\mathrm{Hspa}^{-/-}$males. A significant reduction in the mean number of spermatozoa was found in $\mathrm{Hspa}^{-/-}$males. Analysis of sperm motility and progressive movement showed significant differences only between spermatozoa of wild-type and infertile $\mathrm{Hspa4}^{-/-}$mice (Table 1).

\section{Spermatogenesis is arrested at meiotic prophase stage}

Testis weights of 5-month-old infertile Hspa4-null mice $(51.1 \pm 12.1 \mathrm{mg}, n=5)$ were significantly reduced than those of control males (125.4 $\pm 4.2 \mathrm{mg}, n=5$; Fig. 4A). To elucidate the cause of the reduction in number of spermatozoa, we analyzed cross sections of testes from 5-month-old wild-type and Hspa4-deficient mice. Testes of infertile mutant mice exhibited a diverse range of defects, varying in severity among males. Most seminiferous tubules were markedly smaller than those of wild-type controls (Fig. 4B and C). Tubules of testes from infertile mice contained Sertoli and early stages of spermatogenic cells; however, many pachytene spermatocytes have degenerated nuclei, and round and elongated spermatids were absent in most seminiferous tubules (Fig. 4D and E). Many tubules were vacuolated due to spermatocytes loss. Multinucleated spermatids, which may arise by widening of the intercellular bridges after meiotic division (Dym \& Fawcett 1971), were frequently observed (Fig. 4B and C). Consequently, the mutant epididymides contained a few number of sperm and immature germ cells with compact chromatin were present (Fig. 4F and G).

To identify the spermatogenic stage, at which spermatogenesis is affected by Hspa4 deficiency, testicular sections from different postnatal days were histologically and immunohistologically analyzed. No apparent differences were observed in the histological structure of seminiferous tubules between mutant and wild-type mice at postnatal days 5 and 10 (data not shown). Using the HSPH1 antibody to label gonocytes, the $\mathrm{Hspa}^{-/-}$and $\mathrm{Hspa4}^{+/+}$tubules were observed to

Table 1 Sperm analysis of $\mathrm{Hspa}^{+/+}$and $\mathrm{Hspa}^{-/-}$mice.

\begin{tabular}{cccc}
\hline $\begin{array}{l}\text { Genotype } \\
\text { of mice }\end{array}$ & $\begin{array}{c}\text { No. of sperm in cauda } \\
\text { epididymis }\left(10^{7}\right)\end{array}$ & $\begin{array}{c}\text { Sperm } \\
\text { motility }(\%)\end{array}$ & $\begin{array}{c}\text { Progressive } \\
\text { motility }(\%)\end{array}$ \\
\hline$H_{s p a 4}{ }^{+/+}$ & $2.0 \pm 0.1(5)$ & $63.2 \pm 4.4(5)$ & $42.1 \pm 5.3(5)$ \\
$H_{\text {spa4 }}{ }^{-/-}$ & & & \\
Fertile & $1.1 \pm 0.4^{*}(4)$ & $57.0 \pm 6.5(4)$ & $33.5 \pm 9(4)$ \\
Infertile & $0.2 \pm 0.3^{*}(5)$ & $18.3 \pm 11.4^{*}(4)$ & $9.8 \pm 5.9^{*}(4)$ \\
\hline
\end{tabular}

Data for sperm analysis represent the mean \pm s.D. for the numbers of individual measurements indicated in parentheses. *Value in $\mathrm{Hspa4}^{-1-}$ mice is significantly different from that in $\mathrm{Hspa}^{+/+}$mice $(P<0.01$ by Student's $t$-test). contain equivalent numbers of gonocytes, suggesting that the Hspa4 deficiency does not impair gonocytes or development of gonocytes to spermatogonia (Supplementary Figure 1, see section on supplementary data given at the end of this article). At postnatal day 10, the first spermatocytes are formed. The number of germ cells stained with anti-GCNA1, a marker of pre-meiotic and meiotic germ cells, in mutant and wild-type tubules, was not significantly different at postnatal day 10 , suggesting that mitotic division in mutant testes is not affected (Supplementary Figure 1). However, a few of the seminiferous tubules of $\mathrm{Hspa}^{-/-}$testes contained meiotic germ cells (pachytene spermatocytes) at postnatal day 15 (Fig. 5A and B). By immunohistological staining with anti-HSPA4L, which is highly expressed in germ cells from pachytene spermatocytes (Held et al. 2006), a reduction was observed in the mean number of HSPA4L-immunopositive cells per tubule in $\mathrm{Hspa}^{-/-}$ compared with wild-type testes (Supplementary Figure 1). At P20, spermatogenesis has reached the stage of round spermatids in majority of wild-type tubules. In contrast, mutant tubules were almost completely devoid of round spermatids and contained much fewer number of pachytene spermatocytes (Fig. 5C and D). At day 25, when tubules of wild-type littermates showed elongated spermatids, $\mathrm{Hspa4}^{-/-}$testes showed a severe depletion of germ cells. In Hspa4-deficient testes, very few tubules contained round spermatids as the most advanced germ cells (Fig. 5E and F). To examine whether disrupted spermatogenesis is due to the impairment of chromosomal pairing, we analyzed the formation of the synaptonemal complex in the mutant germ cells. No abnormalities in the chromosome pairing were detected as judged by the proper accumulation of SCPY3 on the synapsed chromosomes during pachytene stage (Supplementary Figure 1). These results suggest that the Hspa4 deficiency resulted in either developmental delay or partial arrest of the first wave of spermatogenesis.

To investigate whether the observed loss of germ cells is a result of enhanced apoptosis in Hspa4-null mice, TUNEL assay was performed on testis section of 10-, 15-, 20-, 25-, and 150-day-old mice. In 5-month-old testes, there were significantly more TUNEL-positive cells in seminiferous tubules of infertile Hspa4-null mice than in those of wild-type littermates (Fig. 6G and H). During postnatal development of testis, there were no significant differences in the number of TUNEL-positive cells between $\mathrm{Hspa}^{+/+}$and $\mathrm{Hspa}^{-/-}$testes at P10 (data not shown). A significant increase of TUNEL-positive spermatocytes was found in Hspa4-null mice at P15, P20, and P25 (Fig. 6A-F and I). These results indicate that germ cells at meiotic stages appear to be the most affected cells in Hspa4-deficient testes.

We then analyzed the expression of different meiotic and post-meiotic marker genes in testes of wild-type, fertile, and infertile mutant mice (Fig. 7A and B). 
A

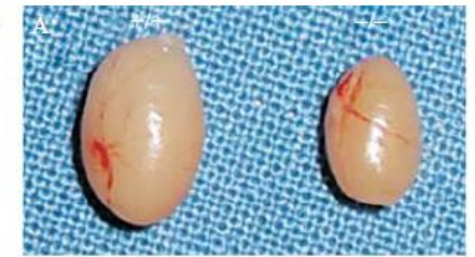

$+/+$
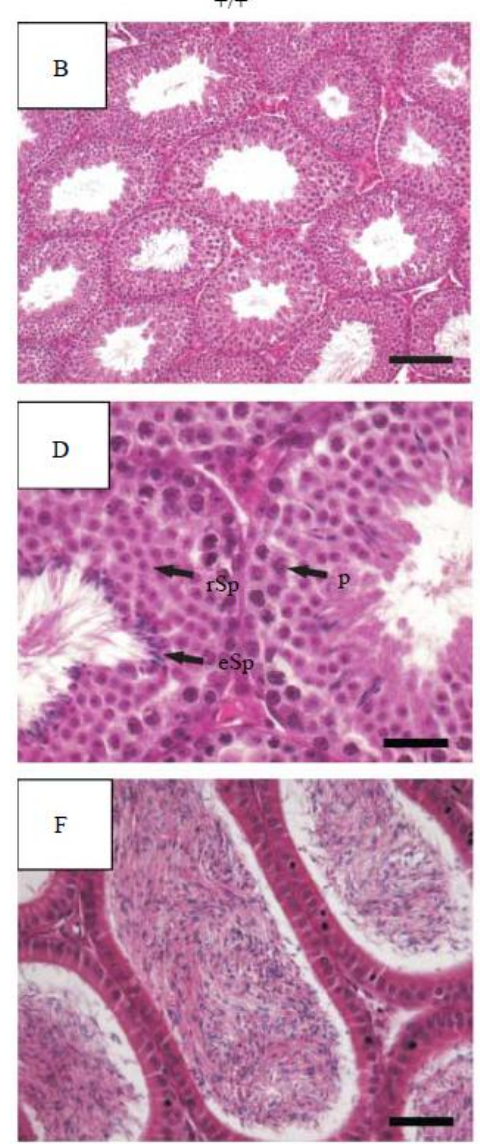
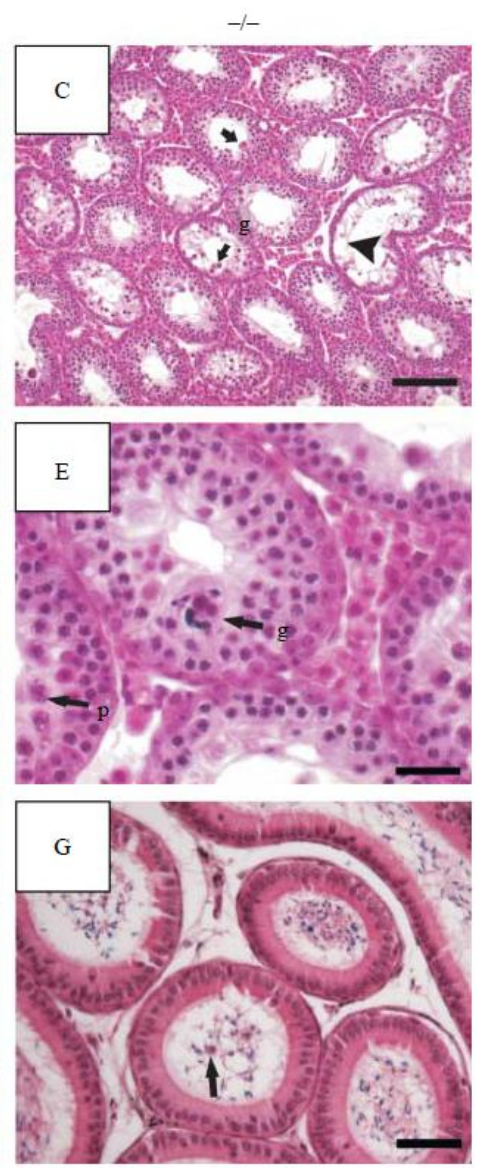

Figure 4 Testes and spermatogenesis of $\mathrm{Hspa}^{+/+}$ and infertile $\mathrm{Hspa}^{-1-}$ mice. (A) Infertile $\mathrm{Hspa}^{-1-}$ mice showed reduced testis size compared with $\mathrm{Hspa}^{+/+}$mice. (B-E) Histological sections from testes of 5-month-old wild-type $(+/+)$ and Hspa $4^{-1-}$ mice $(-/-)$ were stained with hematoxylin and eosin (H\&E). A strongly reduced number of pachytene spermatocytes and round and elongated spermatids are found in most seminiferous tubules of mutant mice ( $\mathrm{C}$ and $\mathrm{E}$ ) compared with wild-type mice (B and D). Furthermore, degenerated germ cells and vacuoles (arrowhead) and presence of multinucleated giant cells (g) are frequently found in testes of infertile $\mathrm{Hspa4}^{-1-}$ mice. P, pachytene spermatocytes; $\mathrm{rSp}$, round spermatids; $\mathrm{eSp}$, elongated spermatids. ( $F$ and $G$ ) H\&E-stained sections of epididymides of 5-month-old mice. Hspa4-deficient epididymides contain a few number of sperm, and immature germ cells with

compact chromatin were present (arrow). Scale bar $(B$ and $C)=100 \mu \mathrm{m} ;(D-G)=50 \mu \mathrm{m}$.
Expression of Sycp3 gene encoding synaptonemal complex protein-3 is restricted to leptotene and zygotene spermatocytes (Lammers et al. 1994). Northern blot analysis revealed that the expression levels of Sycp3 in testes of fertile and infertile $\mathrm{Hspa}^{-/-}$mice are similar to those in wild-type testes. In contrast, expression of testis-specific genes encoding the phosphoglycerate kinase-2 (Pgk2) and acrosin (Acr), which were reported to be expressed in pachytene spermatocytes (Goto et al. 1990, Kashiwabara et al. 1990, Kremling et al. 1991), was markedly reduced in testes of infertile Hspa4-null mice. Similar results were also obtained for transcript levels of post-meiotic genes Hsc70t (Hsp70 homolog gene) and transition nuclear protein 2 (Tnp2; Kleene \& Flynn 1987, Tsunekawa et al. 1999). These results confirm that the disruption of spermatogenesis in Hspa4-deficient mice occurred late in meiotic prophase I.

The mild phenotype in spermatogenesis of Hspa4-null mice may be due to overexpression of other members of HSP110 family. Therefore, we analyzed the expression of HSPA4L and HSPH1 in testes of fertile $\mathrm{Hspa}^{-1-}$ mice. Western blot analysis did not reveal a marked increase in the expression of HSPA4L and HSPH1 in testes of Hspa4-null mice (Fig. 7C). 

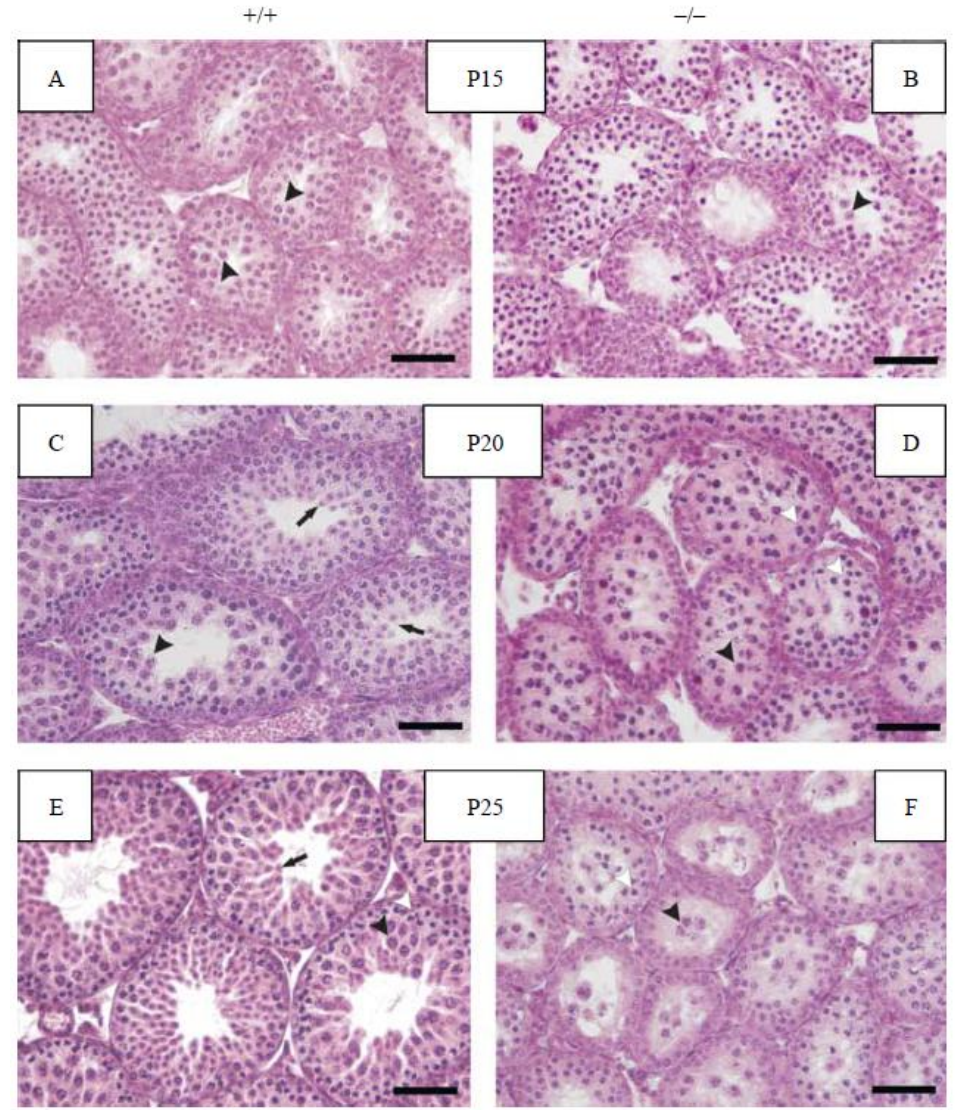

Figure 5 Delayed and disrupted first wave of spermatogenesis in Hspa 4 mutant mice. (A-F) Testicular sections from wild-type $(+/+)$ and Hspa4-null mice $(-/-)$ at postnatal days 15 (P15), 20 (P20), and 25 (P25) were stained with $\mathrm{H} \& \mathrm{E}$. Arrowheads and arrows indicate pachytene spermatocytes and spermatids, respectively. Scale bar $=50 \mu \mathrm{m}$.

\section{Discussion}

This research describes the expression and physiological function of HSPA4 in germ cell development. Expression of HSPA4 is ubiquitously expressed in both somatic and germ cells of testis. However, the expression is highly enriched in male and female germ cells of prenatal gonads. Expression of HSPA4 in male gonocytes is gradually decreased after migration to the basal layers of seminiferous tubules and differentiation to spermatogonia. This preferential expression leads us to study the specific role of HSPA4 in germ cell development. Analyses of Hspa4-deficient mice revealed that all Hspa4-null mice on the hybrid C57BL/6J $\times 129 / \mathrm{Sv}$ genetic background were born at Mendelian ratio and were apparently normal. Although expression of HSPA4 can be detected in all tissues of wild-type mice, male infertility was the most apparent phenotype for Hspa4deficient mice of the second generation. Male infertility is histologically characterized by a decreased number of the post-meiotic germ cells and an increased number of germ cells undergoing apoptosis. Hspa4 mutants display a disruption of the first wave of spermatogenesis in juvenile testes by postnatal day 15, when the most advanced germ cells in the testes remain at the late pachytene spermatocyte stage. The histological results were confirmed by immunohistological and RNA analyses. These results showed the presence of an equivalent number of gonocytes in neonatal Hspa4null testes and a lower percentage of mature spermatids. Expression of early meiosis-specific genes was not affected in Hspa4-deficient testes. In contrast, expression of marker genes for later stages of meiotic prophase I and for post-meiotic germ cells was downregulated in the absence of HSPA4. These results indicate that the Hspa4 deficiency impairs the development of most germ cells in late prophase I.

Numerous proteins that are required for the development of male germ cells through meiotic and postmeiotic stages are mostly translated in the pachytene spermatocyte stage (Eddy \& O'Brien 1998). Failure of molecular chaperones to direct correct folding of newly synthesized proteins might lead to accumulation of misfolded and damaged proteins in pachytene spermatocytes, which could prompt spermatocytes to undergo 

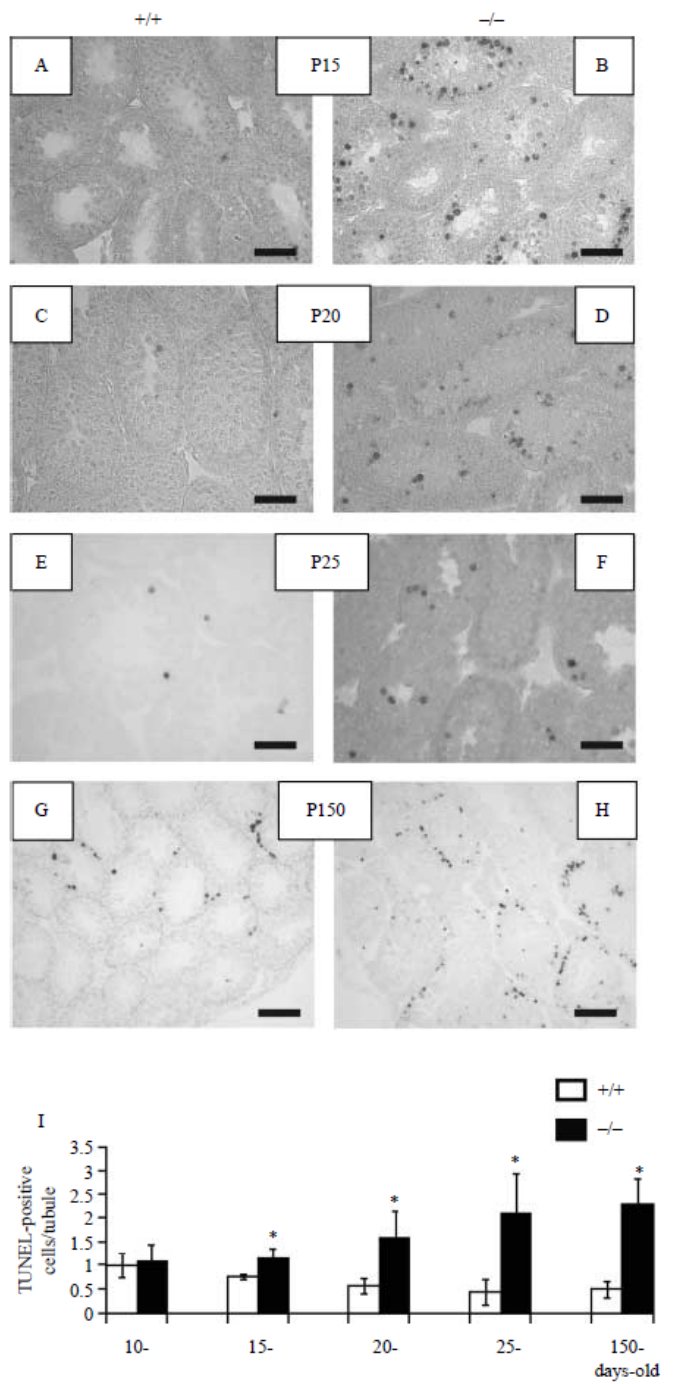

Figure 6 Enhanced apoptosis during germ cell development of Hspa4null mice. (A-H) Histological sections of $\mathrm{Hspa}^{+/+}(+/+)$and $H_{s p a 4}{ }^{-/}$mice $(-/-)$at postnatal days 15 (P15), 20 (P20), 25 (P25), and 150 (P150) were subjected to TUNEL staining. TUNEL-positive cells are mainly pachytene spermatocytes as indicated by their nuclear size and their position in the seminiferous tubules. Scale bar $(\mathrm{A}-\mathrm{F})=$ $50 \mu \mathrm{m} ;(\mathrm{G}$ and $\mathrm{H})=100 \mu \mathrm{m}$. (I) For quantification of TUNEL-positive cells/seminiferous tubule, sections of testes derived from two mice per genotype per stage were microscopically analyzed. Number of the TUNEL-positive cells per tubule in each microscopic field was determined. An average of 10-20 randomly microscopic fields were scored for each genotype and developmental stage ( $n=100-150$ tubules). Then, the mean number of TUNEL-positive cells per tubule and standard deviation were calculated for the examined fields. Paired comparisons of the TUNEL-positive cells/tubule in testis among $\mathrm{Hspa}^{+/+}$and $\mathrm{Hspa}^{-/-}$mice in each stage were performed to determine the statistical significance by using Student's $t$-test. Bar graph represents mean \pm s.D. ${ }^{*} P<0.05$. apoptosis, rather carry on with meiotic division. Based on the high similarity of HSP110 family members, we expected that the molecular chaperones, which also include the NEF members of HSP110 family, would be abnormally or partially affected in $\mathrm{Hspa}^{-/-}$mice. The relatively leaky phenotype of Hspa4-deficient mice led us to suggest that other members of HSP110 family can partially compensate for the loss of HSPA4 function. HSPA4L and HSPH1 are possible candidates, because both proteins are widely expressed and localized in the cytoplasm like HSPA4. Therefore, the possibility of functional compensation between these proteins would be the cause that $\mathrm{Hspa}^{-/-}$mice are viable and display normal development except for disruption of spermatogenesis. This phenotype is also not completely penetrant, because some Hspa4-deficient germ cells were able to progress through spermatogenesis. To check this possibility, we intercrossed Hspa4-deficient mice with previously described $\mathrm{Hspa} 4 \mathrm{l}$ mutant mice to produce mice lacking both genes. We found that $\mathrm{Hspa}^{-/-}$ $\mathrm{Hspa}^{-1-}$ double knockout mice developed pulmonary hypoplasia that subsequently caused neonatal death during the first day of life (unpublished data). These results suggest a redundant function for HSPA4 and HSPA4L in lung maturation.

Expression of some HSP proteins is inducible by environmental stress, but expression of others can be either constitutive or developmentally regulated (Dix et al. 1997). HSPA4 and HSPH1 are ubiquitously expressed proteins and become relatively enriched in gonocytes after colonization of gonads by primordial germ cells (Fig. 2 and our unpublished data). The enrichment of both proteins in germ stem cells suggests their significant role for male and female germ stem cells. The results showed that the gonocytes are not affected in Hspa4-deficient mice, suggesting a redundant function of both proteins in germ cell development. To our knowledge, there is no report describing abnormal spermatogenesis in Hsph1-deficient mice. In one study, Hsph1-null mice were normally fertile (Nakamura et al. 2008). We are, therefore, interested in determining the impact of deleting both HSPA4 and HSPH 1 on germ cell development by generation and characterization of $\mathrm{Hspa}^{-1-} \mathrm{Hsph}^{-9-}$ double knockout mice.

Several reports, which used microarray analysis to identify preferentially expressed genes in different stem cells, revealed that the Hspa4 is highly expressed in embryonic and different tissue-specific stem cells, and its expression is downregulated in their differentiated counterparts (Ramalho-Santos et al. 2002, Bhattacharya et al. 2004). Hspa 4 was one of the 216 enriched genes that were found to be expressed at high levels in embryonic, neural, and hematopoietic stem cells. Our results showing HSPA4 expression in germ stem cells further confirm the requirement of HSPA4 function for germ cell development. Although the physiological role of molecular chaperones for self-renewal of stem cells is 
A

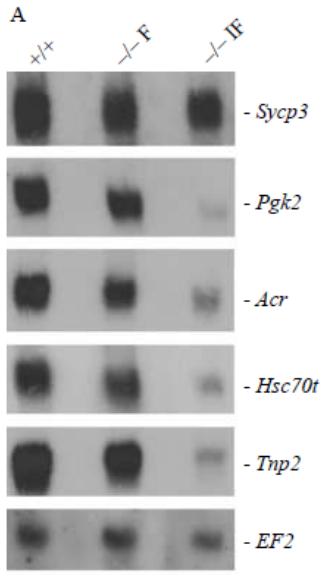

B

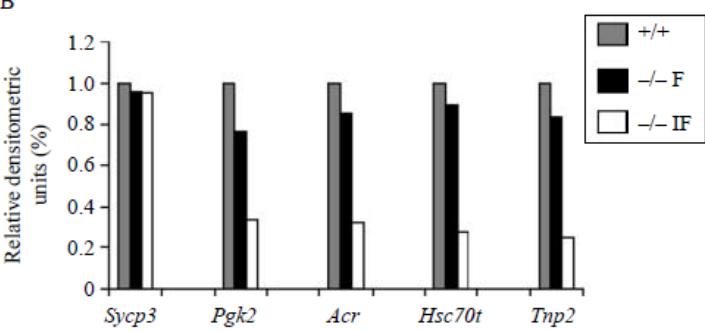

Figure 7 Expression profile of different germ cell markers and members of HSP1 10 family in $\mathrm{Hspa}^{-/-}$testes. (A) Northern blot with total RNA from testes of $\mathrm{Hspa}^{+/+}(+/+)$, fertile $(-/-\mathrm{F})$, and infertile Hspa4 ${ }^{-/-}$ $(-/-$ IF) mice was sequentially hybridized with cDNA probes for the indicated genes. (B) Densitometry analysis for the expression levels of different spermatogenic markers showing in Fig. 7A was determined. Expression level was expressed as relative percentage, with 1.0 given as the expression of spermatogenic marker in wild-type testis. Expression level of EF2 gene was used for normalization. (C) Expression patterns of other members of HSP110 family in testes of wild-type and Hspa4-null mice. Immunoblots were probed with the antibodies shown at the right margin.

not known, it is believed that molecular chaperones may protect stem cells from aging due to oxidative stress (Ramalho-Santos et al. 2002). Caenorhabditis elegans that have an extended life span have elevated levels of molecular chaperones and enzymes that process oxidative free radicals and appear to be resistant to environmental stresses (Finkel \& Holbrook 2000).

The partial penetrance of male infertility among Hspa4-null mice on the hybrid C57BL/6J $\times 129 / \mathrm{Sv}$ genetic background may be reflected by the segregation of genetic modifiers on the hybrid genetic background. Background-related differences in male infertility phenotype have been reported in other mutations (Pearse et al. 1997, Yu et al. 2000, Adham et al. 2001). We have observed increased incidence of male infertility among Hspa4-null mice in F2 generation, which contain a high level of inter-individual genetic variability. The decreased incidence of male infertility observed in the subsequent generation suggests that Hspa4-null males in different genetic background differ in fertility and would impose a selection bias against that genotype of infertile male. The decreased incidence of spermatogenic phenotypes in the following generations has also been described in different knockout mouse lines (Anderson et al. 2008, Burnicka-Turek et al. 2009).

The generation of Hspa4-, Hspa4l- and Hsph1deficient mice constitutes an initial step in the understanding of the physiological role of HSP110 family members in mammals.

\section{Materials and Methods \\ Generation of HSPA4-null mice}

The PAC clone (RPCIP711P18115Q2) containing the Hspa4 locus was isolated from the $129 / \mathrm{Sv}$ genomic library (RZPD, Berlin, Germany). The targeting vector was designed by replacement of exon 1 containing the start codon ATG with the Pgk-neo cassette. The $6 \mathrm{~kb} \mathrm{Spel} / \mathrm{Xhol}$ and $4.5 \mathrm{~kb} \mathrm{BamHl} /$ EcoRI genomic fragments containing the sequences of $5^{\prime}$-flanking region and intron 1 of Hspa4, respectively, were isolated from the PAC clone and inserted on either side of Pgk-neo cassette of pPNT vector (Fig. 3A). The targeting vector was linearized with Notl and used for transfection of RI ES cells. Recombined ES-cells were checked for homologous recombination by Southern blot analysis. Genomic DNA was isolated from ES cells, digested with Xbal, separated in $0.8 \%$ $(\mathrm{w} / \mathrm{v})$ agarose gels, and transferred onto nylon membrane (Amersham Pharmacia). A $0.7 \mathrm{~kb}$ fragment located at $3^{\prime}$ of targeting vector was amplified, radioactive labeled, and used as probe for the Southern blot analysis. Correctly targeted ES cell clones were injected into blastocysts derived from $\mathrm{C} 57 \mathrm{BL} / 6$ ] mice and transferred into pseudo pregnant DBA/Bl6 females to generate chimeric mice. The chimeric founders were mated with $\mathrm{C} 57 \mathrm{BL} / 6 \mathrm{~J}$ to generate heterozygous $\mathrm{Hspa}^{+/-}$mice, which were intercrossed to produce homozygous $\mathrm{Hspa}^{-/-}$ mice. Genotyping of mice was carried out by PCR amplification of tail DNA. A 535 bp PCR product from the wild-type allele was detected using primer F1: 5'-GATCACGGGAAGTGAGTGGT-3' and R1: 5'-GAGCGGGAG TGAGACAGTTC-3'. The targeted allele yielded a 274 bp product with primer F1: and primer PGK $5^{\prime}$-GGATGTGGAATGTGTGCGAGG- ${ }^{\prime}$. The thermal cycling was carried out for 35 cycles of denaturation at $94{ }^{\circ} \mathrm{C}$ for $30 \mathrm{~s}$, annealing at $55^{\circ} \mathrm{C}$ for $30 \mathrm{~s}$, and extension at $72{ }^{\circ} \mathrm{C}$ for $30 \mathrm{~s}$. All animal experiments were reviewed and approved by the Institutional Animal Care and Use Committee of the University of Göttingen.

\section{Northern blot analysis and RT-PCR}

Total RNA was extracted using RNAeasy mini-kit (Qiagen) and resolved $(10 \mu \mathrm{g} /$ line $)$ on an agarose gel containing $2.2 \mathrm{M}$ formaldehyde and transferred onto nylon membrane. Blots were hybridized with 358 and $596 \mathrm{bp}$ cDNA fragments containing the sequences of the C-terminal coding and the 3 -untranslated regions of $\mathrm{Hspa4}$, respectively. The followed 


\section{THeld, A Z Barakat and others}

primers were used to amplify the 358 and the 596 bp cDNA probes: $5^{\prime}$-GAAGAACTAGGGAAGCAAATCC- 3 ' and $5^{\prime}$-TCAATGTCCATCTCAGGAAGC-3'; 5'-GTCCTGTTTAAGAGCCCAGCTA- $3^{\prime}$ and $5^{\prime}$-ATTTACCAT GCCTACACCCAAC- $3^{\prime}$.

RT-PCR assay was performed using $2 \mu \mathrm{g}$ total RNA and a one step RT-PCR kit (Qiagen). Primers to amplify Hspa4 and Hprt transcripts were $5^{\prime}$-GTCGGTGGTGGGCATAGAC-3' and $5^{\prime}$-TTTATGCCCGTTAATCCAGTG; 5'-GTCAAGGGCATATCCAACAACAAAC-3' and 5'-CCTGCTGGATTACATTAAAGCACTG-3', respectively.

Densitometry analysis was performed using the Image) Software (NIH, Bethesda, MD, USA); optic density for expression levels of EF2 in northern blot analysis was used for normalization.

\section{Fertility test and spermatozoa quality}

To examine the fertility of Hspa4-deficient males on a hybrid $129 / \mathrm{Sv} \times \mathrm{C} 57 \mathrm{BL} / 6$ J genetic background, mature $\mathrm{Hspa4}^{-/-}$ males from the second generation were intercrossed, each with two wild-type CD1 females, for at least 3 months. The number and size of litters sired by each male were determined in a 3-month mating period.

Epididymides of ten $\mathrm{Hspa}^{-/-}$and four wild-type males were collected and dissected in IVF medium (MediCult, Jyllinge, Denmark). Sperm number in cauda epididymides was determined using the Neubauer cell chamber. To determine the sperm motility, spermatozoa were incubated for $1.5 \mathrm{~h}$ at $37^{\circ} \mathrm{C}, 5 \% \mathrm{CO}_{2}$. Sperm suspension $(10 \mu \mathrm{l})$ was transferred to the incubation chamber, which was set to $37^{\circ} \mathrm{C}$. Sperm movement was quantified using the CEROS computerassisted semen analysis system (version 10, Hamilton Thorne Research, Beverly, MA, USA).

\section{Histological and immunohistochemical methods}

For histological analysis, tissues were fixed in Bouin's solution and embedded in paraffin. Sections $(6 \mu \mathrm{m})$ were stained with hematoxylin and eosin (H\&E). For immunohistochemistry, sections were preincubated for $1 \mathrm{~h}$ with $5 \%$ normal goat serum in $0.05 \%(\mathrm{v} / \mathrm{v})$ Triton-X-100-PBS; incubated overnight at $4{ }^{\circ} \mathrm{C}$ with either rabbit anti-HSPA4 (N-60; Santa Cruz Biotechnology, Santa Cruz, CA, USA) at 1:200 dilution, antiHSPA4 (N-96; Santa Cruz) at 1:200 dilution, mouse anti-germ cell nuclear protein (GCNA1) at 1:50 dilution, or anti-HSPH1 (Sigma) at 1:200 dilution; washed with PBS; and then incubated with alkaline phosphate-conjugated goat anti-rabbit antibody or anti-rate (Sigma) at 1:500 dilution for $1 \mathrm{~h}$ at room temperature. After washing with PBS, immunoreactivity was detected by incubation of the sections in a solution containing Fast Red TR/naphthol AS-MX phosphate tablets (Sigma). For PLZF and HSPA4 double immunofluorescent staining, sections of 5-day-old testes were incubated overnight at $4{ }^{\circ} \mathrm{C}$ with rabbit anti-HSPA4 and mouse anti-PLZF (D-9, Santa Cruz) antibodies. Sections were washed and then incubated with Cy3conjugated goat anti-rabbit and FITC-conjugated goat anti-mouse antibodies (Sigma) for $1 \mathrm{~h}$ at room temperature. After washing, sections were mounted with Vectashield mounting reagent (Vector, Burlingame, CA, USA) prior to fluorescence microscopy (Olympus, Hamburg, Germany).

TUNEL-positive cells were detected using an ApopTaq peroxidase in situ apoptosis kit (Obiogene, Heidelberg, Germany) according to the manufacturer's instruction.

\section{Western blot analysis}

Tissues were sonicated in RIPA buffer (Santa Cruz). Protein lysates were cleared by centrifugation at $16000 \mathrm{~g}$ at $4{ }^{\circ} \mathrm{C}$ for $20 \mathrm{~min}$, and protein concentration was measured by the Bradford assay (Bio-Rad). Total cell lysate $(20 \mu \mathrm{g})$ was then resolved in $15 \%(\mathrm{w} / \mathrm{v})$ SDS-PAGE gel and electroblotted onto nitrocellulose membrane. After blocking with $5 \%(\mathrm{w} / \mathrm{v})$ skimmed milk in PBS, blots were incubated with either the primary antibodies rabbit anti-HSPA4 (1:500, Santa Cruz), rabbit anti-HSPA4L (1:500, Santa Cruz), rabbit anti-HSPH1 (1:1000, Sigma), or monoclonal anti- $\alpha$-tubulin (1:10000, Sigma) with skimmed milk in PBS overnight at $4{ }^{\circ} \mathrm{C}$. After a washing step, blots were incubated with HRP-conjugated anti-rabbit or antimouse $\operatorname{lgG}(1: 2000$, Sigma). The detection of immunoreactivity was performed using enhanced chemiluminescence (Pierce Chemical, Rockford, IL, USA).

\section{Statistical analysis}

Paired comparisons of the different sperm parameters and the number of apoptotic cells/tubule in testis among $\mathrm{Hspa}^{-1-}$ and $\mathrm{Hspa}^{+}{ }^{++}$mice were performed for statistical significance by calculating means \pm S.D. and Student's $t$-test.

\section{Supplementary data}

This is linked to the online version of the paper at http://dx.doi. org/10.1530/REP-11-0023.

\section{Declaration of interest}

The authors declare that there is no conflict of interest that could be perceived as prejudicing the impartiality of the research reported.

\section{Funding}

B A Mohamed is supported by the DAAD through grant A/07/80490.

\section{Acknowledgements}

We thank MSchindler, S Wolf and U Fünfschilling for their help in the generation and breeding of knockout mice; A Nagy (Mount Sinai Hospital, Toronto, Canada) for providing RI ES cells; and G C Enders (Kansas University, Medical Center, Kansas City, USA) for providing the GCNA1 antibody. Parts of this research are components of the PhD thesis of T Held: 'Zur Strukturellen und Funktionellen Analyse der Murinen Gene der HSP110 Familie'. 


\section{References}

Adham IM, Nayernia K, Burkhardt-Göttges E, Topaloglu O, Dixkens C, Holstein AF \& Engel W 2001 Teratozoospermia in mice lacking the transition protein 2 (Tnp2). Molecular Human Reproduction 7 513-520. (doi:10.1093/molehr/7.6.513)

Anderson EL, Baltus AE, Roepers-Gajadien HL, Hassold TJ, de Rooij DG, van Pelt AM \& Page DC 2008 Stra8 and its inducer, retinoic acid, regulate meiotic initiation in both spermatogenesis and oogenesis in mice. PNAS 105 14976-14980. (doi:10.1073/pnas.0807297105)

Bhattacharya B, Miura T, Brandenberger R, Mejido J, Luo Y, Yang AX, Joshi BH, Ginis I, Thies RS, Amit M et al. 2004 Gene expression in human embryonic stem cell lines: unique molecular signature. Blood 103 2956-2964. (doi:10.1182/blood-2003-09-3314)

Burnicka-Turek O, Shimeshan K, Paprotta I, Grzmil P, Meinhardt A, Engel W \& Adham IM 2009 Inactivation of insulin-like factor 6 disrupts the progression of spermatogenesis at late meiotic prophase. Endocrinology 150 4348-4357. (doi:10.1210/en.2009-0201)

Chubb C 1992 Oligotriche and quaking gene mutations. Phenotypic effects on mouse spermatogenesis and testicular steroidogenesis. Journal of Andrology 13 312-317.

Dix DJ, Allen JW, Collins BW, Poorman-Allen P, Mori C, Blizard DR, Brown PR, Goulding EH, Strong BD \& Eddy EM 1997 HSP70-2 is required for desynapsis of synaptonemal complexes during meiotic prophase in juvenile and adult mouse spermatocytes. Development 124 4595-4603.

Dragovic Z, Broadley SA, Shomura Y, Bracher A \& Hartl FU 2006 Molecular chaperones of the Hsp1 10 family act as nucleotide exchange factors of Hsp70s. EMBO Journal 25 2519-2528. (doi:10.1038/sj.emboj. 7601138)

Dym M \& Fawcett DW 1971 Further observations on the numbers of spermatogonia, spermatocytes, and spermatids connected by intercellular bridges in the mammalian testis. Biology of Reproduction 4 195-215.

Eddy EM 1999 Role of heat shock protein HSP70-2 in spermatogenesis. Reviews of Reproduction 4 23-30. (doi:10.1530/ror.0.0040023)

Eddy EM \& O'Brien DA 1998 Gene expression during mammalian meiosis. Current Topics in Developmental Biology 37 141-200.

Finkel T \& Holbrook NJ 2000 Oxidants, oxidative stress and the biology of ageing. Nature 408 239-247. (doi:10.1038/35041687)

Goto M, Koji T, Mizuno K, Tamaru M, Koikeda S, Nakane PK, Mori N, Masamune Y \& Nakanishi Y 1990 Transcription switch of two phosphoglycerate kinase genes during spermatogenesis as determined with mouse testis sections in situ. Experimental Cell Research 183 273-278. (doi:10.1016/0014-4827(90)90306-U)

Gotoh K, Nonoguchi K, Higashitsuji H, Kaneko Y, Sakurai T, Sumitomo Y, Itoh K, Subjeck JR \& Fujita J 2004 Apg-2 has a chaperone-like activity similar to Hsp110 and is overexpressed in hepatocellula carcinomas. FEBS Letters 560 19-24. (doi:10.1016/S0014-5793(04) 00034-1)

Guan K, Nayernia K, Maier LS, Wagner S, Dressel R, Lee JH, Nolte J, Wolf F, Li M, Engel W et al. 2006 Pluripotency of spermatogonial stem cells from adult mouse testis. Nature 440 1199-1203. (doi:10.1038/nature04697)

Hartl FU 1996 Molecular chaperones in cellular protein folding. Nature 381 571-579. (doi:10.1038/381571a0).

Held T, Paprotta I, Khulan J, Hemmerlein B, Binder L, Wolf S, Schubert S, Meinhardt A, Engel W \& Adham IM $2006 \mathrm{Hspa} 4 \mathrm{l}$-deficient mice display increased incidence of male infertility and hydronephrosis development. Molecular and Cellular Endocrinology 26 8099-8108. (doi:10.1128/ MCB.01332-06

Kaneko Y, Kimura T, Kishishita M, Noda Y \& Fujita J 1997 Cloning of apg-2 encoding a novel member of heat shock protein 110 family. Gene 189 19-24. (doi:10.1016/S0378-1119(96)00807-4)

Kashiwabara S, Arai Y, Kodaira K \& Baba T 1990 Acrosin biosynthesis in meiotic and postmeiotic spermatogenic cells. Biochemical and Biophysical Research Communications 173 240-245. (doi:10.1016/ S0006-291X(05) 81047-2)

Kleene KC \& Flynn JF 1987 Characterization of a cDNA clone encoding a basic protein, TP2, involved in chromatin condensation during spermatogenesis in the mouse. Journal of Biological Chemistry 262 $17272-17277$.
Kremling H, Keime S, Wilhelm K, Adham IM, Hameister H \& Engel W 1991 Mouse proacrosin gene: nucleotide sequence, diploid expression, and chromosomal localization. Genomics 11 828-834. (doi:10.1016/08887543(91)90005-Y)

Lammers $\mathrm{J}$, Offenberg $\mathrm{HH}$, van Aalderen $\mathrm{M}$, Vink $\mathrm{AC}$, Dietrich Al \& Heyting C 1994 The gene encoding a major component of the lateral elements of synaptonemal complexes of the rat is related to X-linked lymphocyte-regulated genes. Molecular and Cellular Endocrinology 14 1137-1146.

Li C, Liu D, Yuan Y, Huang S, Shi M, Tao K \& Feng W 2010 Overexpression of Apg-2 increases cell proliferation and protects from oxidative damage in BaF3-BCR/ABL cells. International Journal of Oncology 36 899-904. (doi:10.3892/ijo_00000568)

Liu Q \& Hendrickson WA 2007 Insights into Hsp70 chaperone activity from a crystal structure of the yeast Hsp110 Sse1. Cell 131 106-120. (doi:10 1016/j.cell.2007.08.039)

Lyon MF, Searle AG 1989 Genetic Variants and Strains of the Laboratory Mouse, 2nd edn. Oxford: Oxford University Press.

Mayer MP \& Bukau B 2005 Hsp70 chaperones: cellular functions and molecular mechanism. Cellular and Molecular Life Sciences 62 670-684. (doi:10.1007/s00018-004-4464-6)

McLean DJ, Friel PJ, Johnston DS \& Griswold MD 2003 Characterization of spermatogonial stem cell maturation and differentiation in neonatal mice. Biology of Reproduction 69 2085-2091. (doi:10.1095/biolreprod. 103.017020)

Nagano R, Tabata S, Nakanishi Y, Ohsako S, Kurohmaru M \& Hayashi Y 2000 Reproliferation and relocation of mouse male germ cells (gonocytes) during prespermatogenesis. Anatomical Record $\mathbf{2 5 8}$ 210-220. (doi:10.1002/(SICI)1097-0185(20000201)258:2<210::AIDAR10>3.0.CO; $2-X)$

Nakamura J, Fujimoto M, Yasuda K, Takeda K, Akira S, Hatayama T, Takagi Y, Nozaki K, Hosokawa N \& Nagata K 2008 Targeted disruption of Hsp1 10/105 gene protects against ischemic stress. Stroke 39 2853-2859. (doi:10.1161/STROKEAHA.107.506188)

Nonoguchi K, Itoh K, Xue JH, Tokuchi H, Nishiyama H, Kaneko Y, Tatsumi K, Okuno H, Tomiwa K \& Fujita J 1999 Cloning of human cDNAs for Apg-1 and Apg-2, members of the Hsp110 family, and chromosomal assignment of their genes. Gene 37 21-28. (doi:10.1016/ S0378-1119(99)00325-X)

Pearse RV, Drolet DW, Kalla KA, Hooshmand F, Bermingham IR Jr \& Rosenfeld MG 1997 Reduced fertility in mice deficient for the POU protein sperm-1. PNAS 94 7555-7560. (doi:10.1073/pnas.94.14.7555)

Polier S, Dragovic Z, Hartl FU \& Bracher A 2008 Structural basis for the cooperation of Hsp70 and Hsp110 chaperones in protein folding. Cell 133 1068-1079. (doi:10.1016/j.cell.2008.05.022)

Ramalho-Santos M, Yoon S, Matsuzaki Y, Mulligan RC \& Melton DA 2002 "Stemness": transcriptional profiling of embryonic and adult stem cells. Science 298 597-600. (doi:10.1126/science.1072530)

Rassoulzadegan M, Paquis-Flucklinger V, Bertino B, Sage J, Jasin M, Miyagawa K, van Heyningen V, Besmer P \& Cuzin F 1993 Transmeiotic differentiation of male germ cells in culture. Cell 75 997-1006. (doi:10. 1016/0092-8674(93)90543-Y)

Raviol H, Sadlish H, Rodriguez F, Mayer MP \& Bukau B 2006 Chaperone network in the yeast cytosol: $\mathrm{Hsp} 110$ is revealed as an $\mathrm{Hsp} 70$ nucleotide exchange factor. EMBO Journal 25 2510-2518. (doi:10.1038/sj.emboj. 7601139)

Schuemann JP, Jiang J, Cuellar J, Llorca O, Wang L, Gimenez LE, Jin S, Taylor AB, Demeler B, Morano KA et al. 2008 Structure of the Hsp110:Hsc70 nucleotide exchange machine. Molecular Cell 31 232-243. (doi:10.1016/j.molcel.2008.05.006)

Steel GJ, Fullerton DM, Tyson JR \& Stirling CJ 2004 Coordinated activation of Hsp70 chaperones. Science 303 98-101. (doi:10.1126/science. 1092287)

Terada K, Yomogida K, Imai T, Kiyonari H, Takeda N, Kadomatsu T, Yano M, Aizawa S \& Mori M 2005 A type I DnaJ homolog, DjA1, regulates androgen receptor signaling and spermatogenesis. EMBO Journal 24 611-622. (doi:10.1038/sj.emboj.7600549)

Tsunekawa N, Matsumoto M, Tone S, Nishida T \& Fujimoto H 1999 The Hsp70 homolog gene, Hsc70t, is expressed under translational control during mouse spermiogenesis. Molecular Reproduction and Development 52 383-391. (doi:10.1002/(SICI)1098-2795(199904)52:4 $<383:$ :AID-MRD7>3.0.CO;2-Z) 
144 T Held, A Z Barakat and others

Vergouwen RP, Jacobs SG, Huiskamp R, Davids JA \& de Rooij DG 1991 Prol iferative activity of gonocytes. Sertoli cells and interstitial cells during testicular development in mice. Journal of Reproduction and Fertility $\mathbf{9 3}$ 233-243. (doi:10.1530/jrf.0.0930233)

Vos MJ, Hageman J, Carra S \& Kampinga HH 2008 Structural and functional diversities between members of the human HSPB, HSPH, HSPA, and DNAJ chaperone families. Biochemistry 47 7001-7011. (doi:10.1021/bi800639z)

Yu YE, Zhang Y, Unni E, Shirley CR, Deng IM, Russell LD, Weil MM, Behringer RR \& Meistrich ML 2000 Abnormal spermatogenesis and reduced fertility in transition nuclear protein 1-deficient mice. PNAS 79 4683-4688. (doi:10.1073/pnas.97.9.4683)
Zimmermann S, Steding G, Emmen JM, Brinkmann AO, Nayernia K, Holstein AF, Engel W \& Adham IM 1999 Targeted disruption of the Insl3 gene causes bilateral cryptorchidism. Molecular Endocrinology 13 681-691. (doi:10.1210/me.13.5.681)

Received 26 January 2011

First decision 21 February 2011

Accepted 12 April 2011 


\subsection{Publication II}

Targeted disruption of Hspa4 gene leads to cardiac hypertrophy and fibrosis

DOI: 10.1016/j.yjmcc.2012.07.014

Belal A Mohamed, Amal Z Barakat, Wolfram-Hubertus Zimmermann, Reginald E Bittner, Christian Mühlfeld, Mark Hünlich, Wolfgang Engel, Lars S Maier, Ibrahim M Adham

Status: Published in Journal of Molecular and Cellular Cardiology (Impact factor 5.50), Volume 53 (2012), pp. 459-468

\section{Author contributions to the work:}

1. Belal A Mohamed: Participated in designing of the experiments, performed the experiments including screening of HSPA4 expression in human and murine heart, analysis of the cardiac hypertrophy and fibrosis induced in Hspa4 $\mathrm{KO}$ mice after TAC, microarray data analysis and verification, molecular studies to identify the affected signaling pathways, neonatal mice cardiomyocyte culture and probing of the ubiquitination status, carried out statistical analysis of the data, participated in data interpretation and was involved in manuscript preparation

2. Amal Z Barakat: Participated in analysis of the baseline cardiac hypertrophy and fibrosis seen in Hspa4 $\mathrm{KO}$ mice, participated in microarray data analysis and verification

3. Wolfram-Hubertus Zimmermann: Helped in establishment of neonatal mouse cardiomyocyte culture, interpretation of the data and gave critical comments and recommendations

4. Reginald E Bittner: Interpreted the data of histological studies

5. Christian Mühlfeld: Carried out electron microscopy analysis

6. Mark Hünlich: Performed echocardiogram analysis and TAC operation in mice

7. Wolfgang Engel: Conceived and designed the experiments, gave critical comments and recommendations, and financial support

8. Lars S Maier: Provided the heart samples from human patients with aortic stenosis, interpreted the data and gave critical comments and recommendations

9. Ibrahim M Adham: Conceived and designed the experiments, interpretation of the data and critical review of the manuscript 
Original article

\title{
Targeted disruption of Hspa4 gene leads to cardiac hypertrophy and fibrosis
}

\author{
Belal A. Mohamed ${ }^{\mathrm{a}}$, Amal Z. Barakat ${ }^{\mathrm{a}}$, Wolfram-Hubertus Zimmermann ${ }^{\mathrm{b}}$, Reginald E. Bittner ${ }^{\mathrm{c}}$,
} Christian Mühlfeld ${ }^{d}$, Mark Hünlich ${ }^{\mathrm{e}}$, Wolfgang Engel ${ }^{\mathrm{a}}$, Lars S. Maier ${ }^{\mathrm{e}}$, Ibrahim M. Adham a,*

a Institute of Human Genetics, University of Göttingen, Germany

${ }^{b}$ Department of Pharmacology/Heart Research Center, University of Göttingen, Germany

c Department of Neuromuscular Research/Center of Anatomy \& Cell Biology, University of Vienna, Austria

d Institute of Anatomy and Cell Biology, University of Giessen, Germany

e Department of Cardiology and Pneumology/Heart Research Center, University of Göttingen, Germany

\section{A R T I C L E I N F O}

\section{Article history:}

Received 24 October 2011

Received in revised form 12 July 2012

Accepted 24 July 2012

Available online 1 August 2012

\section{Keywords:}

HSPA4

Hypertrophy

Fibrosis

Pressure overload

Polyubiquitination

\begin{abstract}
A B S T R A C T
Failure of molecular chaperones to direct the correct folding of newly synthesized proteins leads to the accumulation of misfolded proteins in cells. HSPA4 is a member of the heat shock protein 110 family (HSP110) that acts as a nucleotide exchange factor of HSP70 chaperones. We found that the expression of HSPA4 is upregulated in murine hearts subjected to pressure overload and in failing human hearts. To investigate the cardiac function of HSPA4, Hspa 4 knockout (KO) mice were generated and exhibited cardiac hypertrophy and fibrosis. Hspa4 $\mathrm{KO}$ hearts were characterized by a significant increase in heart weight/body weight ratio elevated expression of hypertrophic and fibrotic gene markers, and concentric hypertrophy with preserved contractile function. In response to pressure overload, cardiac hypertrophy and remodeling were further aggravated in the Hspa4 KO compared to wild type (WT) mice. Cardiac hypertrophy in Hspa4 KO hearts was associated with enhanced activation of gp130-STAT3, CaMKII, and calcineurin-NFAT signaling. Protein blot and immunofluorescent analyses showed a significant accumulation of polyubiquitinated proteins in cardiac cells of $\mathrm{Hspa} 4 \mathrm{KO}$ mice. These results suggest that the myocardial remodeling of $\mathrm{Hspa} 4 \mathrm{KO}$ mice is due to accumulation of misfolded proteins resulting from impaired chaperone activity. Further analyses revealed a significant increase in cross sectional area of cardiomyocytes, and in expression levels of hypertrophic markers in cultured neonatal Hspa4 KO cardiomyocytes suggesting that the hypertrophy of mutant mice was a result of primary defects in cardiomyocytes. Gene expression profile in hearts of 3.5-week-old mice revealed a differentially expressed gene sets related to ion channels, muscle-specific contractile proteins and stress response. Taken together, our in vivo data demonstrate that Hspa4 gene ablation results in cardiac hypertrophy and fibrosis, possibly, through its role in protein quality control mechanism.
\end{abstract}

(C) 2012 Elsevier Ltd. All rights reserved.

\section{Introduction}

Heat shock proteins (HSPs) are the major components of molecular chaperones that facilitate the folding of newly synthesized proteins, prevent the aggregation of misfolded proteins, and promote their refolding in different cellular compartments such as the cytosol or endoplasmic reticulum [1]. HSPs are subdivided according to their molecular weight into the following groups: HSPH (HSP110), HSPC (HSP90), HSPA (HSP70), DNAJ (HSP40), HSPD (HSP60), and HSPB (HSP27) [2]. Binding of newly synthesized polypeptides to HSP chaperones and the subsequent release of folded proteins are regulated by continuous cycles of adenosine triphosphate (ATP) hydrolysis and the exchange of ATP for adenosine diphosphate (ADP). The HSP70 chaperone represents

\footnotetext{
* Corresponding author at: Institute of Human Genetics, University of Göttingen Heinrich-Düker-Weg12, D-37073, Göttingen, Germany. Tel.: +49551 397522.

E-mail address: iadham@gwdg.de (I.M. Adham).
}

the major protein folding machinery in the eukaryotic cytosol, and it complexes with two co-chaperones, HSP40 and HSP110. HSP40 stimulates ATP hydrolysis, whereas HSP110 acts as a nucleotide exchange factor that accelerates ADP dissociation from the HSP70 [3-6].

Several reports have shown that some HSPs have cardioprotective effects against ischemic injury, while others are induced in response to hypertrophy $[7,8]$. The cardioprotective role of HSPs was confirmed by the results showing the development of cardiac hypertrophy and dilated cardiomyopathy in HSP70-1/HSP70-3 double mutants and in mice null for mitochondrial HSP40, respectively $[9,10]$. Moreover, mutations in human BAG3, encoding a co-chaperone of Hsc70, were found in family members with dilated cardiomyopathy [11].

The mammalian genome encodes three cytosolic HSP110 proteins, HSPA4 (APG2), HSPA4L (APG1), and HSPH1 (HSP110), and the endoplasmic reticulum-located protein HYOU1 (GRP175/ORP150). Hspa4 is widely expressed and not inducible by heat shock [12]. Except for impaired male fertility, analyses of Hspa4 KO mice did not reveal other overt abnormalities [13].

0022-2828/\$ - see front matter (C) 2012 Elsevier Ltd. All rights reserved. 
In the present study, we found that the expression levels of HSPA4 were significantly elevated in hearts of pressure overloaded mice subjected to transaortic constriction (TAC) and in human hearts with aortic stenosis. Loss of HSPA4 in mutant mice resulted in the development of cardiac hypertrophy and fibrosis. These phenotypes were accompanied by accumulation of polyubiquitinated proteins in cardiomyocytes. Furthermore, we studied the activity of stress-response signaling, which might mediate the development of cardiac hypertrophy.

\section{Materials and methods}

\subsection{Mice}

Hspa4 KO mice were generated previously [13]. In this study, we analyzed Hspa4 KO on 129/Sv genetic background. All animal experimentations were reviewed and approved by the Institutional Animal Care and Use Committee of the University of Göttingen.

\subsection{Histological analysis and immunohistochemistry}

Excised hearts were rinsed in phosphate buffered saline (PBS) and incubated in Krebs-Hanseleit solution lacking $\mathrm{Ca}^{+2}$ to relax the cardiac muscle before fixation. Heart weight and its respective ratio to body weight were calculated as an index of cardiac hypertrophy. Ventricular tissues were fixed in $4 \%$ paraformaldehyde solution for $16 \mathrm{~h}$ at $4{ }^{\circ} \mathrm{C}$, embedded in paraffin, and sectioned into $5-\mu \mathrm{m}$ sections. Sections were stained with hematoxylin and eosin (H\&E). Myocyte diameter and area were assessed from images taken at $600 \times$ from 2 random fields (from 4 sections of each heart of 3 mice per age and genotype) using NIH Image J software. The diameter and area of 500 myocytes were traced in each group. To determine the distribution of fibrosis in heart tissue samples, sections were stained with Masson's trichrome (Sigma-Aldrich) according to the manufacturer's procedures. For imunofluorescence staining, cardiac sections were reacted with primary anti-Ubiquitin (1:500; DakoCytomation), anti$\alpha$-Actinin (1:500; Sigma), and anti-HSPA4 (1:300; Santa Cruz Biotechnology) followed by secondary Alexa Fluor 488 IgG antibody (1:500; Invitrogen) and Cy3-conjugated anti-Rabbit IgG antibody (Sigma). DAPI was used for nuclear staining. Sections were analyzed by reverse microscope fluorescence equipped microscope (BX60; Olympus, Hamburg, Germany).

\subsection{Quantitative real-time PCR and western blot analyses}

For real-time PCR, total RNAs were treated with RNA free DNase (Promega) for $1 \mathrm{~h}$ at $37^{\circ} \mathrm{C}$, and reverse transcribed using the Superscript II first strand kit (Invitrogen). Quantitative RT-PCR (qRT-PCR) was performed in triplicate on ABI Prism 7900HT sequence detection system (Applied Biosystems) using QuantiTect SYBR Green PCR Master mix as a double-stranded DNA-specific dye according to manufacturer's instruction (QIAGEN). The mRNA expression levels were normalized to either hypoxanthine guanine phosphoribosyl transferase (Hprt) or Succinate dehydrogenase (Sdha) mRNA. Data of QRT-PCR analysis are shown as mean \pm standard deviation (SD). Sequences of used primers are shown in Suppl. Table 1.

For extraction of soluble and insoluble protein fractions, the hearts were homogenized in RIPA buffer (Millipore) containing protease inhibitor cocktail (Roche Diagnostics). The homogenates were centrifuged at $12,000 \mathrm{~g}$ at $4{ }^{\circ} \mathrm{C}$ for $20 \mathrm{~min}$. The supernatants were stored as soluble fraction. The pellet was suspended with $1 \%$ SDS detergent homogenization buffer, sonicated and then centrifuged at $12,000 \mathrm{~g}$ at $4{ }^{\circ} \mathrm{C}$ for $20 \mathrm{~min}$ to obtain a detergent insoluble protein fraction. Protein samples were resolved on 4-12\% SDS-PAGE and transferred onto nitrocellulose membrane (Amersham Pharmacia). Membranes were then blocked for $1 \mathrm{~h}$ with $5 \%$ non-fat milk in $0.1 \%$ Tween 20 in TBS. Blots were probed at $4{ }^{\circ} \mathrm{C}$ overnight with antibodies against total and phosphorylated ERK1/
2, STAT3 (1:1000; Cell Signaling Technology), CaMKII (1:1000; gift from Dr. Bers) [14], P-CaMKII (1:1000; Affinity BioReagents), HSPA4, HSPA4L (1:2000; Santa Cruz), Ubiquitin (1:4000; DakoCytomation), DAB2 (1:1000; BD Transduction Laboratories), HSPH1, HSP70 and $\alpha$-tubulin (1:5000; Sigma), and followed by incubation with a secondary peroxidase-conjugated antibody (1:5000; Sigma). Signals were detected using a chemiluminescent kit (Santa Cruz). Signals were quantified by AlphaView software; Version: 3.2.0 (Cell Biosciences, Inc.).

\subsection{Calcineurin phosphatase activity assay}

Cardiac lysates from 12-week-old Hspa4 WT and KO mice were isolated, and calcineurin activity was measured as the dephosphorylation rate of a synthetic RII phosphopeptide substrate using a calcineurin phosphatase assay kit (BML-AK804; Enzo Life Sciences International) according to the manufacturer's instructions. The released free phosphate was detected photometrically at $620 \mathrm{~nm}$ using a microplate reader.

\subsection{Determination of 20 S Proteasome activity}

Cardiac lysates from 12-week-old Hspa4 WT and KO mice were isolated, and 20S Proteasome activity was measured using 20S Proteasome Assay Kit (10008041; Biomol) according to the manufacturer's instructions. In short, a synthetic 20S substrate, SUC-LLVY-AMC was used which, upon cleavage by the active enzyme, generates a highly fluorescent product that can be measured using excitation and emission wavelengths of $360 \mathrm{~nm}$ and $480 \mathrm{~nm}$, respectively.

\subsection{Neonatal cardiomyocyte culture and immunocytochemistry}

Cardiac cells were isolated from heart ventricles of 1- to 3-day-old mice by multiple rounds of DNase/trypsin digestion as described previously [15]. Cells were pre-cultured in Dulbecco's modified Eagle medium containing $10 \%$ fetal calf serum for $2 \mathrm{~h}$ to reduce non-myocyte content. Non-adherent cells were collected by centrifugation and either used for RNA extraction or cultured on laminin-coated 96-well plates in the presence of Ara-C $(20 \mu \mathrm{M})$ to inhibit proliferation of contaminating fibroblasts. After $96 \mathrm{~h}$, cells were either harvested for RNA isolation or fixed in $4 \%$ paraformaldehyde for $30 \mathrm{~min}$ at $4{ }^{\circ} \mathrm{C}$, permeabilized with $0.1 \%$ triton X-100 in PBS and blocked with $2 \%$ bovine serum albumin in PBS for $1 \mathrm{~h}$. Cells were incubated with a monoclonal antibody against sarcomeric $\alpha$-actinin (Sigma; $1: 700$ ) for $2 \mathrm{~h}$ at $4{ }^{\circ} \mathrm{C}$, washed and incubated with FITC-conjugated goat anti-mouse IgG antibody (Sigma) for $1 \mathrm{~h}$ at $4{ }^{\circ} \mathrm{C}$. After washing, cells were incubated with TRITC-Phalloidin (Sigma) to label f-actin, counterstained with DAPI and examined by reverse microscope fluorescence equipped microscope (BX60; Olympus, Hamburg, Germany). For morphometric analysis, approximately 800 cells costained with both $\alpha$-actinin and f-actin per each genotype ( $n=2$ independent experiment) were randomly chosen, and the cross sectional area (CSA) of cardiomyocytes was measured using $\mathrm{NIH}$ Image J software.

\subsection{Transthoracic echocardiography}

Cardiac dimensions and functions were evaluated by echocardiography (Visual Sonic 770 system, 30-MHz transducer, Toronto, Ontario, Canada) in anesthetized mice. M-mode was recorded (sweep speed, $150 \mathrm{~mm} / \mathrm{s}$ )

\subsection{Induction of hemodynamic overload}

To induce cardiac pressure overload in mice, transverse aortic constriction (TAC) was performed on 8-week-old male mice as previously described [16]. Sham control mice underwent the same procedure except for aortic constriction. 
Volume overload was induced by creating aortocaval shunt according to the method of Garcia and Diebold [17]. The sham-operated control protocol was identical to shunt induction, except no aortic puncture was performed.

\subsection{Human tissue samples}

Cardiac biopsies were obtained from aortic stenosis patients and from normal subjects undergoing aortic replacement and bypass surgery, respectively. The study was approved by the Institutional Ethic Committee of the University Medical Center Goettingen and written informed consent was obtained from all patients.

\subsection{Transmission electron microscopy}

Transmission electronic microscopy analysis was performed as described previously [18] with some modifications. Briefly, a small piece of myocardium was taken from the LV and immediately immersed in fixation solution ( $3 \%$ glutaraldehyde, $1 \%$ Paraformaldehyde in $0.1 \mathrm{M}$ sodium cacodylated buffer, $\mathrm{pH} 7.4$ ) for $8-12 \mathrm{~h}$ at $4{ }^{\circ} \mathrm{C}$. Tissues were then washed in washing buffer (3.4\% Saccharose in $0.1 \mathrm{M}$ Cacodylat buffer, $\mathrm{pH} 7.4$ ) for $2 \mathrm{~h}$. After aldehyde fixation, the pieces were subsequently postfixed with osmium tetroxide, stained en bloc with uranyl acetate and dehydrated in an ascending ethanol series. After epoxy resin embedding and polymerization 50 - to 80 -nm-thick sections were cut with an ultramicrotome, stained with uranyl acetate and load citrate and then observed with a transmission electron microscope (EM 902 Zeiss, Oberkochen, Germany).

\subsection{Microarray analysis}

Total RNA was extracted from heart ventricles of 3.5-week-old Hspa4 WT and KO males ( $\mathrm{n}=3$ mice for each genotype). Using the WT Target Labeling Kit (Affymetrix), cDNA was synthesized according to the manufacturer's recommendations. Global gene expression analysis was applied using the Gene-Chip ${ }^{\circledR}$ Mouse Gene 1.0 ST arrays (Affymetrix). Hybridization was performed for $18 \mathrm{~h}$ at $60 \mathrm{rpm}$ and $45^{\circ} \mathrm{C}$ in the GeneChip ${ }^{\circledR}$ Hybridization Oven 640 . After washing and staining in Gene Chip ${ }^{\circledR}$ Fluidics Station 450 (Affymetrix), the arrays were scanned using the GeneChip ${ }^{\circledR}$ scanner 3000 7G (Affymetrix). Intensity data were extracted using R (Version 2.13.0) and Bioconductor using the rma-function of package Affy (affy_1.30.0) and the CDF-package mogene10stv1mmentrezgcdf_14.1.0 from Brainarray (http://brainarray. mbni.med.umich.edu) and analyzed using the Limma package of Bioconductor $[19,20]$.

The microarray data analysis consists of the following steps: 1. quantile normalization, 2 . global clustering, 3 . fitting the data to a linear model, and 4. detection of differential gene expression. For cluster analysis, we used a hierarchical approach with the average linkage-method. Distances were measured as 1-Pearson's Correlation Coefficient. To estimate the average group values for each gene and assess differential gene expression, a simple linear model was fit to the data, and group-value averages and standard deviations for each gene were obtained. To find genes with significant expression changes between groups, empirical Bayes statistics were applied to the data by moderating the standard errors of the estimated values [19]. P-values were obtained from the moderated t-statistic and corrected for multiple testing with the Benjamini-Hochberg method [21]. Classification of the differentially expressed genes was performed according to the gene ontology (GO) listing found in the DAVID (the database for annotation, visualization and integrated discovery) bioinformatics resources $[22,23]$.

The data discussed in this paper are generated conforming to the MIAME guidelines and have been deposited in NCBI's Gene Expression Omnibus and are accessible through GEO Series accession number GSE32885 (http://www.ncbi.nlm.nih.gov/geo/query/acc.cgi? acc $=$ GSE32885).

\subsection{Statistical analysis}

Data were expressed as mean \pm SD or mean \pm SEM where appropriate. Differences among groups were tested by Student's $t$ test or 2-way ANOVA where appropriate. A P value $<0.05$ was considered to be significantly different.

\section{Results}

\subsection{HSPA4 is up-regulated in pressure overloaded hearts}

To investigate whether myocardial expression of Hspa4 in heart is induced in response to hemodynamic stress, we examined the expression levels of HSPA4 in WT mice subjected to pressure overload by transverse aortic constriction (TAC) and volume overload (Shunt). HSPA4 was significantly upregulated after TAC (Fig. 1A). In contrast, no difference in HSPA4 expression was observed in sham- and shuntoperated mice (Fig. 1B). To substantiate the relevance of this finding in light of a human disease equivalent, we examined the expression of HSPA4 in hearts of human patients with aortic stenosis and normal subjects. In agreement with our mouse data, we observed in patient samples with aortic stenosis profoundly enhanced levels of HSPA4 protein levels (Fig. 1C). These results suggest that afterload is the main stressor inducing the HSPA4 expression in the heart.

To elucidate the cellular distribution of HSPA4 protein, cryosections of hearts isolated from sham-and TAC-operated mice were subjected to immunofluorescent analysis. We observed that the subcellular localization of HSPA4 in the WT cardiac cells of sham- and TAC-operated WT hearts was restricted to the cytosolic compartments (Fig. 1D) with marked increase of fluorescent signals in hearts subjected to TAC surgery. The HSPA4-specific immunoreaction was confirmed by the absence of HSPA4 immunostaining in KO hearts (Fig. 1D).

\subsection{Development of cardiac hypertrophy and fibrosis in Hspa4 $\mathrm{KO}$ mice}

To determine the consequences of HSPA4 deficiency in the heart, we determined the heart weight to body weight ratio (HW/BW) and studied histology of the hearts from 2-, 12-, and 24-week-old Hspa4 WT and KO littermates. No significant changes in HW/BW ratio could be observed between 2-week-old WT and KO mice (Fig. 2B). Hspa4 $\mathrm{KO}$ at 12- and 24-weeks showed a significant increase in HW/BW ratios (Figs. 2A, B). H\&E staining showed an increase in cardiomyocyte diameter in 12- and 24-week-old Hspa4 $\mathrm{KO}$ mice (Figs. 2C; upper panels, D). Ultrastructural analysis of sections from left ventricular myocardium of 8-week-old mice revealed peculiar structural abnormalities in Hspa4 KO cardiomyocytes (i.e. myofibrillar disassembly and nuclear vacuolation; Suppl Fig. 1).

To confirm the development of cardiac hypertrophy at molecular level, expression of hypertrophy response genes, atrial natriuretic peptide (Nppa/Anp), brain natriuretic peptide ( $N p p b / B n p), \beta$-myosin heavy chain $(M y h 7 / \beta-M H C)$ and $\alpha 1$-skeletal actin $(A c t a 1 / \alpha-S A)$ were determined by quantitative RT-PCR. Expression levels of these hypertrophic markers were significantly elevated in Hspa4 $\mathrm{KO}$ hearts (Fig. 2E). These results demonstrate that the depletion of HSPA4 in mice causes baseline cardiac hypertrophy.

To check whether cardiac hypertrophy was associated with the development of cardiac fibrosis, microscopic analysis of Masson's trichrome-stained histological sections was performed. Increased interstitial fibrosis was observed in hearts of 12-week-old Hspa4 KO mice compared with age-matched WT ( Fig. 2C; lower panels). Further analysis of mRNA expression levels of fibrosis markers collagen III (Col3 $\alpha 1$ ) and $\operatorname{Tg} \beta \beta 1$ revealed enhanced expression in KO hearts (Fig. 2F).

To evaluate heart dimensions and functions, echocardiogram on 16-week-old mice was performed. Hspa4 KO mice exhibited significant hypertrophy with increased interventricular septum thickness (IVSD) compared to WT (Fig. 2G). Left ventricular mass (LVM) as well as the 
462

A

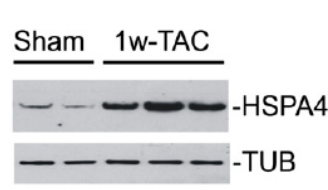

B

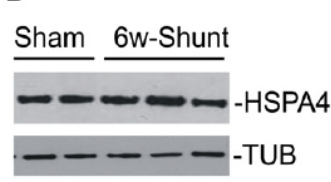

C

D

$+/+$
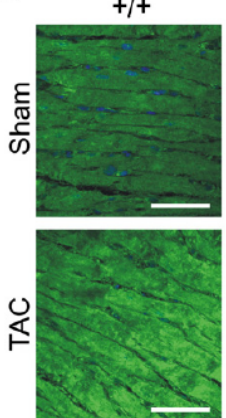

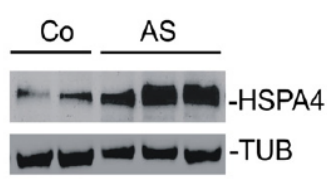

BA Mohamed et al. / Journal of Molec
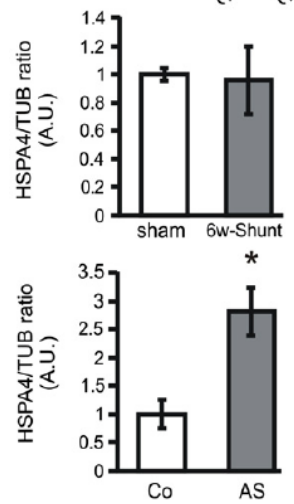

$-1-$
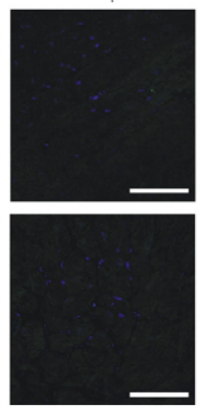

Fig. 1. Upregulation of HSPA4 in response to pressure overload. Heart protein extracts were isolated from mice subjected to transverse aortic construction (TAC) for 1- or 4-weeks (A), from mice subjected to aortocaval shunt operation for 6 weeks (shunt) (B), or from patients with aortic stenosis (AS) (C). Western blots were probed with antibodies directed against HSPA4 and $\alpha$-tubulin (TUB). In the bar graph presenting in tibodies directed against HSPA4 and $\alpha$-tubulin (TUB). In the bar graph presenting in
the right panels, expression levels of HSPA4 were normalized to that of $\alpha$-tubulin. the right panels, expression levels of HSPA4 were normalized to that of $\alpha$-tubulin.
Values are expressed as mean \pm SD. HSPA4 protein levels in hearts of sham-operated Values are expressed as mean \pm SD. HSPA4 protein levels in hearts of sham-operated
mice or human control hearts (Co) samples served as reference. ${ }^{*} P<0.05$ vs control, $n=4-6$ per group. A.U. indicates arbitrary units. (D) Subcellular distribution of HSPA4 in the hearts. Immunofluorescence of HSPA4 (green) in cardiac sections from Hspa 4 WT $(+/+)$ and $\mathrm{KO}(-/-)$ mice 2 wk after sham and TAC operation. Nuclei were stained blue with DAPI. Bar $=30 \mu \mathrm{m}$.

left ventricular mass to body weight ratios (LVM/BW) were higher in Hspa4 KO mice (Figs. 2H, I). However, the increased ratio of LVM/BW was not significant (Fig. 2I). Furthermore, the calculated ratio of wall thickness to heart radius $(\mathrm{h} / \mathrm{r})$ at diastole was significantly increased compared to that of WT mice (Fig. 2J), suggesting concentric hypertrophy. Remarkably, echocardiography showed that left ventricle end diastolic dimension and left ventricle end systolic dimension were both maintained in Hspa4 $\mathrm{KO}$ mice at levels comparable with those of WT excluding the development of dilated cardiomyopathy (Suppl. Table 2). Furthermore, left ventricle fractional shortening (FS), reflecting left ventricular contractile functions, was preserved in Hspa4 $\mathrm{KO}$ mice at a level comparable with that of WT (Fig. $2 \mathrm{~K}$ ), denoting the preservation of LV function.

To rule out any relevant compensation exerted by other members of HSP110 and HSP70 families in Hspa4 KO hearts, we have determined the protein levels of HSPA4L, HSPH1 and HSP70 in the myocardium of Hspa4 WT and KO mice. HSPA4 immunoreactivity was absent in Hspa4 KO heart tissues. Protein levels of HSPA4L, HSPH1 and HSP70 were not markedly different in KO compared with WT hearts, suggesting that the depletion of HSPA4 is not compensated by increased expression of studied HSP proteins in KO hearts (Suppl. Fig. 2).

\subsection{Loss of HSPA4 led to an exaggerated hypertrophic response to} pressure overload

To examine the role of HSPA4 in modulating the response to cardiac pressure overload, we exposed Hspa4 $\mathrm{KO}$ and WT mice to TAC. In response to TAC for 2 weeks, Hspa $4 \mathrm{KO}$ mice developed significant increase in the ratio of HW/BW than WT mice (Figs. 3A, D). Histological analysis demonstrated that TAC resulted in a significant increase in cardiac myocyte cross-sectional area (Figs. 3B, E) and ventricular fibrosis (Figs. 3C, F) in KO mice compared with WT mice. Consistent with the enhanced hypertrophy and remodeling in KO mice, myocardial expression levels of Nppa, Nppb and $\beta-M y h 7$ were significantly higher in KO mice than in WT mice after TAC (Fig. 3G). In line with the observed enhanced remodeling, myocardial expression levels of fibrosis markers Col1 $\alpha 1$, Col $3 \alpha 1$ and Tgf $\beta 1$ were higher in TAC-operated KO hearts compared with TAC-operated WT hearts (Fig. 3H). Compared with the WT TAC group, echocardiogram showed statistically increased IVSD, LVM/ BW, LVM and h/r in the KO TAC hearts (Figs. 3I-L). FS showed significant reduction in KO group after TAC but was not significantly different from that of TAC-operated WT mice (Fig. 3M). These results suggest that HSPA4 ablation aggravates pathological cardiac hypertrophy and remodeling in response to pressure overload.

3.4. Alteration in activity of signaling pathways contributing to the development of cardiac hypertrophy in Hspa4 KO mice

Several molecular pathways are implicated in the molecular response of cardiomyocytes to external stimuli. Alterations in the activity of gp130/STAT3, MAPK, CaMKII, or calcineurin-NFAT signaling can lead to the development of cardiac hypertrophy [24]. To determine the signaling pathway that is affected in the heart of Hspa4 $\mathrm{KO}$ mice and which might be responsible for development of the observed cardiomyopathy, we studied the expression levels of some of the genes and proteins involved in these pathways. Westem blot analysis did not reveal detectable differences in activated mitogen-activated protein kinases pERK1/2 (Fig. 4A). In contrast, expression levels of phosphorylated STAT3 were elevated in KO hearts, suggesting enhanced activation of gp130-STAT3 signaling (Fig. 4A). We also found a significant increase in the levels of phosphorylated CaMKII (Fig. 4B). In addition, the expression levels of Rcan 1.4/ Mcip1-4, which is a gene directly targeted by the activated transcription factor (NFAT), was elevated 14-fold in KO hearts (Fig. 4C). Examination of total calcineurin phosphatase activity from $\mathrm{KO}$ hearts revealed a significant increase compared with that of WT (Fig. 4D). These results confirm the activation of calcineurin-NFAT signaling in Hspa4 KO heart. These findings suggest that elevated gp130-STAT3 activity, phosphorylated CaMKII, and the calcineurin-NFAT-dependent signaling pathway are all intimately involved in the cardiac remodeling of $\mathrm{Hspa} 4 \mathrm{KO}$ mice.

3.5. Increased accumulation of polyubiquitinated proteins in the heart of Hspa4 KO mice

Molecular chaperones mediate the proper folding of newly synthesized proteins and refolding of misfolded proteins. Impaired chaperone functions lead to increased misfolded proteins and subsequent 

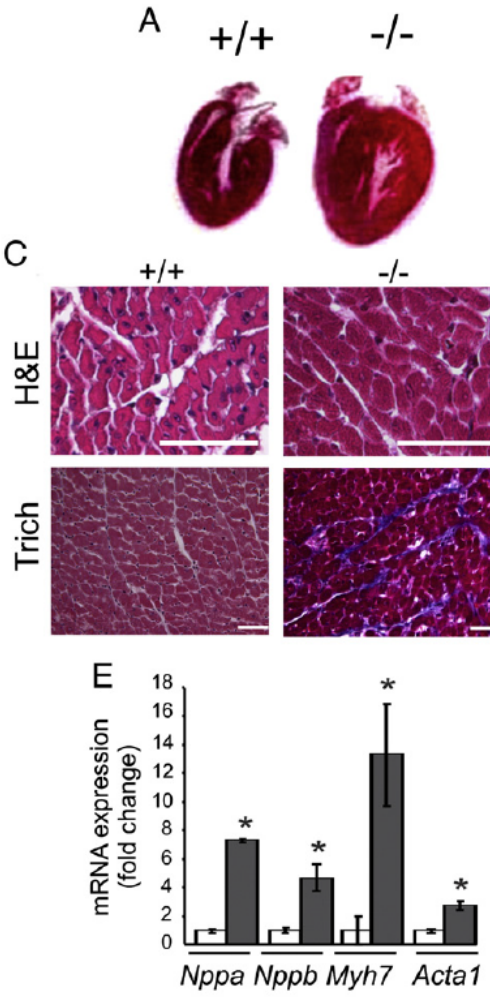
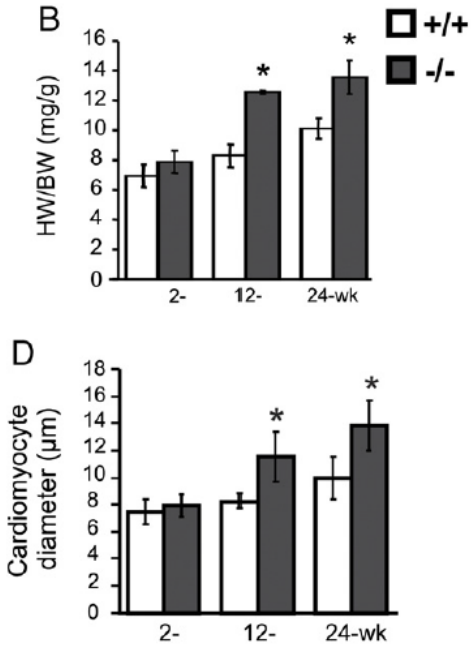

F

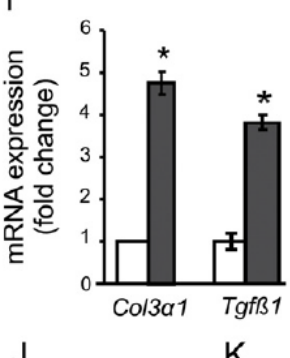

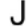

$\mathrm{K}$

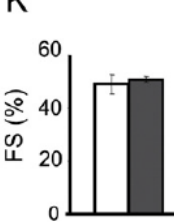

Fig. 2. Development of cardiac hypertrophy in Hspa $4 \mathrm{KO}$ mice. (A) Representative longitudinal sections of hearts from 24-week-old $\mathrm{Hspa4}$ WT (+/+) and KO ( $-/-$ ) mice. (B) HW/ BW ratio of 2-, 12-, and 24-week-old WT and KO mice. Seven to ten animals per age, stage and genotype were used in this analysis. Ratio is presented as mean \pm SD, ${ }^{*} P<0.05$ vs WT. (C) Representative H\&E- (upper panels) and Masson's trichrome-staining (Trich, lower panels) of transverse myocardial sections of 12-week-old mice showing enlarged Hspa4 KO cardiomyocytes and marked increased interstitial fibrosis. Bar $=20 \mu \mathrm{m}$ in upper panels; $50 \mu \mathrm{m}$ in lower panels. (D) Quantitative analysis of cardiomyocytes diameters in 2-, 12- and 24-week-old Hspa 4 WT and KO mice. ${ }^{*} P<0.05$ vs WT, $n=3$ hearts per group and stage. (E, F) RNA isolated from heart ventricles of 12 -week-old mice was used to determine the expression levels of hypertrophic markers Nppa, Nppb, Myh7, and Acta1 (E) and fibrosis markers Col3 $\alpha 1$ and Tgf $\beta 1$ (F) by qRT-PCR. Values of expression levels normalized by Sdha are presented as mean \pm SD. Transcript levels in hearts of WT mice were expressed as 1.0. ${ }^{*} P<0.05$ vs WT, $n=3$ per age and genotype. (G-K) Mean echocardiographic parameters of 16-week-old WT and KO mice. (G) Interventricular septum dimension (IVSD); (H) left ventricular mass (LVM); (I) ratios of left ventricular mass to body weight (LVM/BW); (J) ratios of wall thickness to heart radius ( $h / r)$ and (K) fractional shortening (FS). Data are mean \pm SEM. ${ }^{*} P<0.05$ vs WT, $n=6-8$ per group.

accumulation of ubiquitinated proteins [25]. To determine whether the HSPA4 depletion results in an increased polyubiquitinated protein level, soluble and insoluble protein fractions of myocardial extracts isolated from 4- and 12-week-old Hspa4 WT and KO mice were probed with anti-ubiquitin. As shown in Fig. 5A, levels of polyubiquitinated proteins in soluble and insoluble fractions were markedly increased in KO hearts compared with WT controls at both ages. Further analysis did not show elevated levels of ubiquitinated proteins in skeletal muscle and brain of KO mice (Fig. 5B and data not shown). Immunofluorescent analysis revealed a prominent accumulation of ubiquitin conjugates in cardiac sections of KO mice. In contrast, microscopic analysis failed to detect any ubiquitin aggregates in WT cardiac tissues (Fig. 5C). Ubiquitinated proteins are proteolytically degraded by enzymatic activities of proteasome
[26]. We determined the chymotrypsin-like activity in crude protein extracts of KO and WT hearts using a synthetic fluorogenic substrate to compare proteasome activity. No significant differences could be observed in KO hearts compared with WT hearts (Fig. 5D).

\subsection{Hspa4 KO neonatal cardiac cells exhibited hypertrophy}

Hspa4 is ubiquitously expressed in different tissues [12,13]. To prove whether the hypertrophic cardiomyocyte phenotype is due to an intrinsic heart defect, cardiac cells were isolated from newborn Hspa 4 WT and KO mice and cultured (Fig. 6A). After 4 days of culture, the CSA of cardiomyocytes was measured and the ratios of cardiomyocytes with CSA of $100-200,200-300$, and $300-400 \mu \mathrm{m}^{2}$ 
464
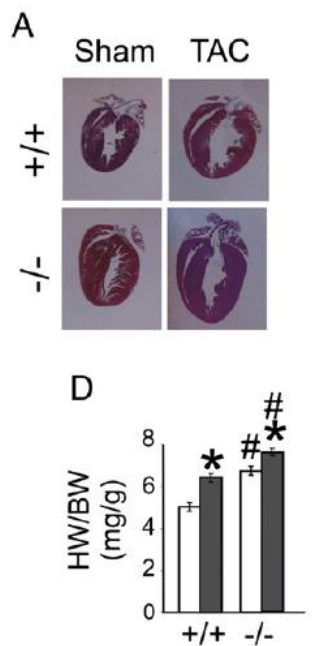

BA Mohamed et al. / Journal of Molecular and Cellular Cardiology 53 (2012) 459-468
B

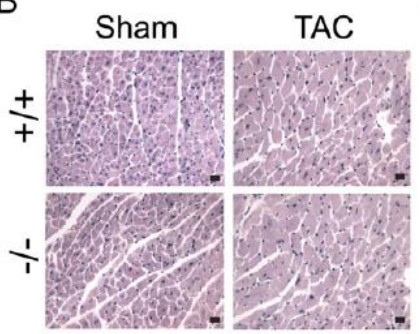

E

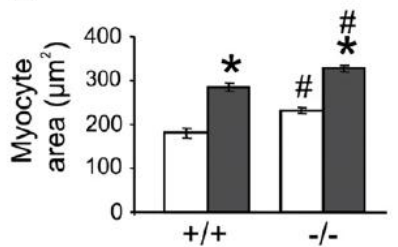

C

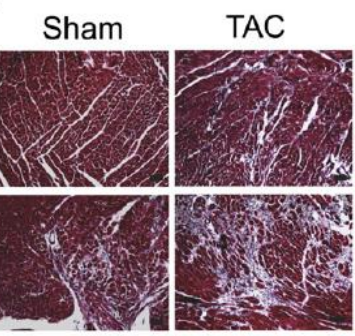

$\mathrm{F}$ $\square$ sham

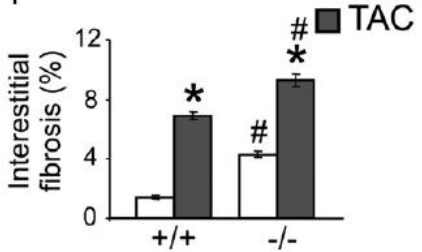

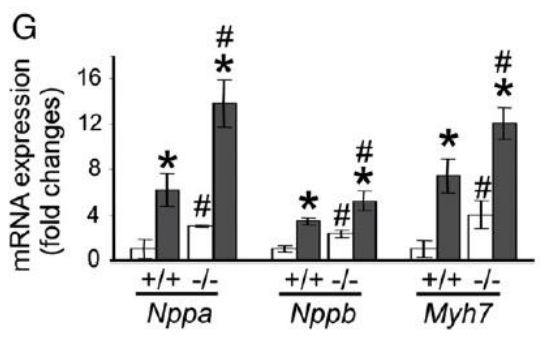
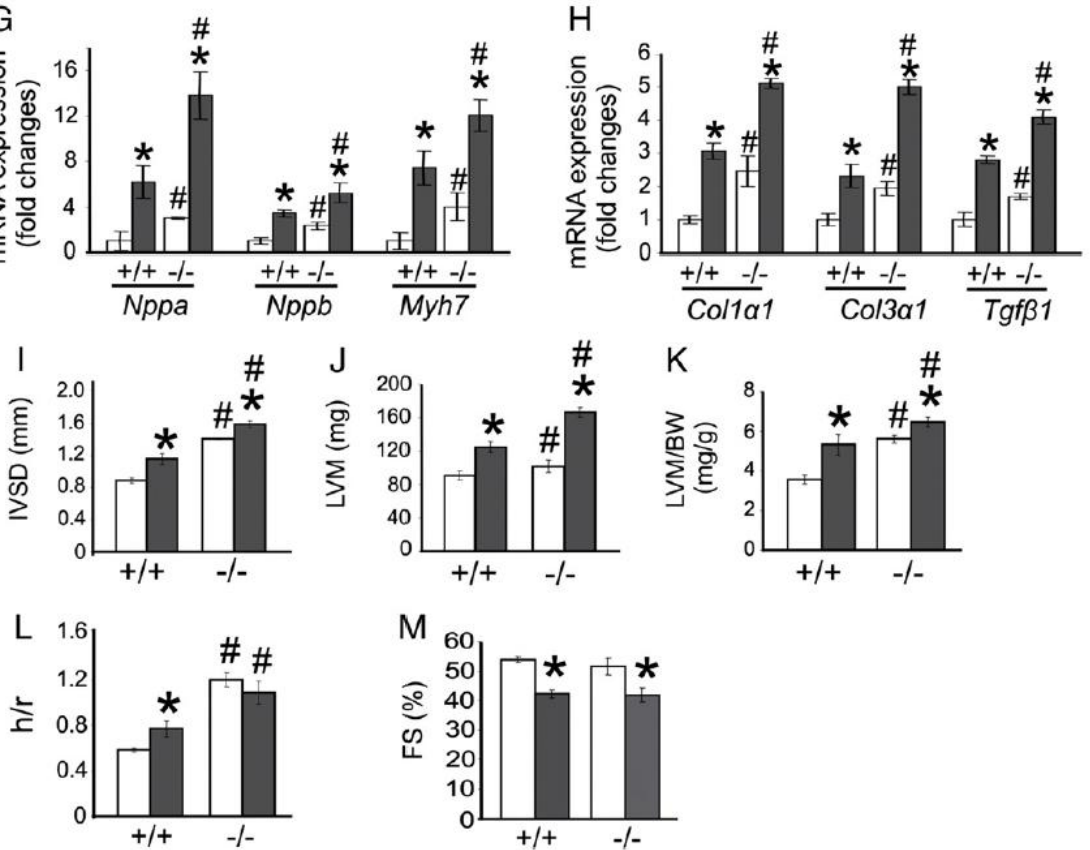

Fig. 3. Aggravation of cardiac hypertrophy and fibrosis in $\mathrm{Hspa} 4 \mathrm{KO}$ mice after TAC operation. (A) Representative longitudinal sections of hearts from 10 -week-old $\mathrm{Hspa} 4 \mathrm{WT}$ ( $+/+$ ) and KO $(-1-)$ mice following 2 weeks of sham and TAC surgery, (B, C) H\&E- (B) and Masson's trichrome-stained (C) myocardial sections of sham- and TAC-operated WT and KO hearts. Bar $=20 \mu \mathrm{m}$ in B; 50 um in C. (D-F) Mean HW/BW ratio (D), quantification of mean area of cardiomyocytes (E) and volume of interstitial fibrosis (F) of $H$ spa 4 WT and KO hearts after 2 weeks of operation. Data were obtained from 4 hearts per group. Data are mean \pm SD. ${ }^{*} P<0.05$ versus sham of the same genotype. ${ }^{\#} P<0.05$ versus WT of the same treatment. (G, H) Quantitative RT-PCR analysis of mRNA levels of hypertrophic marker genes $(G)$ and fibrosis marker genes $(\mathrm{H})$. Expression levels normalized by Hprt are presented as mean \pm SD. Transcript levels in hearts of sham WT mice were expressed as $1.0 .{ }^{*} P<0.05$ versus sham of the same genotype. ${ }^{*} P<0.05$ versus WT of the same treatment, $n=3-4$ per genotype. (I-M) Mean echocardiographic parameters of WT and KO mice after 2 week of TAC. (I) Interventricular septum dimension (IVSD); (J) left ventricular mass (LVM); (K) ratios of left ventricular mass to body weight ( $\mathrm{LVM} / \mathrm{BW}$ ); ( $\mathrm{L}$ ) ratios of wall thickness to heart radius ( $\mathrm{h} / \mathrm{r})$ and $(\mathrm{M})$ fractional shortening (FS). Data are mean \pm SEM. ${ }^{*} P<0.05$ versus sham of the same genotype. ${ }^{\#} P<0.05$ versus WT of the same treatment.

were determined. As shown in Fig. 6B, the ratio of cardiomyocytes with a CSA of less than $200 \mu \mathrm{m}^{2}$ was significantly lower in cultures of Hspa4 KO cells than that of WT. In contrast, the ratio of mutant cardiomyocytes with a CSA of more than $300 \mu \mathrm{m}^{2}$ was significantly increased in cultured KO cells compared with WT. The increased size of Hspa4 KO myocytes in culture suggests strongly that the cardiac hypertrophy of $\mathrm{KO}$ mice is a result of primary alterations in cardiomyocytes. At the molecular level, significantly elevated expression levels of 
hypertrophic markers, $\mathrm{Nppa}$ and $\mathrm{Nppb}$, were found in neonatal $\mathrm{Hspa} 4 \mathrm{KO}$ cardiomyocytes (Fig. 6C).

\subsection{Differential gene expression in hearts of Hspa4 KO mice}

In an attempt to identify potential molecular targets, which are involved in the initiation of cardiac remodeling, we compared the global gene expression profiles of 3.5-week-old Hspa4 WT and KO hearts by microarray analysis. We selected 3.5 weeks for generation of RNA because this time largely precedes any pathological manifestations in the deficient heart and therefore secondary alterations are excluded.

The cDNA generated from three independent ventricles isolated from Hspa4 WT and KO hearts were used to screen Affymetrix Mouse Genome 1.0 ST Arrays. Between both genotypes, approximately 97 sequences were differentially expressed ( $\geq 1.4$-fold with $P$ values of $<0.05$; Fig. 7A; Suppl. Tables 4 and 5). Notably, results of microarray analysis revealed increased expression of fetal genes, Nppa, Nppb, Myh7 and Acta1 that are associated with the cardiac stress response. Among the differentially expressed genes, several encode for proteins that are involved in ion channel signaling, including the voltage-gated potassium channels KCNE1 and KCND2, the potassium/sodium hyperpolarization-activated cyclic nucleotide-gated channel 1 (HCN1), sodium channel-gated, type IV, alpha subunit (SCN4A) and leucine glioma inactivation 1 (LGI1) that regulates the activity of voltage-gated potassium channels [27]. Furthermore, Hspa4 KO hearts also had significant alterations in expression of transcriptional factors such as iroquois related homeobox 4 (IRX4) and GATA6 $[28,29]$. Noteworthy, membrane metalloendopeptidase (MME/NEF), monoamine oxidase B (MAOB) and guanine nucleotide binding protein, alpha $\mathrm{O}$ (GNAO1) genes known to be involved in molecular pathways related to oxidative response, were also differentially expressed [30-32]. Quantitative RT-PCR was performed to verify changes in the transcription levels of ion channel-related genes and some other differentially expressed genes in hearts of 3.5-week-old Hspa4 WT and KO mice (Fig. 7B).

Moreover, we verified the expression of some differentially expressed gene by Western blot analysis. Connective tissue growth factor (CTGF) plays an important role in the development of fibrosis in different tissues, including the heart [33]. Adapter molecule DAB2 (DOC-2) inhibits collagen synthesis in cardiac fibroblasts [34]. In the microarray analysis, Ctgf mRNA was found to be up-regulated in the Hspa4 KO hearts (Suppl. Table 4). On the other hand, Dab2 mRNA was downregulated (Suppl. Table 5). In agreement with the microarray data, Western blot analyses showed significant increase and decrease in protein levels of CTGF and DAB2 in Hspa4 KO hearts, respectively (Fig. 7C).

Further classification of the differentially expressed genes according to the gene ontology illustrated the biggest sector of the differentially expressed genes were those related to the ions transport and binding (38/97), cytoskeleton and structural proteins (32/97), nucleotide binding and transcription related factors (26/97) and nucleotide binding proteins (25/97) (Fig. 7D).

\section{Discussion}

Under physiological conditions, the heart is constantly subjected to a variety of stresses that progressively increase with age. One way the heart overcomes stress-induced damage is to increase cardiomyocyte size in order to adapt to an increased workload. Increased protein synthesis in hypertrophic cardiomyocytes requires the elevated expression of molecular chaperones to repair misfolded proteins. Failure of molecular chaperones to correctly fold newly synthesized polypeptides might lead to the accumulation of misfolded and damaged proteins, triggering cardiomyocytes to initiate cell death [35]. Enhanced expression of HSPA4 in response to pressure overload suggests that HSPA4 may either be involved in disease progression or plays a protective role against mechanical stress-induced pathological hypertrophy. The induction of
HSPA4 expression in hearts of patients with aortic stenosis provides evidence for a similar function of this protein in human heart. The elevated expression of HSPA4 in response to hypertrophic stress is in line with the expression pattern of some HSPs, which are induced by hypertrophic stimuli $[7,36,37]$.

The cardioprotective effect of HSPA4 is supported by the studies investigating the effects of Hspa4 deficiency on heart development. Analysis of Hspa4 KO hearts demonstrates the development of cardiac hypertrophy and fibrosis, characterized by increases in the expression of hypertrophic and fibrosis markers, LVM, IVSD and LVPWT, along with histological changes. In response to pressure-overload, the Hspa4 $\mathrm{KO}$ mice developed a further exaggeration in the degree of cardiac hypertrophy and fibrosis compared with their littermate controls.

The development of hypertrophic cardiomyopathy in $\mathrm{KO}$ mice was accompanied by alterations in the activity of numerous signaling pathways involved in the protection of the heart against a variety of stressors. Our results reveal that the transcriptional activity of NFAT and the expression levels of activated CaMKII are significantly elevated in Hspa4 KO hearts. Both proteins participate in signaling pathways that play critical roles in regulating hypertrophic growth of the heart [38]. Activated NFAT in collaboration with GATA4 induces the expression of fetal genes $[39,40]$. Similarly, activated CaMKII promotes MEF2 transcriptional activity, which induces the expression of prohypertrophic genes [41].

The increased activity of gp130-STAT3 signaling in response to extracellular stress was reported to induce myocardial hypertrophy $[42,43]$.

A
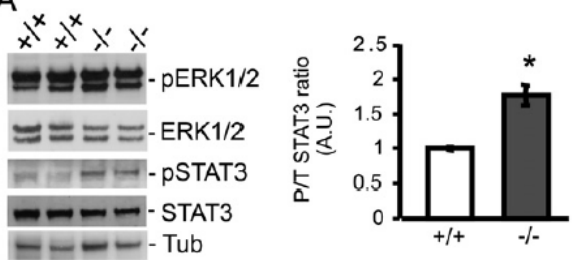

B

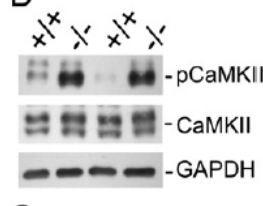

C
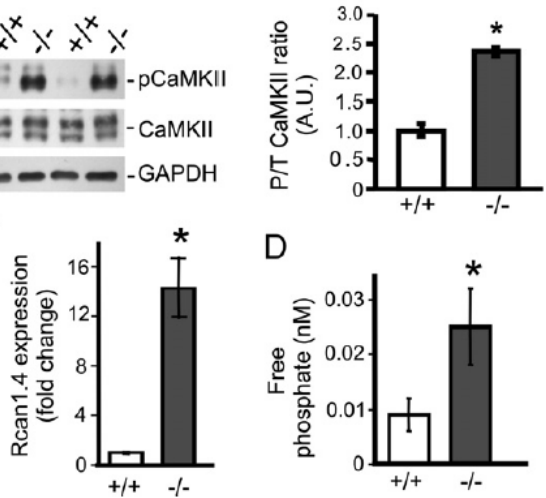

D

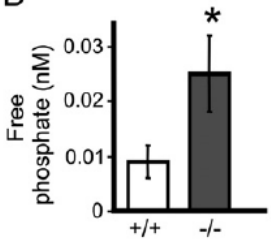

Fig. 4. Effect of Hspa4 deficiency on the activity of ERK1/2, STAT3, CaMKII, and Calcineurin/NFAT signalings. (A and B) Western blot analysis for the expression of total and phosphorylated ERK1/2, STAT3 (A), and CaMKII (B) in 12-week-old Hspa4 WT $(+/+)$ and KO $(-/-)$ hearts (left panels). Histograms show relative intensity of phosphorylated to total protein levels of STAT3, ERK1/2, and CaMKII (right panels). $\alpha$-tubulin (Tub) was used as a loading control. Phosphorylated protein ratio in hearts of WT mice was expressed as 1.0 . ${ }^{*} P<0.05$ vs WT, $n=3$ animals per genotype. A.U. indicates arbitrary units. (C) Expression levels of Rcan $1.4 \mathrm{mRNA}$ in hearts of 12-week-old mice were determined by qRT-PCR. Values of expression levels normalized to Sdha are presented as mean \pm SD. Transcript levels in hearts of WT mice were expressed as 1.0 . * $P<0.05$ vs WT $n=3$ animals per genotype. (D) Bar graphs showing calcineurin phosphatase activity in the hearts of 12 -week-old ice. Data are expressed as the meas$\mathrm{SD}, \mathrm{n}=4-6$ per group. ${ }^{*} P<0.05$ vs. WT. 

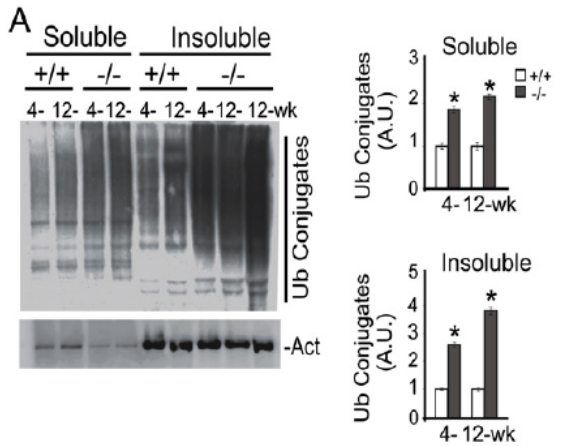

B

Soluble Insoluble

C
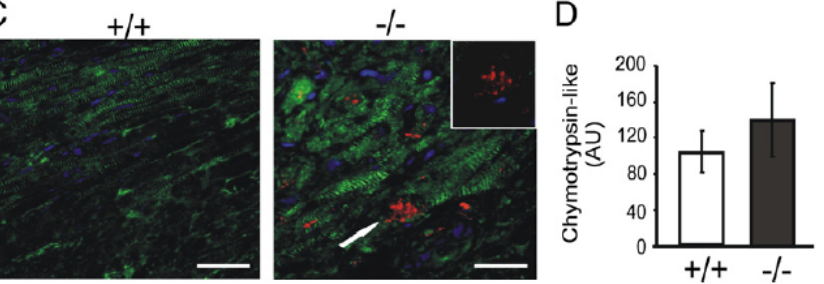

Fig. 5. Increased accumulation of ubiquitinated proteins in Hspa4 KO hearts. (A) Total ubiquitinated proteins in ventricular soluble and insoluble protein extracts from 4- and 12-week-old Hspa4 WT $(+/+)$ and KO $(-/-)$ mice were analyzed by immunoblots (left panels). Histograms show relative abundance of ubiquitinated proteins in soluble and insoluble protein extracts (right panels). $\alpha$ - actinin (Act) was used as a loading control. Values are expressed in mean \pm SD. Ubiquitinated proteins in WT samples were expressed as $10^{*} \mathrm{P}<0.05$ vs WT, $\mathrm{n}=4$ per group. A.U. indicates a bitrary units. (B) Westem blot analysis for the expression of ubiquitinated proteins in the skeletal muscles of 4 - and 2-week-old Hspa4 WT and KO. (C) Cryosections of hearts from 12-week-old Hspa4 WT and KO mice were double immunolabeled for ubiquitin (red) were stained blue with DAPI. Inset is the enlarged images of the arrow-pointed area. Bar $=30 \mu \mathrm{m}$. (D) Bar graph showing myocardial chymotrypsin peptidase activities in Hspa4 WT and KO mice.

In this study, we also show a marked increase in protein levels of phosphorylated STAT3. These results suggest that the gp130-STAT3 signaling also participates in cardiac remodeling in Hspa4 $\mathrm{KO}$ mice. It remains to be determined whether the observed increase in the activity of these prohypertrophic signaling pathways is, on the one hand, the result of the development of cardiac hypertrophy in Hspa4 KO hearts. On the other hand, it might also result from an increase of misfolded proteins in cardiomyocytes, causing intracellular stress and the activation of stress-induced signaling pathways.

A noteworthy finding of transcriptional profiles is that many genes related to ion channel signaling are differentially expressed in the mutant heart. It remains to be addressed whether the observed alterations in the expression of these genes could lead to electric remodeling in Hspa4 KO hearts; and further, if this is responsible for development of cardiac hypertrophy.

Protein quality control in the cells facilitates proper folding of nascent proteins and refolding of misfolded proteins by molecular chaperones and promotes degradation of misfolded and aggregated proteins by ubiquitin-proteasome system (UPS). Functional defects in chaperones result in an increase of misfolded proteins with consequent accumulation of polyubiquitinated proteins, which are removed by proteasome [25]. Consistent with this, we have shown increased levels of ubiquitinated proteins in Hspa $4 \mathrm{KO}$ hearts. These results suggest that the depletion of HSPA4 affects the folding capacity of chaperones. Recent reports demonstrated that increased accumulation of misfolded proteins above the threshold level impairs the functional capacity of the proteasome [44]. Overexpression of mutant desmin or $\alpha \mathrm{B}$ crystallin results in accumulation of misfolded proteins which impairs the proteolytic functions of proteasome. Mice of both mutant lines develop cardiac hypertrophy $[45,46]$. In human heart with dilated or hypertrophic cardiomyopathies, abnormal protein aggregations and accumulation of ubiquitinated proteins are common phenomenon $[47,48]$.
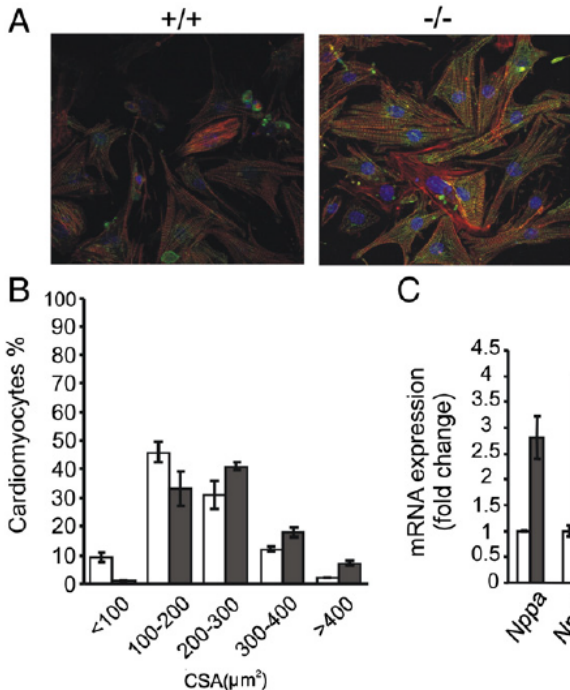

C
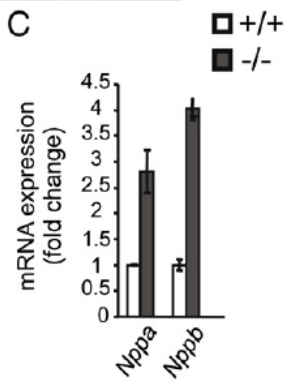

Fig. 6. Neonatal cardiomyocytes of $\mathrm{Hspa} 4 \mathrm{KO}$ mice display hypertrophic properties. (A) Immunofluorescence analysis of $\mathrm{Hspa} 4 \mathrm{WT}(+/+)$ and $\mathrm{KO}(-/-)$ neonatal cardiomyocyte culture using $\alpha$-actinin (green) antibody and phalloidin (red). (B) Histogram shows that the ratio of cardiomyocytes with increased CSA in primary (B) Histogram shows that the ratio of cardiomyocytes with increased CSA in primary culture of neonatal Hspa $4 \mathrm{KO}$ heart is significantly elevated compared with that of
WT culture. CSA was measured in cells costained with both $\alpha$-actinin and phalloidin ( $n=800$ cells per genotype of 2 independent experiments). (C) Expression levels of Nppa and Nppb in neonatal cardiomyocytes of Hspa4 WT and KO hearts were determined by qRT-PCR. Values of expression levels normalized by Hprt are present as mean \pm SD. Transcript levels in cardiomyocytes of WT mice were expressed as 1.0 . ${ }^{*} P<0.05$ vs WT. 


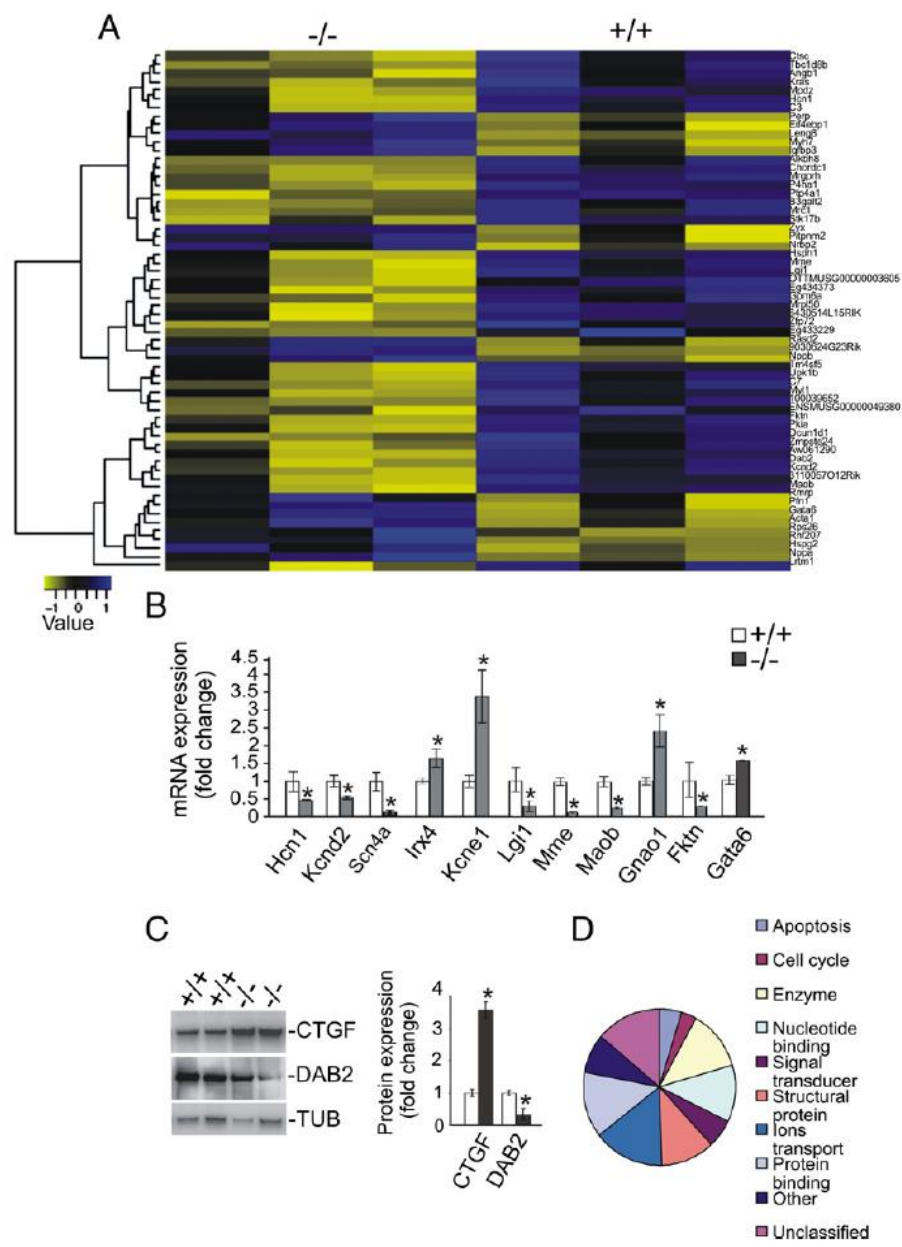

Fig. 7. Assessment of global gene expression in hearts of $\mathrm{Hspa} 4 \mathrm{KO}$ mice. (A) Heat map of genes showing the significantly altered expression in hearts of 3.5 -week-old $\mathrm{Hspa} 4 \mathrm{WT}$ ( $+/+$ ) and $\mathrm{KO}(-/-)$ mice. Yellow represents increased expression and blue represents diminished expression. (B) Differential expression of the set of genes was validated using qRT-PCR Values of expression levels normalized by Sdha are presented for each gene as mean \pm SD. Transcript levels of each gene in WT hearts were expressed as 1.0 . Data are mean \pm SD. Values of expression levels normalized by Sdha are presented for each gene as mean \pm SD. Transcript levels of each gene in WT hearts were expressed as 1.0 . Data are mean \pm SD.
${ }^{*} P<0.05$ vs WT, $n=3$ mice/genotype. (C) Western blot analyses for the expression of CTGF and DAB2 in 12-week-old Hspa 4 WT and KO hearts (left panels). Histogram shows relative ${ }^{*} P<0.05$ vs WT, $n=3$ mice/genotype. (C) Western blot analyses for the expression of CTGF and DAB2 in 12-week-old Hspa4 WT and KO hearts (left panels). Histogram shows relative
intensity of CTGF and DAB2 (right panel). $\alpha$-tubulin (TUB) was used as a loading control. Values are expressed in mean \pm SD. Protein levels in hearts of WT mice samples were expressed as $1.0{ }^{*} P<0.05$ vs control, $n=4$ per group. (D) Pie diagram illustrating the categorization of differentially expressed genes based on molecular function using Gene Ontology. Note that some genes may have more than one function and be categorized in several groups.

In conclusion, the present study demonstrates that lack of HSPA4 leads to cardiac hypertrophy and fibrosis. Moreover, our data reveal the distinct, non-redundant role of HSPA4 in the protein quality control that maintains the proper protein folding and homeostasis in the cardiomyocytes.

Supplementary data to this article can be found online at http:// dx.doi.org/10.1016/j.yjmcc.2012.07.014.

\section{Disclosures}

None declared.

\section{Acknowledgments}

B.A.M. was supported by Deutscher Akademischer Austausch Dienst (DAAD) through grant A/07/80490. Dr. Maier (MA 1982/ $4-1 \& 2-2$ ) is funded by the DFG and by the Foundation Leducq
Transatlantic Network of Excellence on "Redox and Nitrosative Regulation of Cardiac Remodeling: Novel Therapeutic Approaches for Heart Failure" as well as the "Alliance for CaMK Signaling in Heart Disease". Dr. Zimmermann is funded by the DFG (ZI 708/ 7-1,8-1\&10-1) and BMBF (DZHK, 01GN0827, 01GN0957). We are grateful to L. Opitz and G. Salinas-Reister for kindly helping us in Microarray data analysis. We also would like to thank T. Sowa and I. Quentin for their expert technical assistance.

\section{References}

[1] Hartl FU. Molecular chaperones in cellular protein folding. Nature 1996;381: 571-9.

[2] Vos M], Hageman J, Carra S, Kampinga HH. Structural and functional diversities between members of the human HSPB, HSPH, HSPA, and DNAJ chaperone families. Biochemistry 2008:47:7001-11.

[3] Dragovic Z, Broadley SA, Shomura Y, Bracher A, HartI FU. Molecular chaperones of the Hsp1 10 family act as nucleotide exchange factors of Hsp70s. EMBO J 2006;25: 2519-28. 
[4] Raviol H, Sadlish H, Rodriguez F, Mayer MP, Bukau B. Chaperone network in the yeast cytosol: Hsp110 is revealed as an Hsp70 nucleotide exchange factor. yeast cytosol: Hsp110 is
EMBO J 2006;25:2510-8.

[5] Polier S, Dragovic Z, Hartl FU, Bracher A. Structural basis for the cooperation of Hsp70 and Hsp110 chaperones in protein folding. Cell 2008;133:1068-79.

[6] Schuermann JP, Jiang J, Cuellar J, Llorca O, Wang L, Gimenez LE, et al. Structure of the Hsp110:Hsc70 nucleotide exchange machine. Mol Cell 2008;31:232-43.

[7] Kumarapeli AR, Su H, Huang W, Tang M, Zheng H, Horak KM, et al. Alpha B-crystallin suppresses pressure overload cardiac hypertrophy. Circ Res 2008;103:1473-82.

[8] Latchman DS. Heat shock proteins and cardiac protection. Cardiovasc Res 2001;51:637-46.

[9] Kim YK, Suarez J, Hu Y, McDonough PM, Boer C, Dix DJ, et al. Deletion of the inducible 70-kDa heat shock protein genes in mice impairs cardiac contractile function and calcium handling associated with hypertrophy. Circulation 2006:113: 2589-97.

[10] Hayashi M, Imanaka-Yoshida K, Yoshida T, Wood M, Fearns C, Tatake RJ, et al. A crucial role of mitochondrial $\mathrm{Hsp} 40$ in preventing dilated cardiomyopathy. Nat Med 2006;12:128-32.

[11] Norton N, Li D, Rieder M], Siegfried JD, Rampersaud E, Züchner S, et al. Genome-wide studies of copy number variation and exome sequencing identify rare variants in BAG3 as a cause of dilated cardiomyopathy. Am J Hum Genet 2011;88:273-82.

[12] Kaneko Y, Kimura T, Kishishita M, Noda Y, Fujita J. Cloning of apg-2 encoding a novel member of heat shock protein 110 family. Gene 1997;189:19-24

[13] Held T, Barakat AZ, Mohamed BA, Paprotta I, Meinhardt A, Engel W, et al. Heat-shock protein HSPA4 is required for progression of spermatogenesis. Reproduction 2011;142:133-44.

[14] Huke S, Bers DM. Temporal dissociation of frequency-dependent acceleration of relaxation and protein phosphorylation by CAMKII. J Mol Cell Cardiol 2007;42: 590-9.

[15] Zimmermann WH, Fink C, Kralisch D, Remmers U, Weil J, Eschenhagen T, Three-dimensional engineered heart tissue from neonatal rat cardiac myocytes. Biotechnol Bioeng 2000;68:106-14

[16] Müller P, Kazakov A, Semenov A, Böhm M, Laufs U. Pressure-induced cardiac overload induces upregulation of endothelial and myocardial progenitor cells. Cardiovasc Res 2008;77:151-9.

[17] Garcia R, Diebold S. Simple rapid and effective method of producing aortocava shunts in the rat. Cardiovasc Res 1990;24:430-2.

[18] Peng X, Kraus MS, Wei H, Shen TL, Pariaut R, Alcaraz A, et al. Inactivation of focal adhesion kinase in cardiomyocytes promotes eccentric cardiac hypertrophy and fibrosis in mice. J Clin Invest 2006:116:217-27.

[19] Smyth GK. Linear models and empirical bayes methods for assessing differential expression in microarray experiments. Stat Appl Genet Mol Biol 2004;3 (Article 3).

[20] Gentleman RC, Carey V], Bates DM, Bolstad B, Dettling M, Dudoit S, et al. Bioconductor: Open software development for computational biology and bioinformatics. Genome Biol 2004;5:R80.

[21] Benjamini Y, Hochberg Y. Controlling the false discovery rate: A practical and powerful approach to multiple testing. J R Statist Soc Ser B 1995;57:289-300.

[22] Huang da W, Sherman BT, Tan Q Kir J, Liu D, Bryant D, et al. DAVID Bioinformatics Resources: expanded annotation database and novel al arithms to better extract biology from large gene lists. Nucleic Acids Res 2007;35:W169-75.

[23] Huang da W, Sherman BT, Lempicki RA. Systematic and integrative analysis of large gene lists using DAVID bioinformatics resources. Nat Protoc 2009;4:44-57.

[24] Frey N, Olson EN. Cardiac hypertrophy: the good, the bad, and the ugly. Annu Rev Physiol 2003:65:45-79.

[25] Patterson C. Search and destroy: the role of protein quality control in maintaining cardiac function. J Mol Cell Cardiol 2006;40:438-41.

[26] Glickman MH, Ciechanover A. The Ubiquitin-Proteasome Proteolytic Pathway: Destruction for the Sake of Construction. Physiol Rev 2002;82:373-428.

[27] Schulte U, Thumfart JO, Klöcker N, Sailer CA, Bildl W, Biniossek M, et al. The epilepsy-linked Lgi1 protein assembles into presynaptic Kv1 channels and inhibits inactivation by Kvbeta1. Neuron 2006;49:697-706.
[28] He W, Jia Y, Takimoto K. Interaction between transcription factors Iroquois proteins 4 and 5 controls cardiac potassium channel Kv4.2 gene transcription. Cardiovasc Res 2009;81:64-71.

[29] Van Berlo JH, Elrod JW, van den Hoogenhof MM, York AJ, Aronow BJ, Duncan SA, et al. The transcription factor GATA-6 regulates pathological cardiac hypertrophy. Circ Res 2010:107:1032-40.

[30] Wang Z, Yang D, Zhang X, Li T, Li J, Tang Y, et al. Hypoxia-induced down-regulation of neprilysin by histone modification in mouse primary cortical and hippocampal neurons. PLoS One 2011;6:e19229.

[31] Naoi M, Maruyama W, Akao Y, Yi H, Yamaoka Y. Involvement of type A monoamine oxidase in neurodegeneration: regulation of mitochondrial signaling leading to cell death or neuroprotection. J Neural Transm Suppl 2006;71:67-77.

[32] Nishida M, Maruyama Y, Tanaka R, Kontani K, Nagao T, Kurose H. G alpha(i) and C alpha(o) are target proteins of reactive oxygen species. Nature 2000;408:492-5.

[33] Ahmed MS, Øie E, Vinge LE, Yndestad A, Øystein Andersen G, Andersson Y, et al. Connective tissue growth factor: a novel mediator of angiotensin Il-stimulated cardiac fibroblast activation in heart failure in rats. J Mol Cell Cardiol 2004;36: 393-404.

[34] Kumbar DH, VanBergen A, Ocampo C, Muangmingsuk S, Griffin AJ, Gupta M. Adapter molecule DOC-2 is differentially expressed in pressure and volume overload hypertrophy and inhibits collagen synthesis in cardiac fibroblasts. J Appl Physiol 2007;102:2024-32,

35] Kumarapeli AR, Wang X. Genetic modification of the heart: chaperones and the cytoskeleton. J Mol Cell Cardiol 2004;37:1097-109.

36] Osaki J, Haneda T, Kashiwagi Y, Oi S, Fukuzawa J, Sakai H, et al. Pressure-induced expression of heat shock protein $70 \mathrm{mRNA}$ in adult rat heart is coupled both to protein kinase A-dependent and protein kinase C-dependent systems. J Hypertens 1998; 16:1193-200.

[37] Kee HJ, Eom GH, Joung H, Shin S, Kim JR, Cho YK, et al. Activation of histone deacetylase 2 by inducible heat shock protein 70 in cardiac hypertrophy. Circ Res 2008;103:1259-69.

[38] Wilkins BJ, Molkentin JD. Calcineurin and cardiac hypertrophy: where have we been? Where are we going? J Physiol 2002;541:1-8.

[39] Molkentin JD, Lu JR, Antos CL, Markham B, Richardson J, Robbins J, et al. A calcineurin-dependent transcriptional pathway for cardiac hypertrophy. Cell 1998:93:215-28.

[40] Olson EN, Williams RS. Calcineurin signaling and muscle remodeling. Cell 2000:101:689-92

[41] Passier R, Zeng H, Frey N, Naya FJ, Nicol RL, McKinsey TA, et al. CaM kinase signaling induces cardiac hypertrophy and activates the MEF2 transcription factor in vivo. J Clin Invest 2000;105:1395-406.

[42] Kunisada K, Tone E, Fujio Y, Matsui H, Yamauchi-Takihara K, Kishimoto T. Activation of gp 130 transduces hypertrophic signals via STAT3 in cardiac myocytes. Circulation 1998;98:346-52.

[43] Kunisada K, Negoro S, Tone E, Funamoto M, Osugi T, Yamada S, et al. Signal transducer and activator of transcription 3 in the heart transduces not only a hypertrophic signal but a protective signal against doxorubicin-induced cardiomyopathy. Proc Natl Acad Sci USA 2000;97:315-9.

[44] Bennett EJ, Bence NF, Jayakumar R, Kopito RR. Global impairment of the ubiquitin-proteasome system by nuclear or cytoplasmic protein aggregates precedes inclusion body formation. Mol Cell 2005:17:351-65.

[45] Liu J, Chen Q Huang W, Horak KM, Zheng H, Mestril R, et al. Impairment of the ubiquitin-proteasome system in desminopathy mouse hearts. FASEB J 2006;20: $362-4$.

[46] Chen Q Liu JB, Horak KM, Zheng H, Kumarapeli AR, Li J, et al. Intrasarcoplasmic amyloidosis impairs proteolytic function of proteasomes in cardiomyocytes by amyloidosis impairs proteolytic function of proteasomes in
compromising substrate uptake. Circ Res 2005;97:1018-26.

[47] Heling A, Zimmermann R, Kostin S, Maeno Y, Hein S, Devaux B, et al. Increased expression of cytoskeletal, linkage, and extracellular proteins in failing human myocardium. Circ Res 2000;86:846-53.

[48] Kostin S, Pool L, Elsässer A, Hein S, Drexler HC, Arnon E, et al. Myocytes die by multiple mechanisms in failing human hearts. Circ Res 2003;92:715-24. 


\section{List of Publications}

1) Held T, Barakat AZ, Mohamed BA, Paprotta I, Meinhardt A, Engel W, Adham IM (2011): Heat-shock protein HSPA4 is required for progression of spermatogenesis. Reproduction 142,133-44

2) Mohamed BA, Barakat AZ, Zimmermann WH, Bittner RE, Mühlfeld C, Hünlich M, Engel W, Maier LS, Adham IM (2012): Targeted disruption of Hspa4 gene leads to cardiac hypertrophy and fibrosis. J Mol Cell Cardiol 53, 459-468

3) Burnicka-Turek O*, Mohamed BA*, Shirneshan K*, Thanasupawat T, HombachKlonisch S, Klonisch T, Adham IM (2012): INSL5-Deficient Mice Display an Alteration in Glucose Homeostasis and an Impaired Fertility (Endocrinology, In press)

(*) contributed equally to this work

\section{Manuscript in Submission Stage}

1) Mohamed BA, Barakat AZ, Held T, Elkenani MM, Mühlfeld C, Männer J, Adham IM: Simultaneous deletion of $\mathrm{Hspa} 4 \mathrm{l}$ and $\mathrm{Hspa} 4$ genes causes pulmonary immaturity and early neonatal lethality in mouse 


\section{Acknowledgments}

To Prof. Dr. I. M. Adham, for readily accepting me as a doctoral student in his lab, for closely supervising my thesis through the entire course of my MD study, for helpful comments and insightful conversations, and above all for his constant support such that I could finish my thesis in a "decent" time-frame.

To Prof. Dr. med. Dr. h. c. Wolfgang Engel, for taking out his "precious" time to go through my thesis, as well as for those fruitful discussions that lead to the generation of novel ideas, and for encouraging me to participate actively in meetings and seminars, and also for his genuine feedback on various manuscripts.

To Prof. Dr. W.-H. Zimmermann for expert guidance and support during the neonatal mice cardiomyocyte culture work as well as for fruitful scientific discussions and suggestions.

To Prof. Dr. L. S. Maier for providing us with cardiac samples of human patients with Aortic stenosis, for his help in TAC operation and Echo measurement, as well as for helpful comments.

To Dr. S. Lutz for guidance and support during the generation of recombinant Adenovirus work.

To Xingbo, Christian and Dr. Pantakani, for invaluable help and continuous support throughout the course of my thesis.

To my lab mates and to all my institute colleagues for their friendship, discussions, advices, help. 


\section{Curriculum Vitae}

I was born in 18.10.1978 as a second child of Mohamed Awd and Nadjia Soliman.

From 1984 till 1994, I visited the Primary and Secondary schools in Mansoura, Egypt. I passed the Secondary school final examination in 1994. From 1994 till 2000, I studied Medicine in the Faculty of Medicine, Mansoura University. In 2000, I got my Bachelor degree in Internal Medicine and General Surgery. From 2001 till 2002, I did training courses as a rotatory internship in the Mansoura University Hospitals. From 2002 till 2003, I did my Military service as a soldier. Since 2003, I studied in the Department of Medical Biochemistry and Molecular Biology as a Demonstrator. In 2006, I finished my Master thesis entitled "Coagulation Profile in chronic liver diseases" and I got my Master degree in the field of Medical Biochemistry and Molecular Biology. From 2006 till now, I am working as an Assistant Lecturer in the Department of Medical Biochemistry and Molecular Biology. In 2008, I got a scholarship from DAAD to do my MD study in Germany. In 2009, I started my MD thesis entitled "The molecular role of the heat shock protein family110 (HSP110)" in the Institute of Human Genetics, University of Göttingen. 